Portland State University

PDXScholar

Dissertations and Theses

Dissertations and Theses

5-9-1973

\title{
Sculpture for the Secondary Level
}

Joanne Beckett Peekema

Portland State University

Follow this and additional works at: https://pdxscholar.library.pdx.edu/open_access_etds

Part of the Art Education Commons, and the Secondary Education and Teaching Commons Let us know how access to this document benefits you.

\section{Recommended Citation}

Peekema, Joanne Beckett, "Sculpture for the Secondary Level" (1973). Dissertations and Theses. Paper 1763.

https://doi.org/10.15760/etd.1762

This Thesis is brought to you for free and open access. It has been accepted for inclusion in Dissertations and Theses by an authorized administrator of PDXScholar. Please contact us if we can make this document more accessible: pdxscholar@pdx.edu. 
AN ABSTRACT OF THE THESIS OF Joanne Beckett Peekema for the Master of Science in Teaching presented May 9, 1973.

Title: Sculpture for the Secondary Level

APPROVED BY MEMBERS OE THE THESIS COMMITTEE:
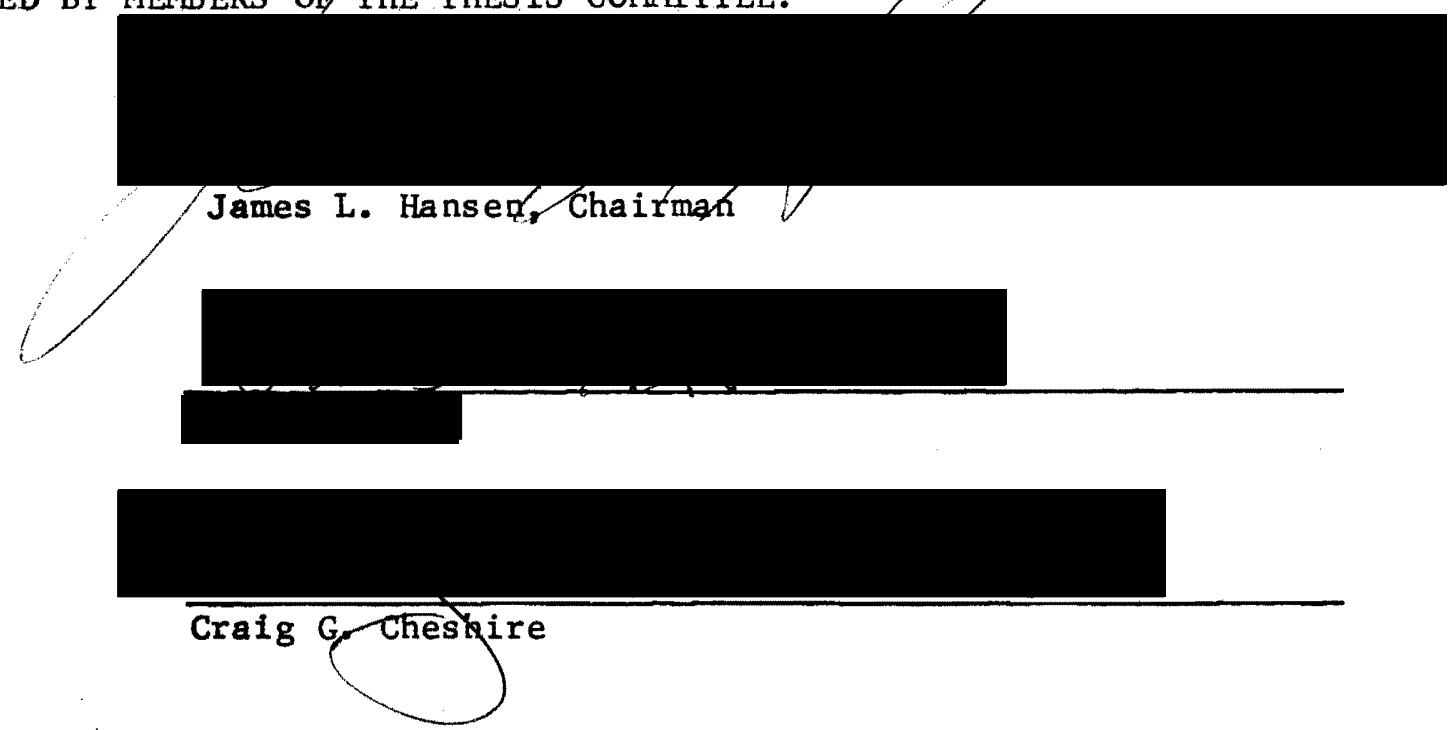

The goal of this thesis was to illustrate that secondary students, when motivated to express themselves, can effectively apply to their own work those elements of design relevant to sculptural form.

This unit sought, first, to develop in secondary students a knowledge of sculptural techniques for handing terracotta; second, this unit sought to inspire or motivate the secondary students by utilizing a subject of great interest to them, their own images; third, this unit sought to bring together the students' understanding of the material and their motivation for self expression -- to transform their ideas into three-dimensional works of art; fourth, this unit sought to introduce to the students those art concepts related to sculpture that would be 
immediately helpful to them while working.

The projects of this unit were organized into a series of progressively more challenging subjects to gradually increase the students' confldence in handling the material and to develop the students' understanding of sculptural design. The choice of the sculptural material and method was limited to a single material using a simple method -- namely, terracotta with the additive method to illustrate that the expressive possibilities of sculpture can be learned and experienced in depth with this simple approach.

This unit in terracotta sculpture lasted approximately seven weeks and was presented in part to a general art class consisting of approximately twenty-nine students at Adams High School and in part to three classes at the Museum Art School totaling thirty students. The students in a11 classes ranged in age from thirteen to eighteen years of age.

The results of these projects were generally successful. The work produced by the students demonstrated an understanding of the use of clay, an awareness of the expressive possibilities of sculpture, and an awareness of some elements of design relevant to sculpture. As the projects progressed, the students became more confident in the manipulation and control of the clay. They began to realize that sculpture can be a very interesting art form due to its three dimensionality, and that clay due to its plasticity, can be used expressively. As their work progressed, they developed an awareness of form, content, and the organization of sculpture as tools for creating effective and interesting sculptures.

It was concluded that students on the secondary age level are capable of understanding mature art concepts and, furthermore, are interested in experiencing these concepts if they can be applied 
immediately to specific needs related to the students' work. These concepts must have the purpose of helping the student express himself more effectively and must be immediately applicable to a subject in which the student is very interested. 
SCULPTURE FOR THE SECONDARY LEVEL

by

JOANNE BECKETT PEEKEMA

A thesis submitted in partial fulfillment of the requirements for the degree of

MASTER of SCIENCE in TEACHING

in ART

Portland State University

1973 
TO THE OFFICE OF GRADUATE STUDIES AND RESEARCH:

The members of the Committee approve the thesis of Joanne Beckett Peekema, presented May 9, 1973.

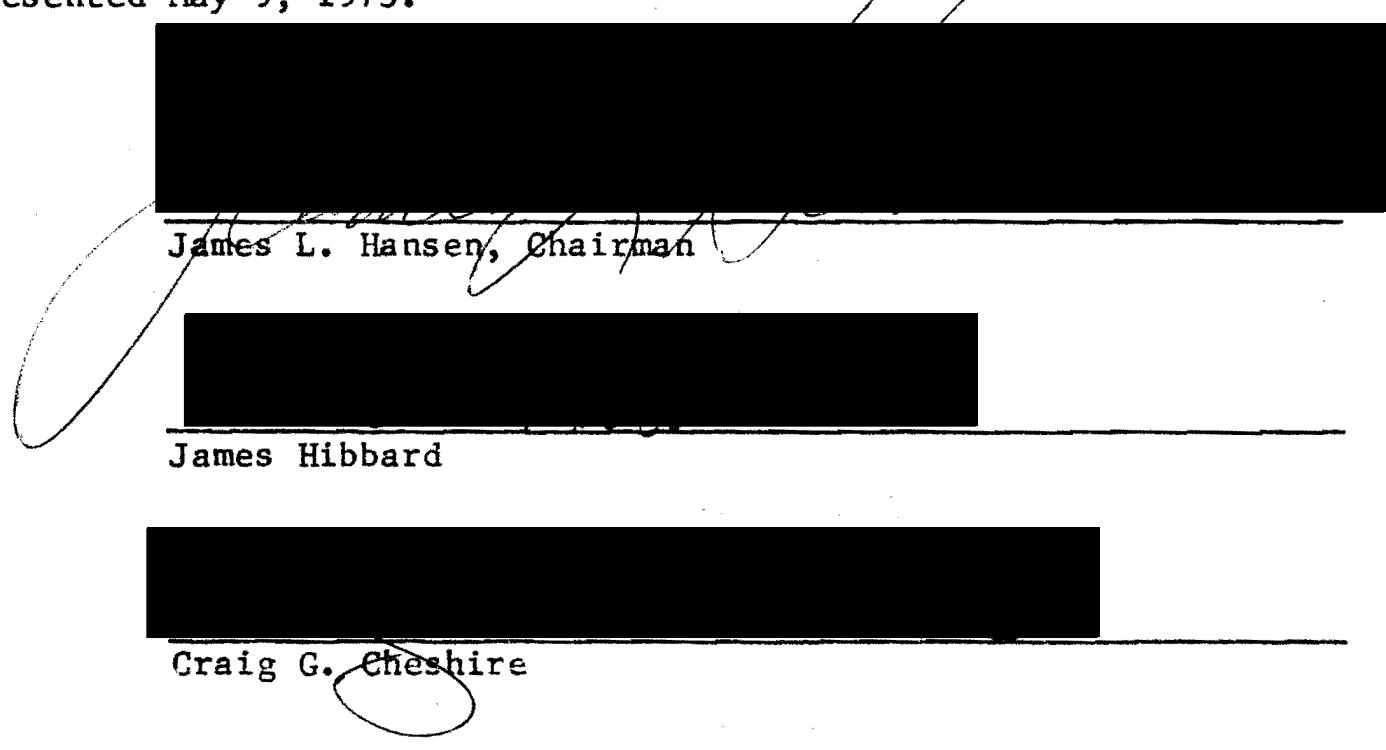

APPROVED:

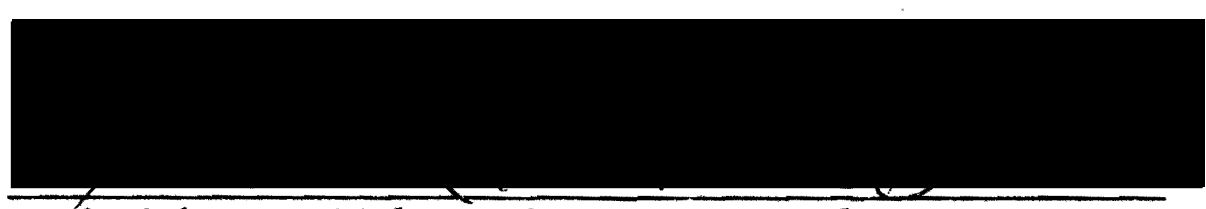

Frederick H. Heidel, Head, Department of Art

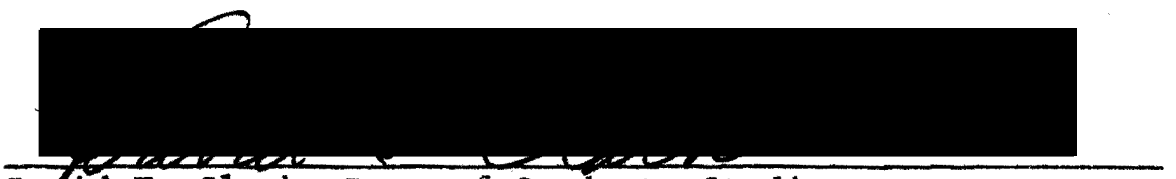

Dafid T. Clark, Dean of Graduate Studies

May 9, 1973 


\section{ACKNOWLEDGMENTS}

With the assistance of some marvelous people, the task of completing this thesis was made possible. I am indebted to the following friends:

James Hansen, sculptor and teacher, whom I was privileged to have as a thesis advisor.

Kenneth Lovea11, photographer, whose black and white photographs enhanced each sculptured image.

Darla Kofner, typist, who patiently transformed reams of scribbled words into this attractive document.

George Peekema, my husband, whose moral support never, never waivered. 
TABLE OF CONTENTS

PAGE

LIST OF FIGLRES . . . . . . . . . . . . . . . . iv

CHAPTER

I DESCRIPTION OF THE PROBLEM $. . . \cdot . . . . . . . . \cdot 1$

II A POSSIBLE SOLUTION TO THE PROBLEM . . . . . . . . 5

III PROJECT OBJECTIVES, METHODS AND TECHNIQUES . . . . . . 11

I. An Introduction of Terracotta Techniques

With the Flat Form .............. 11

II. An Expansion of the Use of Terracotta

Techniques With a Freestanding Form ....... 16

III. An Exploration of the Use of Two Forms,

Relating Them and Unifying Them Into

a Single Sculpture in Terracotta ........ 23

IV. CONCLUSION .................. 27

A LIST OF WORKS CONSULTED . . . . . . . . . . . . . . . 31

APPENDIX I: ClAY TEChNIQUES, IllUSTRATED . . . . . . . . . . 56

APPENDIX II: THE AUTHOR'S WORK . . . . . . . . . . . 68 


\section{LIST OF FIGURES}

FIGURE

PAGE

1. Results of Problem 2, p. 16. .......... 32

2. Results of Problem 2, p. 16 (continued). ...... 33

3. Results of Problem 2, p. 16 (continued). ...... 34

4. Results of Problem 2, p. 16 (continued). ...... 35

5. Results of Problem 2, p. 16 (continued). ...... 36

6. Results of Problem 2, p. 16 (continued). ...... 37

7. Results of Problem 2, p. 16 (continued). ...... 38

8. Results of Problem 3, p. 22. ............ 39

9. Results of Problem 3, F. 22 (continued). ...... 40

10. Results of Problem 3, p. 22 (continued). ....... 41

11. Results of Problem 3, p. 22 (continued). ....... 42

12. Results of Problem 3, p. 22 (continued). ...... 43

13. Results of Problem 3, p. 22 (continued). ...... 44

14. Results of Problem 3, p. 22 (continued). ...... 45

15. Results of Problem 3, p. 22 (continued). ...... 46

16. Results of Problem 3, p. 22 (continued). ...... 47

17. Results of Problem 3, p. 22 (continued). ...... 48

18. Results of Problem 3, p. 22 (continued). ...... 49

19. Results of Problem 4, p. 23. .......... 50

20. Results of Problem 4, p. 23 (continued). ...... 51

21. Results of Problem 4, p. 23 (continued). ...... 52 
22. Results of Problem 4; p. 23 (continued). . . . . . 53

23. Results of Problem 4, p. 23 (continued). ....... 54

24. Results of Problem 4, p. 23 (continued). ....... 55 


\section{CHAPTER I}

DESCRIPTION OF THE PROBLEM

For the secondary student an understanding of the compositional elements of sculpture can and should develop as a result of his creative involvement in his art work and out of his desire to express himself effectively. "Aesthetic criteria cannot be separated from creative development as a whole." 1 An understanding of the compositional elements of sculpture can develop according to the specific needs of the individual while his work is in progress. "If these aesthetic criteria are taught academically -- as subject matter in itself, detached from the work -- they become dead knowledge which will inhibit rather than help an intuitive urge. $"{ }^{2}$ In other words, rather than be asked to learn by rote certain academic facts about sculpture, it is better that a student be given the opportunity to explore the aesthetic criteria such as form, organization, and content, ${ }^{3}$ techniques in handling materials, etc. -- all as a means for enabling that student to express what is in his mind more easily and effectively.

If the content, or subject matter, were important to the student, then it is possible that he would be motivated enough to want to develop

${ }^{1}$ Viktor Lowenfeld and W. Lambert Brittain, Creative and Mental Growth, 4th ed. (New York: Macmillan, 1964), p. 352 .

2 Lowenfeld, p. 352.

3 Marjorie Elliot Bevlin, Design Through Discovery, 2nd ed. (New York: Holt, 1970), pp. 259-264. 
the organization and form of the pieces to express his idea effectively. A proper choice of subject would encourage individual expression while at the same time help prolong the motivational energy required to complete a piece of sculpture.

Before choosing the subject matter for the sculpture projects, consideration would have to be given to the individuality of the students. For example a choice of subject would hopefully appeal to the visuallyminded as well as the subjective minded youngsters. There is a distinction in the sensory reactions of youngsters toward their artistic experiences in that some prefer visual stimuli and some others are concerned with subjective experiences. Visual experiences are characterized by those relating to the optical senses such as the objective observation of the environment as though seen from the outside. Subjective interpretations emphasize the emotional reaction to the external world in reference to the body itself. ${ }^{4}$

As we approach the crisis of adolescence, during which preferences toward these different experiences crystallize, we have to pay increasing attention in our motivation to both of these important experiences. We would discourage a visually minded person by motivating him in referring to subjective experiences, emotional qualities, or body experiences; in the corresponding way we would inhibit a subjective minded person if we were to motivate him by mere visual experiences. Since traditional art education is mainly built upon visual stimuli, a great deal of our young people must feel not only neglected but frustrated. 5

Although the psychological aspects of art education will not be the subject of this paper, this author decided to give careful consideration

\footnotetext{
${ }^{4}$ Lowenfeld, p. 217 .

${ }^{5}$ Lowenfeld, p. 217.
} 
to the choice of subject matter for the projects so that all the students would have the opportunity to be uniquely individual in their responses to that subject. By their unique responses, the students would also have an opportunity to learn more about themselves.

Another aspect of the problem to be considered is a choice of sculpture material. This material would hopefully fulfill a number of requirements. One of these requirements is that it would easily embody those elements of design relevant to sculpture, namely form, organization (which includes line, texture, light and shadow) and content (which is the idea that the student is trying to express.) ${ }^{6}$ A material easy to manipulate would also give the student the experience of exploring principles of design such as unity, balance, and movement of the piece. The proper material would be malleable enough to give each student freedom to develop his idea in an exploratory fashion and be plastic enough to record each student's reactions to the material and subject. In addition the material would have to be easy enough to use to assure the student the satisfaction of completing a piece without insurmountable technical difficulties. Finally, the material should be readily available and economically feasible to use in any art class.

A summarization of the description of the problem could be made by stating the general goals of this unit in sculpture. These goals are:

1. To encourage the students to be aware of and to utilize the aesthetic criteria of sculpture as their needs arise during the project.

2. To help the students express their ideas more effectively by the use of these aesthetic criteria.

${ }^{6}$ Bevlin, Pp. 259-264. 
3. To find subject matter for the sculpture projects that would allow for unique and personal responses to it by the students.

4. To select subject matter that would appeal to the interests of the students so that motivation would be sustained throughout the project.

5. To choose a material that would easily embody those elements of design relevant to sculpture.

6. To select a material that would give immediate physical evidence of the creative responses of the students.

7. To give each student the chance to complete works of sculpture that would not only expand his understanding of sculpture but would also expand his understanding of himself as a unique individual. 


\section{A POSSIBLE SOLUTION TO THE PROBLEM}

One way to introduce sculpture to secondary students is to limit the material and the method throughout a series of progressively more challenging sculptures. The utilization of a single modeling material and the simple additive method to develop increasingly more challenging pieces would increase the student's confidence in his ability to handle the material in an expressive way.

A widely used modeling material is terracotta (baked earth) which is inexpensive and almost universally available. It has two properties that make it very valuable as a material for scuipture. The first property is its extreme malleability. "With just the right amount of moisture it can become a marvelous non-sticky and highly plastic material that will record accurately the impression of even a fingerprint." 7 The second property that makes terracotta a valuable sculpture material is its hardness and durability after the firing process. "This process of firing, which bricks and pottery also undergo, makes it possible for the sculptor to work in plastic clay and then turn his model, more or less as it stands, into something hard and permanent." 8

Because terracotta sculpture is a medium that requires a certain amount of technical skill, secondary students should be given an

7L. R. Rogers, Sculpture, The Appreciation of the Arts/2 (London: Oxford, 1969), p. 202.

${ }^{8}$ Rogers, p. 204. 
opportunity to develop confidence in handling the material before attempting difficult projects. One way to develop this confidence in secondary students is to initiate a project involving the flat-slab form. The flat-slab or relief form will introduce the students to the characteristics of terracotta, to the techniques for handling the material, and to the processes required in caring for clay pieces while they are in progress. In addition the student can be introduced to those elements of design related to relief sculpture, as well as freestanding sculpture. The relief form would act as a transition between the student's understanding of two-dimensional design elements found in drawing and painting and those design elements relevant to three-dimensional freestanding sculpture.

Reliefs combine some of the qualities of paintings and drawings with some of those of fully three-dimensional sculpture. The 'three-dimensional' forms in paintings and drawings exist in an illusory, or notational space and have no actual three-dimensional properties. Their depth is represented pictorially on a plane surface by means of a variety of projective systems ranging from the unsophisticated mixed methods of primitive and child art to the complex and precise methods of perspective projection. Reliefs inhabit a world that lies somewhere between this illusory pictorial space and the real everyday space inhabited by the fully threedimensiona1 sculpture. ${ }^{9}$

By limiting the first project to the flat-slab or relief form, the students can learn manipulation techniques for the terracotta without the more difficult added problem of constructing a larger freestanding form. In this way the students would be more confident about the use of clay when the larger projects are introduced. In addition they would be ready

$$
{ }^{9} \text { Rogers, p. } 156 .
$$


To accept the freestanding three-dimensionality of the more challenging projects.

In approaching three-dimensional art, modelling, carving, constructing, or assembling, the artist -- child or adult -must undergo a period of experimentation or play. He must explore and exploit the material to discover its potential and its response to his involvement, his unique way of working. Each student can leave his stamp on a carving. Once he has conquered or controlled the chosen matter to his satisfaction, has learned the vocabulary or range of the material in terms of his concept of what he wishes to do or say with it, he is able to make it distinctly his own useful tool. 10

Eventually the student's more subjective response to the material

and to sculptural form as a means of self-expression can be developed by the introduction of the self portrait as subject matter. The entering behaviors of secondary students indicate that each has a strong interest in himself as an adult, in life and its relationships, and there is a strong response to 1 ife situations as subject matter. ${ }^{11}$ "As development progresses from the pre adolescent stage toward maturity, there is an ever increasing awareness of the self-concept." 12

The use of the self portrait can be expanded to include a subjective response to activities related to special head gear worn by the student. The emotional aspect of the piece must go beyond a mere smile on the face of the portrait, or wide open eyes or other facial expressions alone. The concept of movement working through a piece of sculpture can be introduced

${ }^{10}$ Kelly Fearing, et al, Art and the Creative Teacher (Austin: Benson, 1971), p. 99 .

${ }^{11}$ Italo L. De Francesco, Art Education, Its Means and Ends (New York, 1958), p. 359.

12 John A. Michael, "Art Experience During Early Adolescence," in Art Education: The Sixty-fourth Yearbook for the Study of Education, ed. W. Reid Hastie (Chicago: University, 1965), p. 90 . 
by the use of the visible affect of the emotion or activity upon the shoulders, neck, and head positions of the portrait. The subjective response by the student to his self-portrait would hopefully encourage his involvement in the sculpture as a whole, not just in separate parts (like a smiling mouth).

It has long been an accepted assumption that we unconsciously, as well as consciously, project ourselves into our art expression whenever we become deeply involved in it and express ourselves in our own unique, personal, and individual manner. This projection is especially discernible in realistic representation. Here, a youngster begins to see himself mirrored in his art work. He begins to recognize his interests, attitudes, thoughts, values and feelings as he sees manifestations of them unfold before him in his art. Herein, art expression serves as a means of self-discovery and for arriving at subjective truth. 13

The final project can go beyond the simple self-portrait bust to include more of the figure in relation to another form -- an animal form that evokes a strong response in the student at the outset. This last project would enable the student to deal with a more complex sculpture, using more than the single portrait form by adding a second form, an anima1. The student could then experience the task of balancing and unifying these forms into a single sculpture.

The student's relationship to the animal would visibly unite forms and content. Form and content, for a sculptor, are extricably interwoven. "He creates a living thing, or substantive object, out of the matter with which he works, imbuing the wood, stone, clay, metal, or other material with a vitality that makes it a work of art rather than merely a mass of matter."

$$
\begin{aligned}
& 13 \text { Michael, p. } 90 . \\
& { }^{14} \text { Fearing, p. } 96 .
\end{aligned}
$$


The self portraits expressing a mood or relating to an animal could be appealing subject matter to both the visually minded and subjective minded youngsters as described by Lowenfeld. ${ }^{15}$ Those students who were visually minded would have the opportunity to view themselves as objectively as they wished with the use of mirrors to attain a likeness that satisfied them; conversely, the subjective minded students would have the opportunity to rely on their expressionistic response to the subject without concern for a visually realistic likeness. "Images of man can relate directly to our bodily feelings, so that we find ourselves totally involved, emotionally and physica11y as we11 as intellectually while we contemplate them." 16

This use of self portrait as subject matter should evoke a personal response, and should establish motivation and interest in the student so that the student in a natural way will develop an understanding of sculpture as an art form for creative self-expression. By methods of participation and discovery the student will have the opportunity to gain an awareness of:

1. The differences between the two types of sculpture -relief and freestanding.

2. Basic formative techniques with terracotta.

3. The care of terracotta sculpture.

4. The differences between the additive method and the subtractive method.

5. The variety of materials other than terracotta used by the sculptors.

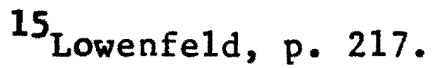

${ }^{16}$ Alan Bowness, Modern Sculpture (New York: Dutton, 1965), p. 9. 
6. Some elements of design relevant to sculpture.

7. The development and implementation of a creative idea into a three-dimensional form.

This unit in terracotta. sculpture lasted approximately seven weeks and was presented in part to a general art class consisting of approximately twenty-nine students at Adams High School, and in part to three classes at the Museum Art School totalling thirty students. The students in all classes ranged in age from thirteen to eighteen years of age. Although the interest of the students at the Museum Art School seemed easier to motivate at times than at Adams High School, there was no appreciable difference between these groups. Most of the students in each situation had not had the experience of working in sculpture with terracotta. 
CHAPTER III

PROJECT OBJECTIVES, METHODS AND TECHNIQUES

\section{AN INTRODUCTION OF TERRACOTTA TECHNIQUES \\ WITH THE FLAT FORM}

Problem 1 .

The following materials were provided:

Terracotta clay

Wirecutter

Rolling pins and $1 / 2$ " bats

Oil cloth pieces

Plastic bags with twist closers and rags

Nails and other materials for staming textures

and patterns

Tongue depressors to manipulate clay

Spray can to keep the pieces moist while in progress

Containers for slip like paper cups

Large pan for washing water (to protect the drains)

Grog to sprinkle on drying shelves to permit the

flat forms to shrink easily

Kiln for firing pieces when they are dry

Before beginning these projects in terracotta sculpture an

evaluation was made of the work space, the class size, and the time

allotment.

The work space included the following areas:

1. A separate area for the clay source, for the washing water, and for the board and tool storage.

2. A smal1 work space for each student at a table or stand.

3. Storage areas in cupboards for unfinished pieces and for other pieces that are drying.

The class size was dependent upon the work space available for

each student. The classes in which these projects were taught fluctuated 
hand-sized hole which contained a variety of tactilly interesting objects attached to the inside. The students seemed to enjoy this experiment while at the same time developing an awareness that both the visual and tactile surface characteristics of sculpture are an important part of the enjoyment of this art form. They were also invited to handle and to feel various pieces of sculpture that were placed about the room. They noticed how line in sculpture can be created by various edges and by places where shapes came together.

The importance of form revealing light and shadow was demonstrated by placing various pieces of sculpture in different kinds of light. Throughout the projects the students evaluated their own work in various kinds of light -- neon light, daylight, and exaggerated light from a sma11 flood lamp in a dark corner in the room. They noticed the patterns of light and shadow that were distributed over their relief scuiptures. They noticed how these patterns of light and shadow moved about their freestanding sculptures as they were turned in the exaggerated light.

The students were introduced to the terracotta the first day. Techniques for wedging the clay were demonstrated, such as cutting with a wire cutter, wedging for the elimination of air bubbles, maintaining the moisture of the pieces with a sprayer, and storage of the pieces between work sessions by wrapping them tightly in moist rags and plastic. The hesitancy of some of the students in handling the material disappeared the first day with the simplicity of developing the flat slab form.

First the students used drawing pencils and newsprint to develop at least one design to scale for the flat slab form. They were encouraged to base this design on any subject that interested them, utilizing either 
Imagined images or real images. They developed an outer shape that was Interesting to them, then within these shapes they continued the development of the designs with patterns and textures.

Each student selected a design to be developed into a terracotta relief form using as many methods as they could discover to develop three-dimensional patterns and textures. Each student was encouraged to be experimental in the manipulation of the clay.

During the seven class periods required to complete this project, the behavioral objectives were generally met which gave each student the opportunity:

1. To develop an idea by making sketches.

2. To develop a terracotta slab form with rolling pins and $1 / 2$ " bats.

3. To apply this planned design to the flat slab form.

4. To treat the surface of this form in a designconscious manner with consideration to line, texture, pattern, light and shadow.

5. To be aware of both the visual and the tactile qualities of the form.

6. To use limited tools such as nails, tongue depressors, and the hand itself to explore techniques for manipulating the clay.

7. To give proper care to the piece between work sessions, including storage in a plastic bag after dampening the piece.

8. To develop an understanding of the techniques for building with terracotta clay.

9. To evaluate the work during its progress in various kinds of 1 ight.

10. To prepare the piece for firing by troughing the back to eliminate warpage, and by placing it on shelves sprinkled with grog to facilitate shrinkage. 
The element of color in relation to sculpture was discussed, and the students noticed how the natural material of sculpture (clay, wood, stone, etc.) can be left visible in many cases. In some cases color is desired by the artist, and this can be applied in numerous ways. Some students chose to glaze their reliefs in the ceramics department, and others chose to leave the naturalness of the clay visible. Oil and turpentine washes, shoe polish, and paste wax were suggested as simple possibilities for adding a finish to their pieces. The students noticed that a single patina evenly applied would allow the three-dimensional qualities of the relief to remain visible.

With the aid of an overhead projector the following reproductions were shown to illustrate various bas and haut relief sculptures utilizing a variety of materials:

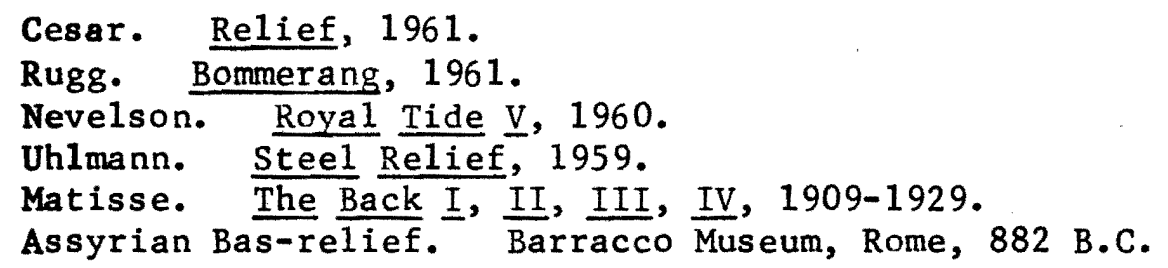

The students displayed enthusiasm for the material. Some discovered that by adding clay to the relief form they could increase the physical depth of the design. This in turn increased the contrast of the lights and shadows. They also noticed that the high points or design could be made to look as though detached from the background or as though a definite part of the background, depending on the depth of undercutting. ${ }^{17}$ Some students chose to develop very low reliefs while others cut into the clay ground and also added additional clay to increase the depth of the design.

$$
17 \text { Rogers, p. } 158 .
$$


They attached these reliefs to an upright board in exaggerated light to evaluate the strength of the darks and lights from various distances. They learned that they could actually control this light by the way they manipulated the clay.

The firing of these reliefs was accomplished two weeks after the completion of the project to assure successful firing. The firing of the remaining terracotta pieces followed weeks of drying time; this is an important aspect to be considered before attempting a terracotta project. Firing can be undertaken by other teachers in ceramics departments if the art teacher does not have access to a kiln.

\section{AN EXPANSION OF THE USE OF TERRACOTTA TECHNIQUES WITH A FREESTANDING FORM}

Problem 2. Self-Portrait Expressing a Mood

The following materials were provided:

Terracotta clay

Plywood boards to hold pieces in progress

Wirecutter for cutting clay

Wire sculpture tools or spoons for hollowing each piece; tongue depressor for sculpture tool

Containers and brushes for slip

Plastic bags, rags for storage of each piece between sessions

Spray gun to moisten pieces periodically

Tables with boxes or sculpture stands to hold each piece at eye level, and to allow the student to turn his piece often while working

Individual hand mirrors for some of the students who wished to use them

Approximately eight hours of class time was needed to complete the project which consisted of a nearly life sized self-portrait expressing a mood.

During the first day a review of the wedging process of clay was made in order to emphasize the importance of building the pieces without 
holes which trap expanding air during the firing process. Other techniques for building the solid terracotta form were introduced such as applying the clay firmly, building the whole piece gradually and uniformly. The students also learned that the solid terracotta form would eventually be hollowed out so that it might be fired without breaking.

The students noticed the major difference between relief sculpture and freestanding sculpture in that the freestanding form is meant to be seen from all sides. Because of this three-dimensionality, a sculptor has the task of developing the piece so that it is interesting from all sides. 18 The students experimented with their stands to see that they could indeed turn easily.

The students were introduced to the subject which was a nearly 1Ife-sized self-portrait bust including their head, neck, and shoulders. The possible affect of emotion upon their body, neck, and head positions was tried out. The students noticed how a sad mood for example might cause a general slump to the figure. The students were asked to choose an emotion that they had felt at one time, or that was perhaps characteristic of their general outlook at this period in their lives. The students were asked to determine at the outset how that emotion would affect all the parts of their portrait bust. They could determine this by visual means with mirrors or by physically feeling the affect in their own bodies as they worked. Later they learned that they were unifying the piece of sculpture with a sense of movement that began with

18 Ray Faulkner and Edwin Ziegfeld, Art Today, 5th ed. (New York: Ho1t, 1969), P. 450 . 
the shoulder position and worked its way up through the neck, then into the head position. This understanding developed as a result of each student building a portrait form which displayed a logical series of movements resulting from the emotional content.

A photograph of Rodin's "Burghers of Calais" was shown to the students to point out an example of tenseness in the figure holding the key which was evidenced in the face and stiff position of the body. The students noticed how the other figures also displayed emotions that were very evident to us. They noticed how the rough surface qualities seemed to relate to the subject. The students decided that

The expressive qualities of the forms of each individual figure change considerably with changes of mood. If a person looks alert, tense, sad, relaxed, vigorous, or languorous this is because there have taken place subtle alterations in the quality and relationships of the forms whose repercussions pervade a great deal of the sculpture of the figure. 19

The following reproductions were shown with the use of the overhead projector to illustrate further how portrait heads and busts are affected by emotion:

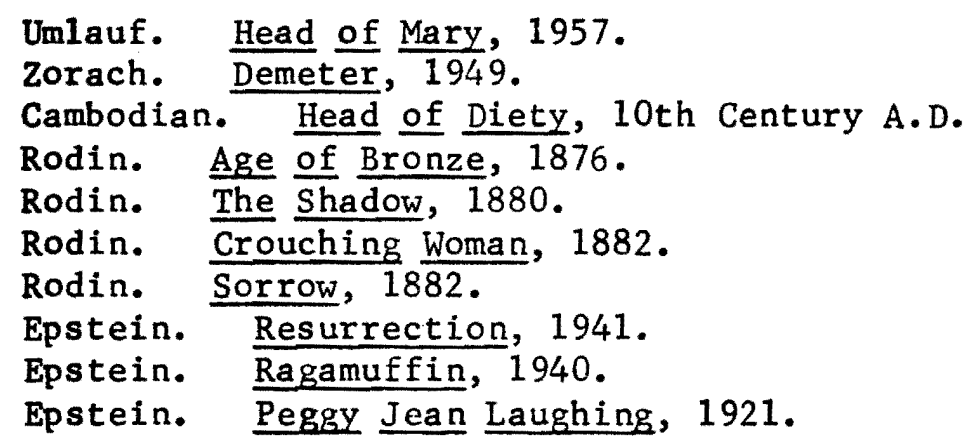

Because beginners in sculpture tend to look for minute detail too soon in their work, the students were encouraged to develop the shoulders, ${ }^{19}$ Rogers, pp. 98-99. 
neck, and head form first before developing anything related to the surface of the piece. After evaluating the positions of these forms in relation to their emotion they could then develop the major hollows and ridges of these forms. Later the use of detail was to be evaluated carefully as to its contribution to the whole effect of the piece.

The students noticed how the use of movement and the quality of the terracotta surface texture alone could evoke a sense of emotion and could be expressive alone without facial features. A strong attemt was made to develop in the students a mature appreciation for the expressive qualities possible in sculptural form. "If we are to appreciate a sculpture as a work of art we must be able to perceive the expressive character of its component forms both in themselves and in the context of the expressiveness of the sculpture as a whole." 20

When the students reached that stage in their pieces where consideration of the surface was necessary a simple demonstration was made to illustrate the relationship of the surface to the form itself. A banana was peeled to illustrate that the surface of a piece of sculpture was not to be likened to the peel, but rather to the fruit itself.

Part of what is involved in appreciating sculpture is noticing the variations that occur on the surfaces of the volumes, but far more importantly, it involves relating these variations and building them into an apprehension of the yolumes as completely three-dimensional expressive forms. 21

The students noticed the simplicity of the shape of the fruit, its

$$
\begin{aligned}
& 20_{\text {Rogers, }} \cdot 18 . \\
& 21_{\text {Rogers, p. } 34 .}
\end{aligned}
$$


"quiet" form, and how the soft, uninterrupted surface of the fruit related directly to the character of the form.

The following reproductions were shown with an overhead projector to illustrate how content (or the idea about the subject to be conveyed) can be reflected in the form and surface characteristics of portraits:

Bourdelle. Beethoven, Grand Masque Tragique, 1901. Rosso. Ecce Puer, 1906-7. Boccioni. Anti-Gracefu1 (The Artist's Mother), 1912. Brancusi. Mlle. Pogany, 1920.

The students were also asked to look at and feel the various sculptures on exhibit in the Portland Art Museum's court that deal with the subject of womanhood in various ways: Henry Moore's "Reclining Figure", Auguste Renior's "Venus Victorious", and Wilhelm Lehmbruck's "Standing Woman". The students noticed the artists' different approaches to the subject of women. The students, for example, noticed how Henry Moore's rough, bone-1ike forms suggested an ancient, fossilized symbol of mother earth, ${ }^{22}$ whereas, Renior's monumental, voluptuous figure seemed more ideally feminine, and symbolic of mother nature. ${ }^{23}$

In addition to discussing form, content, and surface characteristics, the importance of light as a revealing agent was emphasized. The students were again encouraged to evaluate their pieces in various kinds of light -this time from all sides. After the major forms of the portraits had been established, all lights were turned off in the room except for one bank of spot lights situated directly in front of a large window. With this exaggerated ob1ique 1 ight source the students noticed that they

22 Bowness, p. 99.

$23 \mathrm{John}$ Canady, Mainstreams of Modern Art (New York: Holt, 1959) p. 221. 
could see the forms, the lights, shadows, textures and line more easily In their pieces. They looked for a balance of lights and darks about their pieces and learned that by the use of concavities and convexities, they could create darks and lights where they wanted them. Later a spot light was set up in a dark corner of the room and was used by the students throughout the project. The students took turns rotating each others portraits in this strong revealing light so that the artist could evaluate it from a distance. By doing this, the students noticed that "The play of 1ight on sculpture -- freestanding (in the round) and relief (attached to a background) -- is essential to bring out the actual depth and volume that exists in varying degrees in every work." 24

The last two hours of the project were spent hollowing the pieces to prepare them for firing. 25

It was a delight to see the students' involvement in their portraits. They handled the more difficult technical requirements of the freestanding sculpture very well through the project. As the portraits began to take on $\dot{a}$ sense of life, each student became especially enthusiastic about the project. One boy said, "It's weird. I feel like I'm looking at myself."

In summary, during this project each student had the opportunity:

1. To choose a strong personal feeling that would affect his body with a general sense of movement.

2. To build a freestanding sculpture in his own likeness which bore evidence of this emotion throughout (by movement, surface qualities, and facial expression).

${ }^{24}$ Fearing, p. 101.

${ }^{25}$ See Illustrations for Hollowing Sculpture. 
3. To build this sculpture gradually in a uniform manner with consideration given to all sides.

4. To evaluate the piece in different kinds of light for form and organizational elements.

5. To hollow the sculpture in preparation for firing.

Problem 3. A Self-Portrait Wearing Head Gear

An alternative to the self-portrait expressing an emotion is a self-portrait which reacts to the activity that is related to head gear worn by the student, for example, the bust of the student might show the tension felt by a skier (wearing a ski cap) about to descend a steep slope.

In this problem the same concepts were presented and the same approach was taken with a few exceptions. First, the students were encouraged to chose head gear that they would like to have, or that they already had so that a choice could be made between an imaginative or a real situation. The students were also invited to wear the head gear if they wished to attain a visually realistic likeness with mirrors, or they could rely on how they thought this activity would make them look and feel.

The second exception was the addition of a fourth form (besides the shoulders, neck and head) and this was the head gear itself. The students noticed that the hat in most cases was merely an extension of the head form.

After presenting the two portrait projects to different classes and comparing the results, one conclusion was made that the head gear provided an added element of interest to the students. They tended to 
add the clothing that was related to the head gear and this provided more opportunity for line, texture, 1ight and shadow.

The following additional reproductions were shown with the overhead projector to illustrate portraits wearing head gear:

Epstein. Self Portrait in a Cap, 1912.

Epstein. Tin Hat, 1916.

Epstein. Romi11y John, 1907-8.

III. AN EXPLORATION OF THE USE OF TWO FORMS, RELATING AND UNIFYING THEM

INTO A SINGLE SCULPTURE IN TERRACOTTA

Problem 4. Self-Portrait With An Anima1

The final problem extended the students' exploration of the threedimensional form by relating and unifying a self-portrait form and an animal form into a single sculpture in terracotta. The subjective motivation used to carry their efforts through the project was each student's personal expression of how he felt about himself in relation to any animal. The visual motivation was each student's understanding of how he would look in relation to any animal. All or part of each figure could be used.

By manipulating the clay to build the forms the students had the opportunity to explore the problems of balancing these forms, relating them, and unifying them into a single sculpture that would be a personal expression as well. Some students chose to build the self-portraits and the animal simultaneously, one growing out of the other so that the whole sculpture slowly developed as a single piece. Other students developed their sculpture with the incorporation of negative spaces, and moved the forms about freely to find the best relationship. 
The students were encouraged to be totally free in their choice of an animal which could be domestic or wild, a pet, a fish or fowl, or a fantastic animal such as one dating from prehistoric times. Their relationship to this animal could be imaginative or real. It could be one of total admiration, fear, hate, joy or any other feeling. Their relationship could be symbolic of the way they felt about themselves and others, or the way they saw thenselves.

A number of reproductions were shown to the class with the overhead projector to illustrate the relationship of man to animal in real, imaginative, and symbolic situations as portrayed by various sculptors. Leonard Baskin's Oppressed Man, 1960, was shown to illustrate the use of two similar forms together.

The man's features are pulled out of position and distorted into the shape of anguish. The head rests directly on the base and is severed altogether from the body. There is perhaps a riddle in the bird, which, ordinarily a symbol of freedom, is here the only visible source of the oppression wrought upon the head. 26

John Flanagan's Jonah and the Whale, 1937, was shown to illustrate that

There is a handsome contrast between the huge simplicity of the whole and the subtle treatment of the figure of Jonah trapped in the whale's belly, and Flanagan has humorously conveyed the discomfort of both participants in the sculptural drama. 27

Charles Salerno's Sad Victory, 1946, was shown to illustrate the use of symbolism for social commentary, as Salerno explains: "This work is the ${ }^{26}$ Faulkner, p. 460 . 27 Ibid. 
antithesis of the Greek Winged Victory which is happy in spirit. In Sad victory, I feel there would be no Peace so the dove is dead." 28 William Zorach's Child and Cat, 1926, was shown to illustrate a more conventional, very real and tender relationship between the two forms which are united in a very well-balanced and compact sculpture. ${ }^{29}$ A series of Marino Marini's Horse and Rider sculptures, 1940-1950, were shown to illustrate the use of complete human and animal forms in various relationships. 30

A collection of source books was also on hand for each class period and the students were encouraged to use them freely on a more individual basis. The students were encouraged to take their time in making their choices and developing their ideas. To clarify their ideas the students made sketches with drawing pencils on bond paper, then worked out some of their favorite ideas in small quick clay sketches. This helped them to visualize the pieces before beginning on the large sculpture. Each student discussed his choices at length. Most technical and aesthetic questions were answered during this exploratory period. By making these sketches the students established the content for their sculptures. They experimented with the forms that their pieces would take in relation to that content. They explored the use of compact single sculptures and sculptures using negative space. Later the use of texture, 1ight and shadow would be emphasized as the large pieces developed.

${ }^{28}$ Dona 2. Meilach, Contemporary Stone Sculpture: Aesthetics, Methods, Appreciation (New York: Crown, 1970), p. 22.

29 Meilach, p. 17.

${ }^{30}$ Eduard Trier, The Sculpture of Marino Marini (New York: Praeger, 1961) pp. 66-73. 
During the ten hours required to complete the portrait with an animal, each student had the opportunity to:

1. Experience the three-dimensionality of sculptural form.

2. Develop competence in the handling of terracotta.

3. Improve his understanding of the elements of design related to sculpture such as content, form, and organization.

4. Utilize elements of design to develop a well-balanced unified piece of sculpture with two related forms.

5. Evaluate the piece as it progressed in various kinds of 1 ight and at different distances.

6. Express himself in a personal way in a threedimensional art form.

7. Have the satisfaction of developing a work of art over an extended period of time to a point of completion.

8. To hollow the piece and prepare it for firing.

The students' committment to their ideas, and the involvement and effort which they displayed to express their ideas was a delight to see. 
CHAPTER IV

CONCLUSIONS

\begin{abstract}
Design lies in a knowledge of materials, of their possibilities and limitations and of the skill required to achieve their fullest expression. It exists in the body and mind of the artist, who receives inspirations through his senses. And it is through the crucible of his creative power that he transforms them into new entities of his own making. 31
\end{abstract}

This unit sought, first, to develop in secondary students a knowledge of sculptural techniques for handling terracotta; second, this unit sought to inspire or motivate the secondary students by utilizing a subject of great interest to them, their own images; third, this unit sought to bring together the students' understanding of the material and their motivation for self expression -- to transform their ideas into three-dimensional works of art; fourth, this unit sought to introduce to the students those art concepts related to sculpture that would be immediately helpful to them while working.

Admittedly it is not possible in just four projects to teach secondary students an understanding of sculpture that has taken accomplished sculptors years of work to discover. However, this author is convinced that secondary students are capable of understanding mature art concepts and, furthermore are interested in experiencing these 31 Bevlin, p. 366 . 
concepts if they could be applied immediately to specific needs related to their own work. In other words, these concepts related to sculptural form, organization, and content must have the purpose of helping the student express himself more effectively and must be immediately applicable to a subject in which the student is very interested.

...The rigid teaching of composition may be more harmful than useful when function of expression is more important than learning rigid rules. If, however, composition grows out of individual needs, if it becomes a means of helping the student to express what is in his mind, it will be an important tool. 32

The projects of this unit were organized into a series of progressively more challenging subjects to gradually increase the students' confidence in handling the material and to gradually develop the students' understanding of sculptural design. The choice of the sculptural material and method was limited to a single material using a simple method -- namely, terracotta with the additive method to illustrate that the expressive possibilities of sculpture can be learned and experienced in depth with this simple approach.

After the students' confidence in handling clay was established with the flat slab form they produced a series of sculptures dealing with the self-portrait. One portrait dealt with the self-portrait expressing a mood; another portrait expressed the students' reaction to special head gear chosen by the student; the third dealt with the portrait in direct relationship to an animal. By experiencing the expressive qualities of their self-portraits the students learned that

${ }^{32}$ Lowenfeld, p. 352. 
In our perception of three-dimensional form we do not simply apprehend its geometric properties, its shape as such; we become aware also of its expressive character. These two aspects are in fact inseparable; we perceive not just forms, but expressive forms. 33

Not until the students had experienced this concept personally with their own expressive forms could they truly understand what this means from an artist's point of view.

Even in this single unit there was evidence that

The more visually inclined student will be more concerned with surface appearances and differences in size and proportions, whereas the student who is more haptically inclined will concentrate more on his subjective expression and kinesthetic experiences in sculpture. 34

For example, some students completely ignored the use of mirrors in developing their self-portraits expressing a mood; they contorted their heads and grimaced their faces in physical response to the emotion. On the other hand, other students were at times very dissatisfied that they couldn't obtain a very realistic image of themselves; they worked very hard to obtain this likeness, sometimes by using two mirrors at once.

It was interesting to learn that in all of these classes that were involved in this unit, the students were asked whether or not they had ever had sculpture projects like these before. All of the students answered that they had never made three-dimensional self-portraits before. Nearly all the students described their past experiences in clay as being related to ceramics. This unit attempted to illustrate that

$$
\begin{aligned}
& 33_{\text {Rogers, p. } 17} \\
& 34 \text { Lowenfe1d, p. } 337 .
\end{aligned}
$$


secondary students also have a need for projects dealing with three-

dimensional expressive forms related to sculpture because "At all levels of creative performance children need to have the encouragement to progress beyond their present capabilities and to come closer to a genuinely creative spirit." 35 


\section{A LIST OF WORKS CONSULTED}

Bevlin, Marjorie E. Design Through Discovery, 2nd ed. New York: Holt, Rinehart and Winston, Inc., 1970.

Bowness, Alan. Modern Sculpture. London: Studio Vista Ltd., 1965.

Canady, John. Mainstreams of Modern Art. New York: Ho1t, Rinehart and Winston, 1959.

Faulkner, Ray and Edwin Ziegfeld. Art Today, 5th ed. New York: Ho1t, Rinehart and Winston, 1969.

Fearing, Kelly, Evelyn Beard, Nik Krevitsky, and Clyde Martin. Art and the Creative Teacher. Austin: W. S. Benson and Company, 1971.

Hoffman, Malvina. Sculpture: Inside and Out. New York: Bonanza Books, 1939.

Lederer, Helmut and Eduard Trier. The Sculpture of Marino Marini. New York: Praeger, 1961.

Lansing, Kenneth M. Art, Artists, and Art Education. New York: McGraw Hil1, 1970 。

Lowenfeld, Viktor and Lambert Brittain. Creative and Mental Growth, 4th ed. New York: Macmillan, 1964.

Meilach, Dona Z. Contemporary Stone Sculpture: Aesthetics, Methods, Appreciation. New York: Crown, 1970.

National Society for the Study of Education. Art Education. Ed Reid Hastie. Chicago: University of Chicago Press, 1965.

Read, Herbert. A Concise History of Modern Sculpture. New York: Praeger, 1964 .

Rogers, L. R. Sculpture: The Appreciation of the Arts/2. London: Oxford University Press, 1969. 


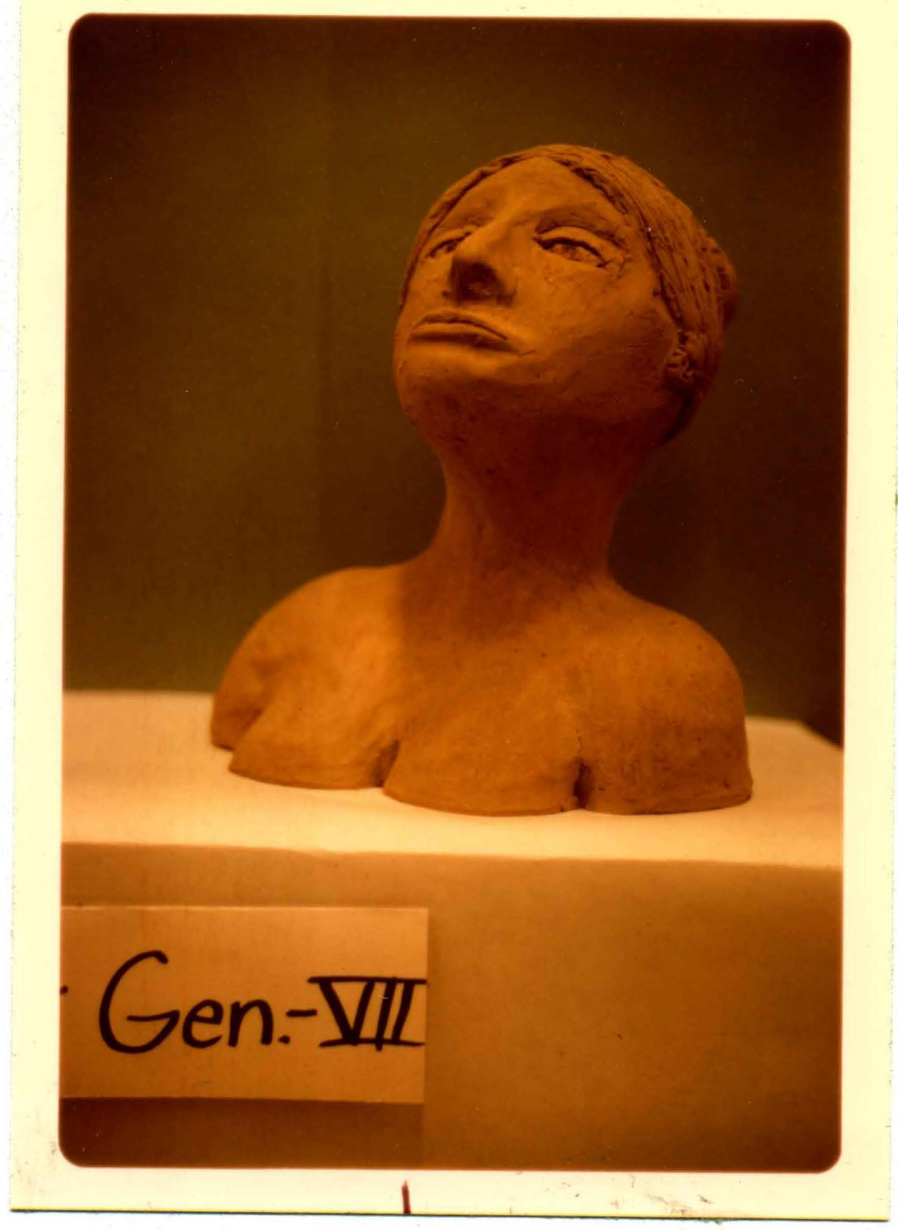

Mood: Pride

Figure 1. Results of Problem 2, p. 16. 


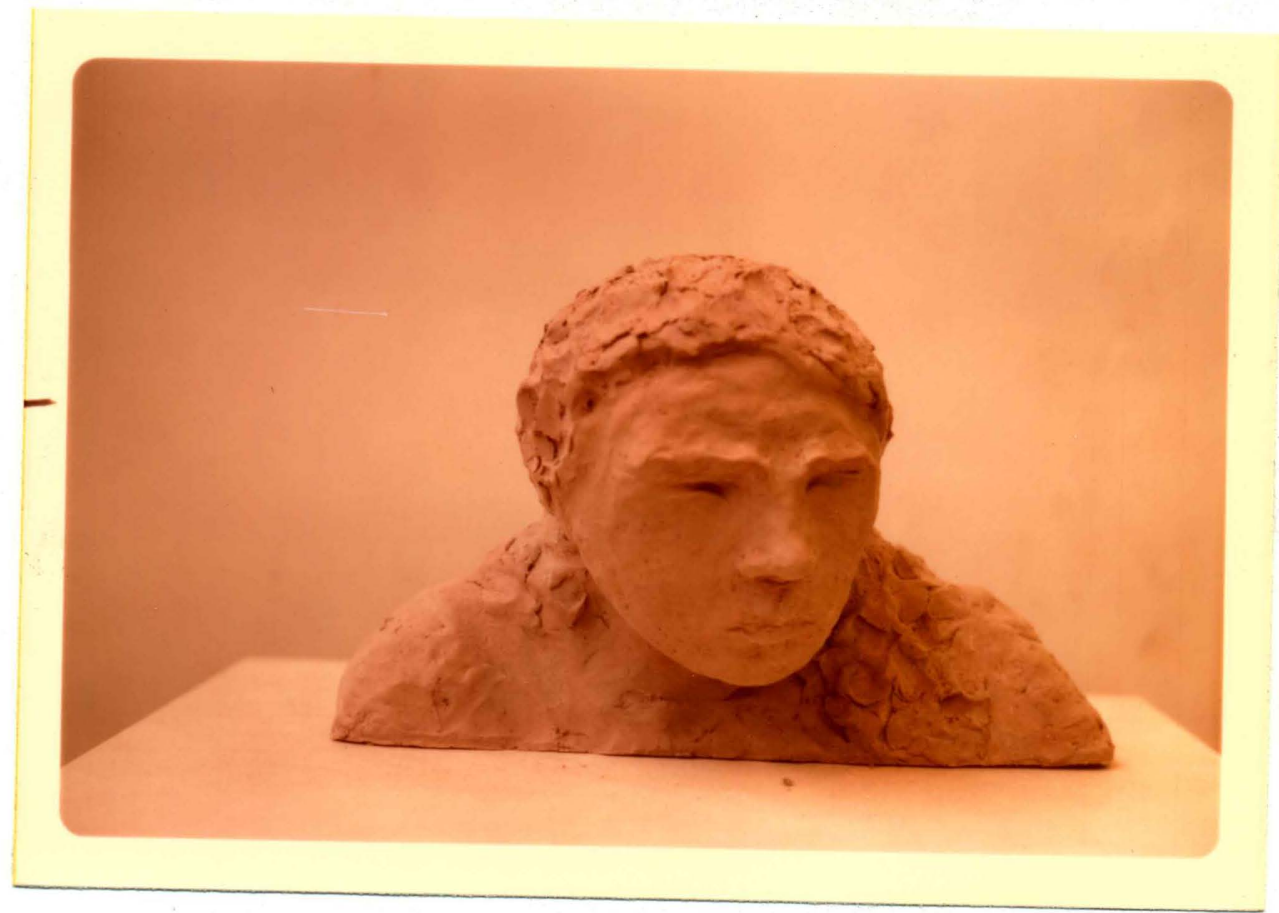

Mood: Anger

Figure 2. Results of Problem 2, p. 16 (continued). 


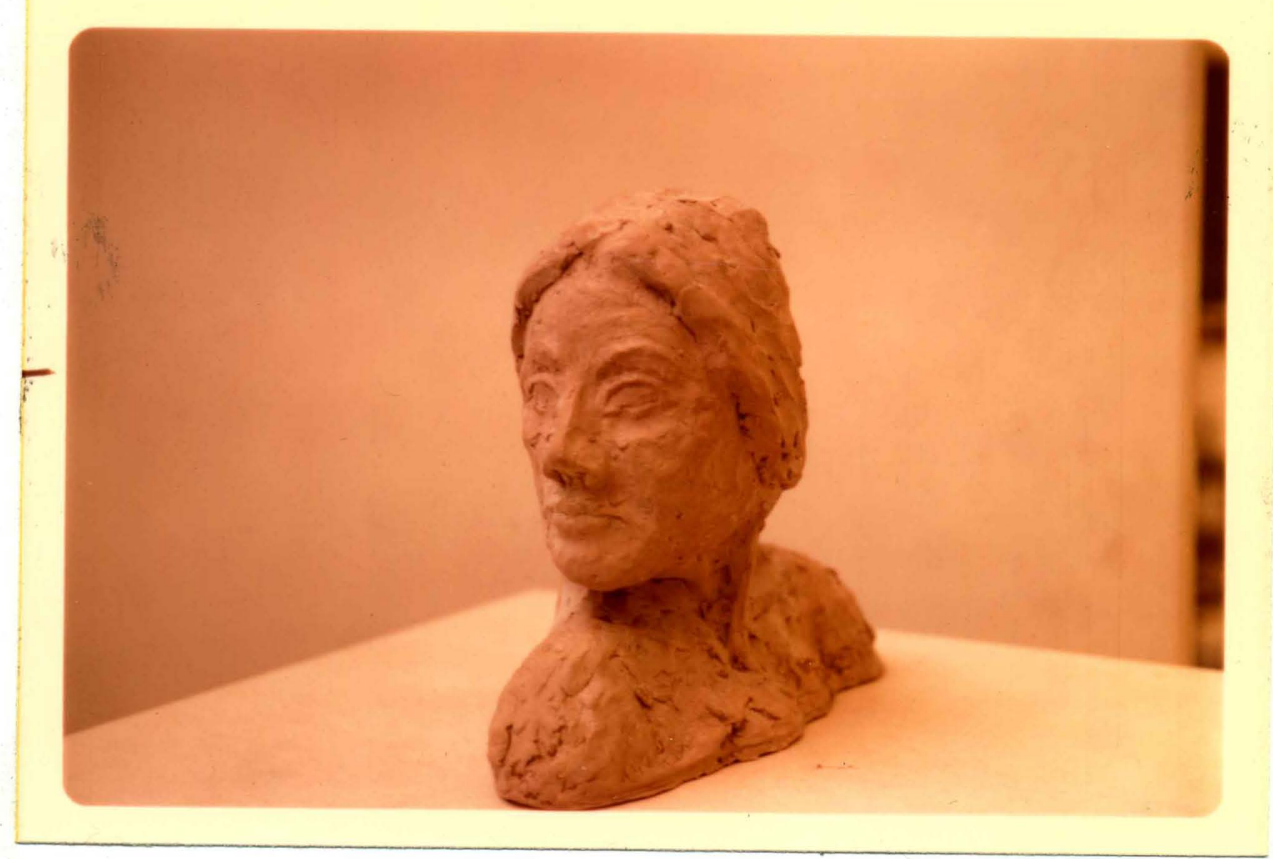

Mood: Wonder

Figure 3. Results of Problem 2, p. 16 (continued). 


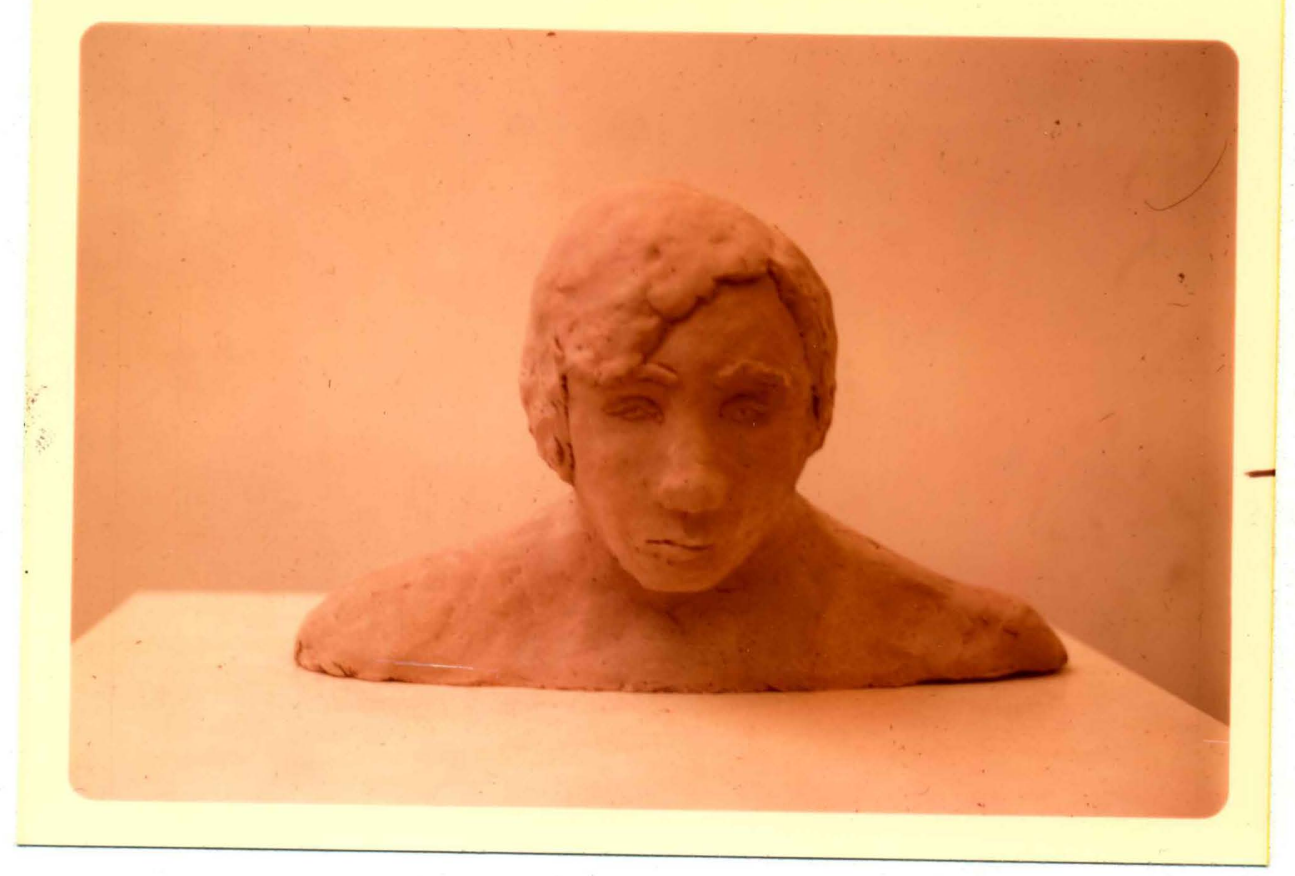

Mood: Sadness

Figure 4. Results of Problem 2, p. 16 (continued). 
-

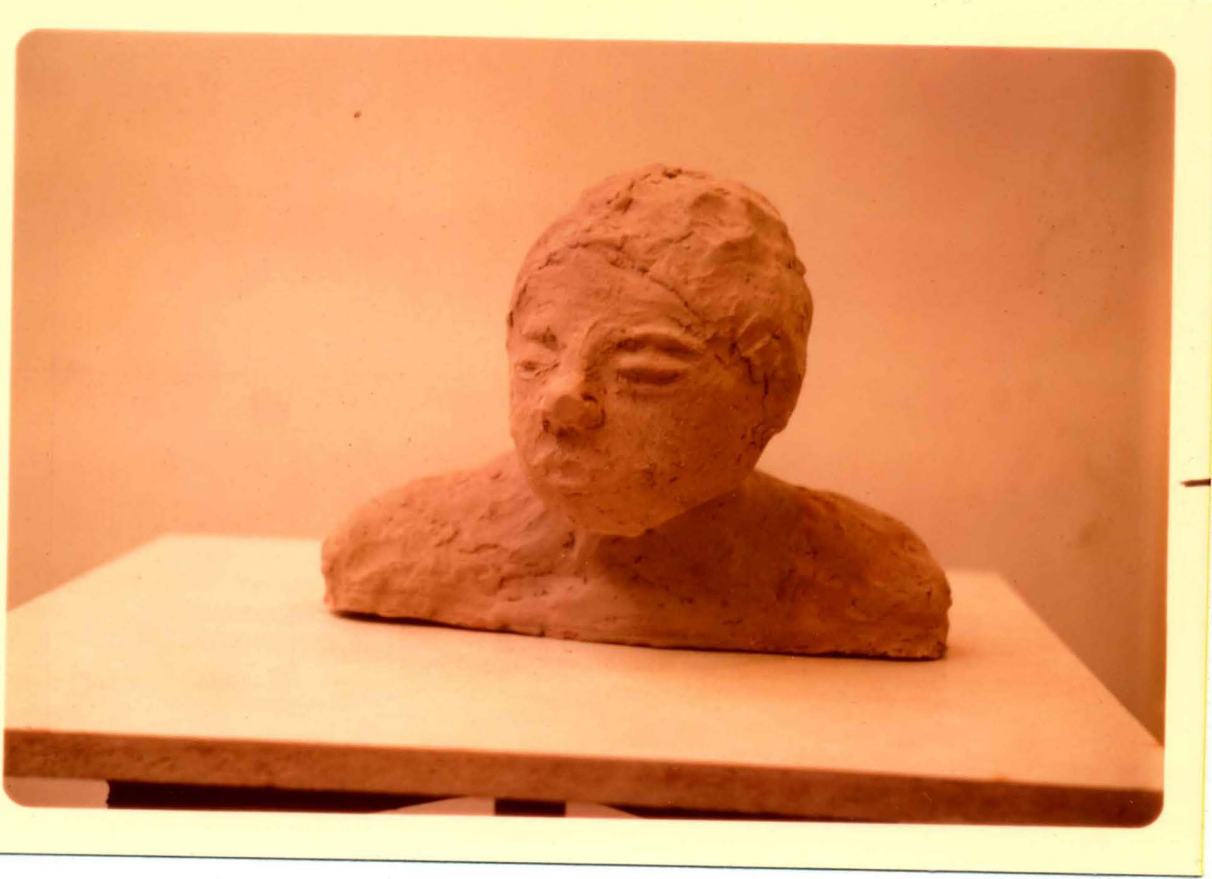

Mood: Disgust

Figure 5. Results of Problem 2, p. 16 (continued) 


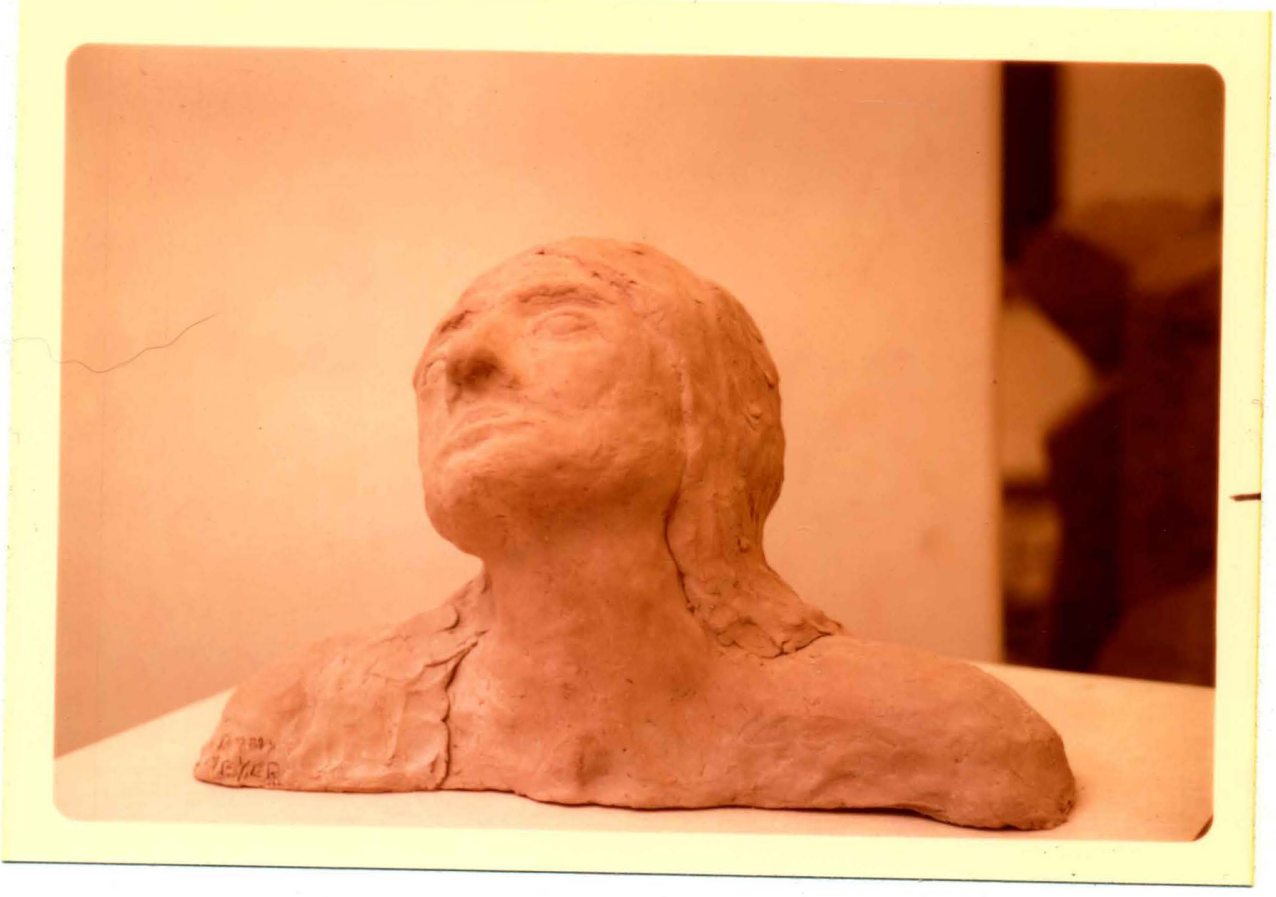

Mood: Dreamy

Figure 6. Results of Problem 2, p. 16 (continued) 


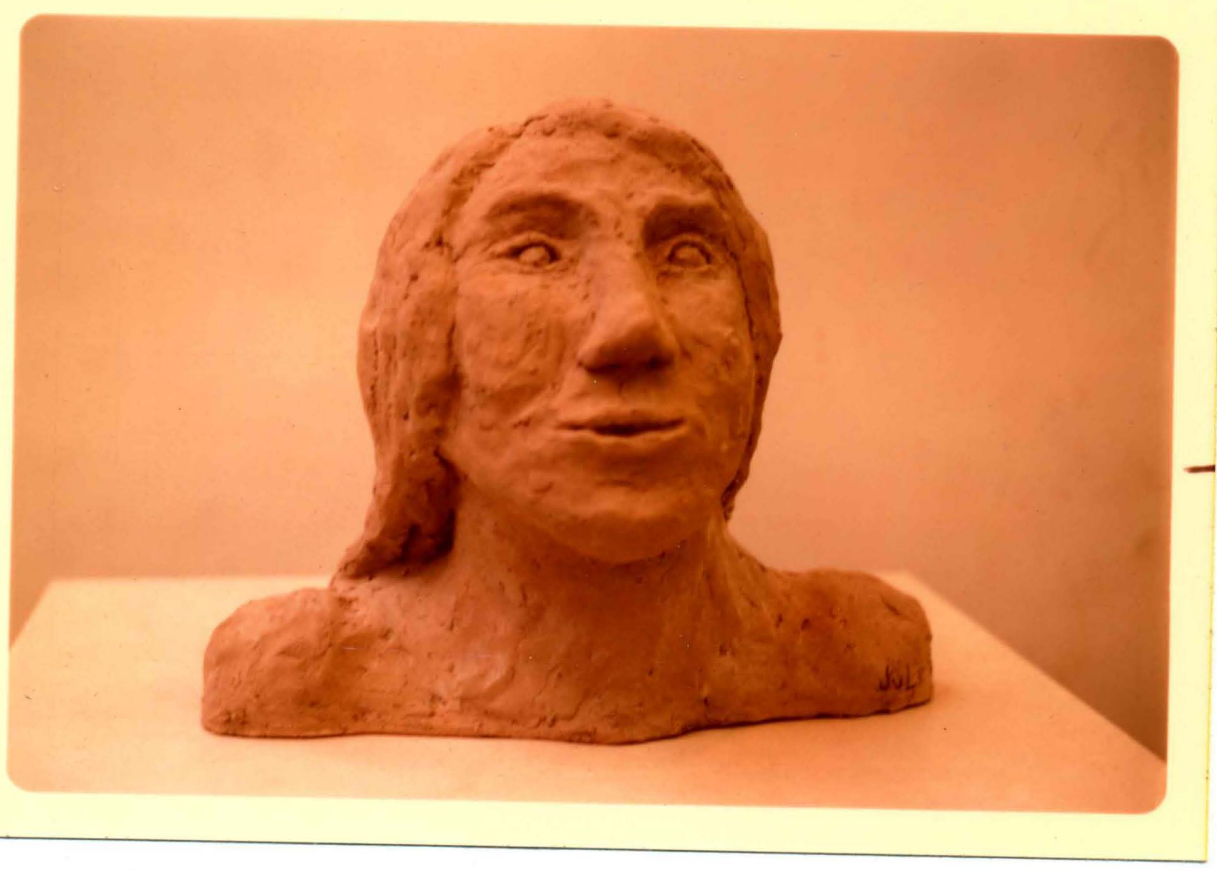

Mood: Surprise

Figure 7. Results of Problem 2, p. 16 (continued). 


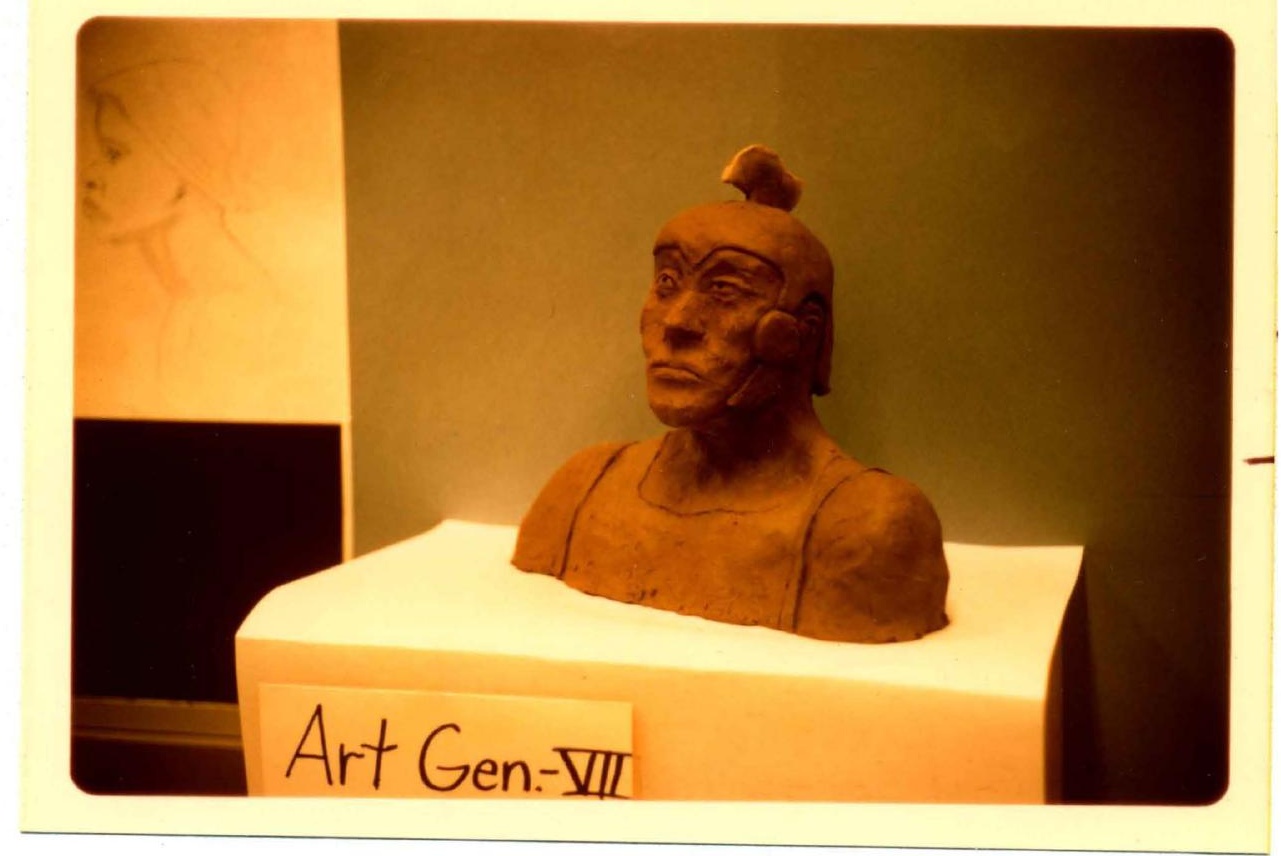

Headgear: Roman Warrior's Helmet

Figure 8. Results of Problem 3, p. 22. 

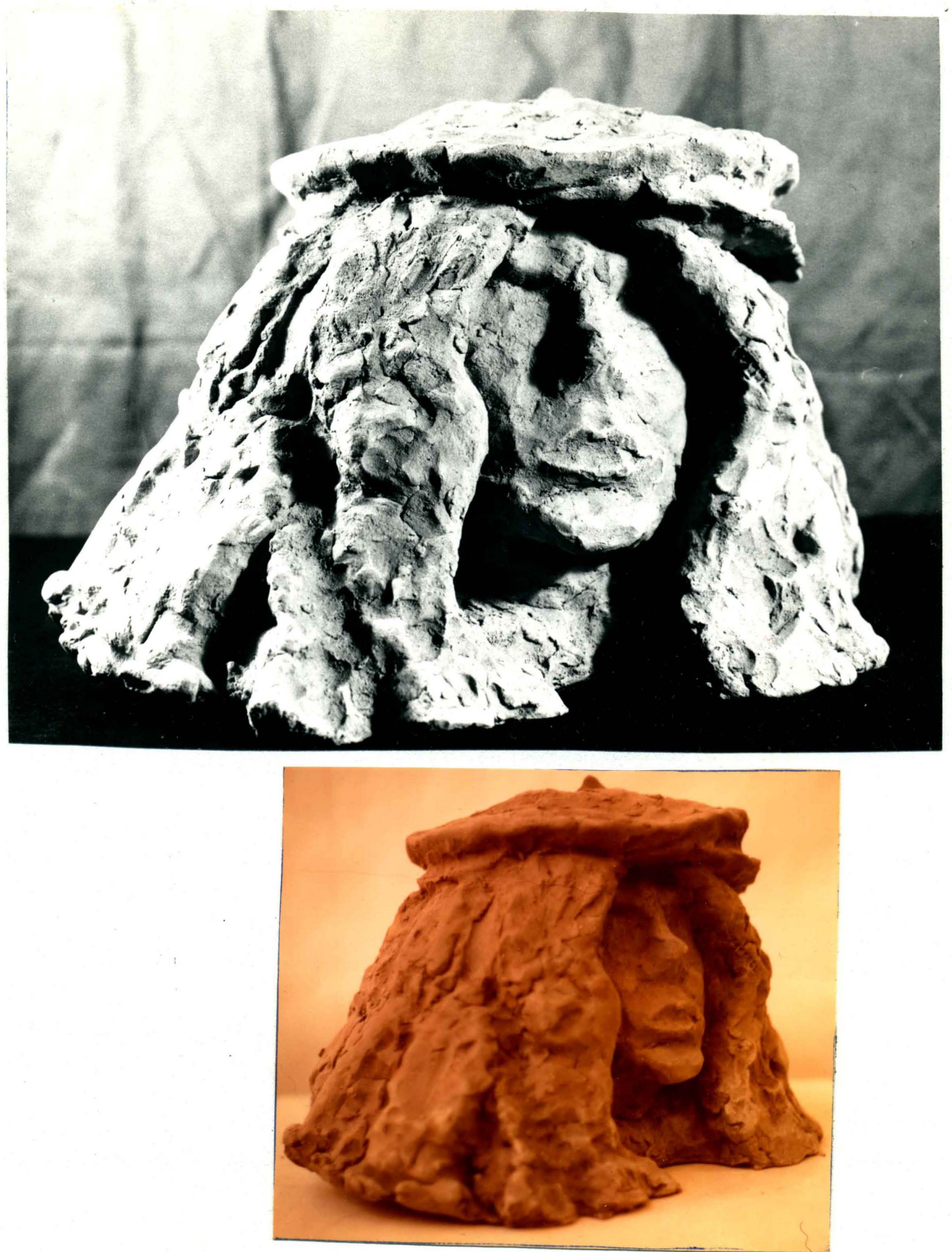

Headgear: Thinking Cap

Figure 9. Results of Problem 3, p. 22 (continued). 


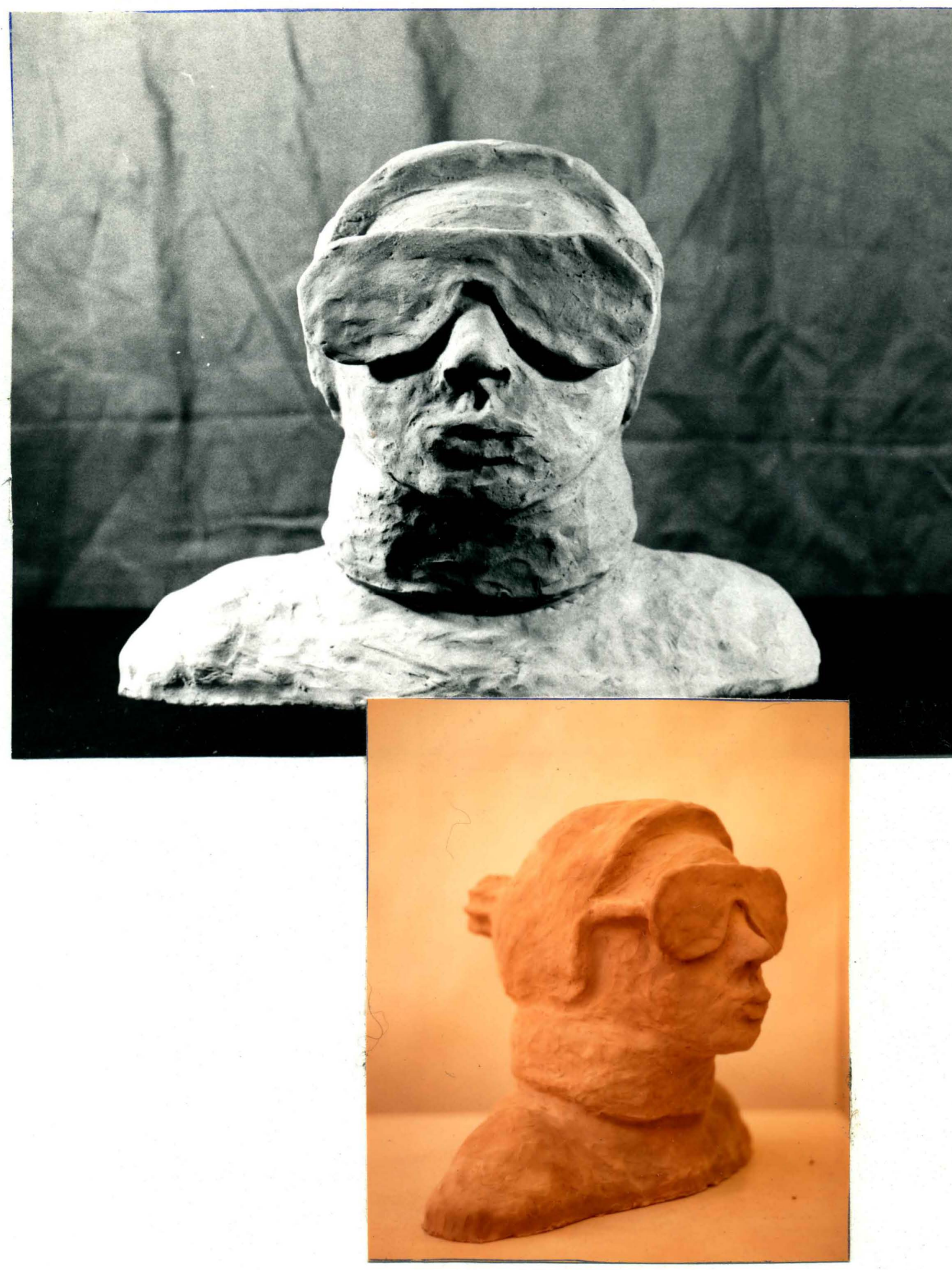

Headgear: Skier's Hat and Goggles

Figure 10. Results of Problem 3, p. 22 (continued) 


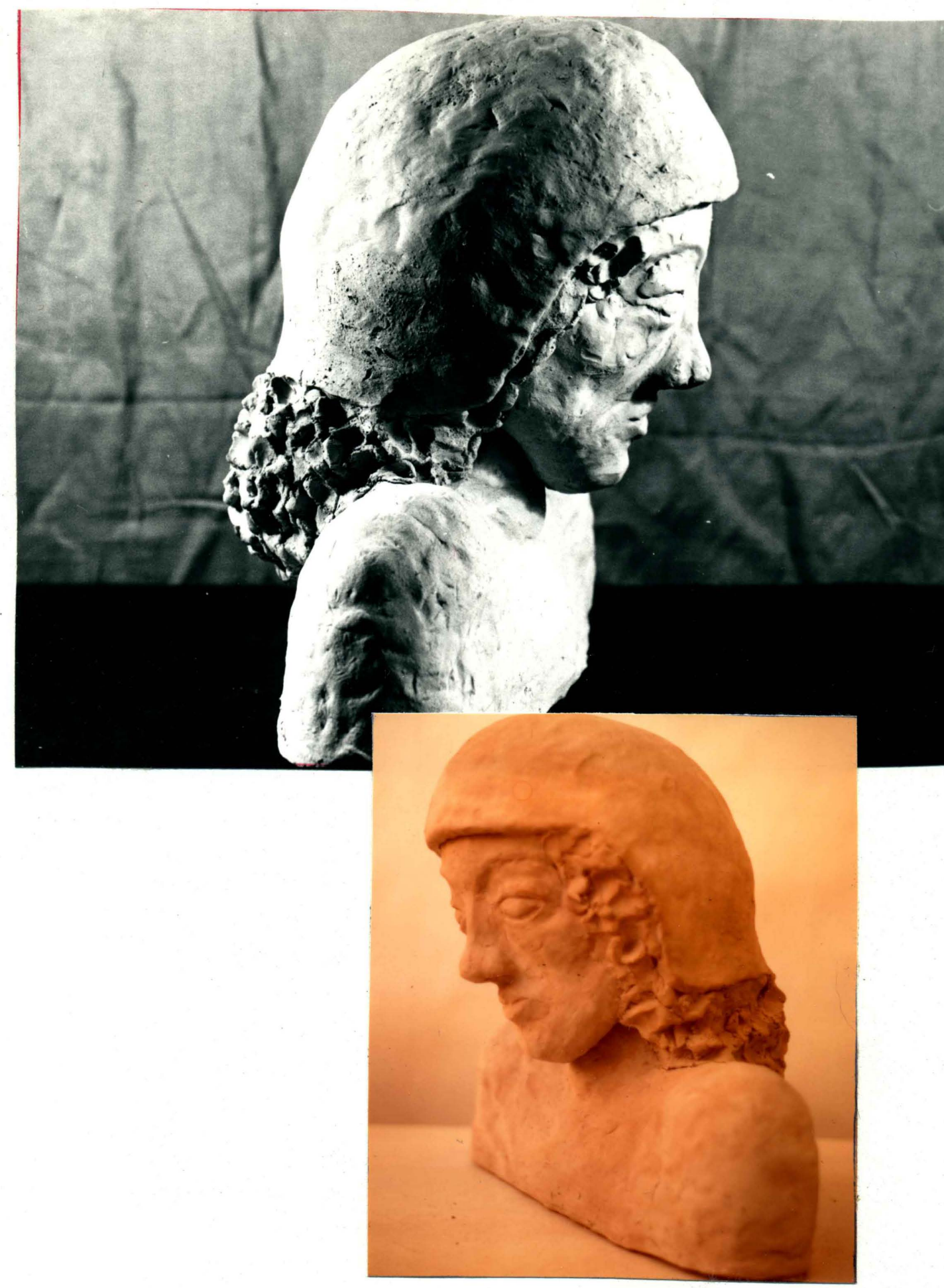

Headgear: Snow Hat

Figure 11. Results of Problem 3, p. 22 (continued). 

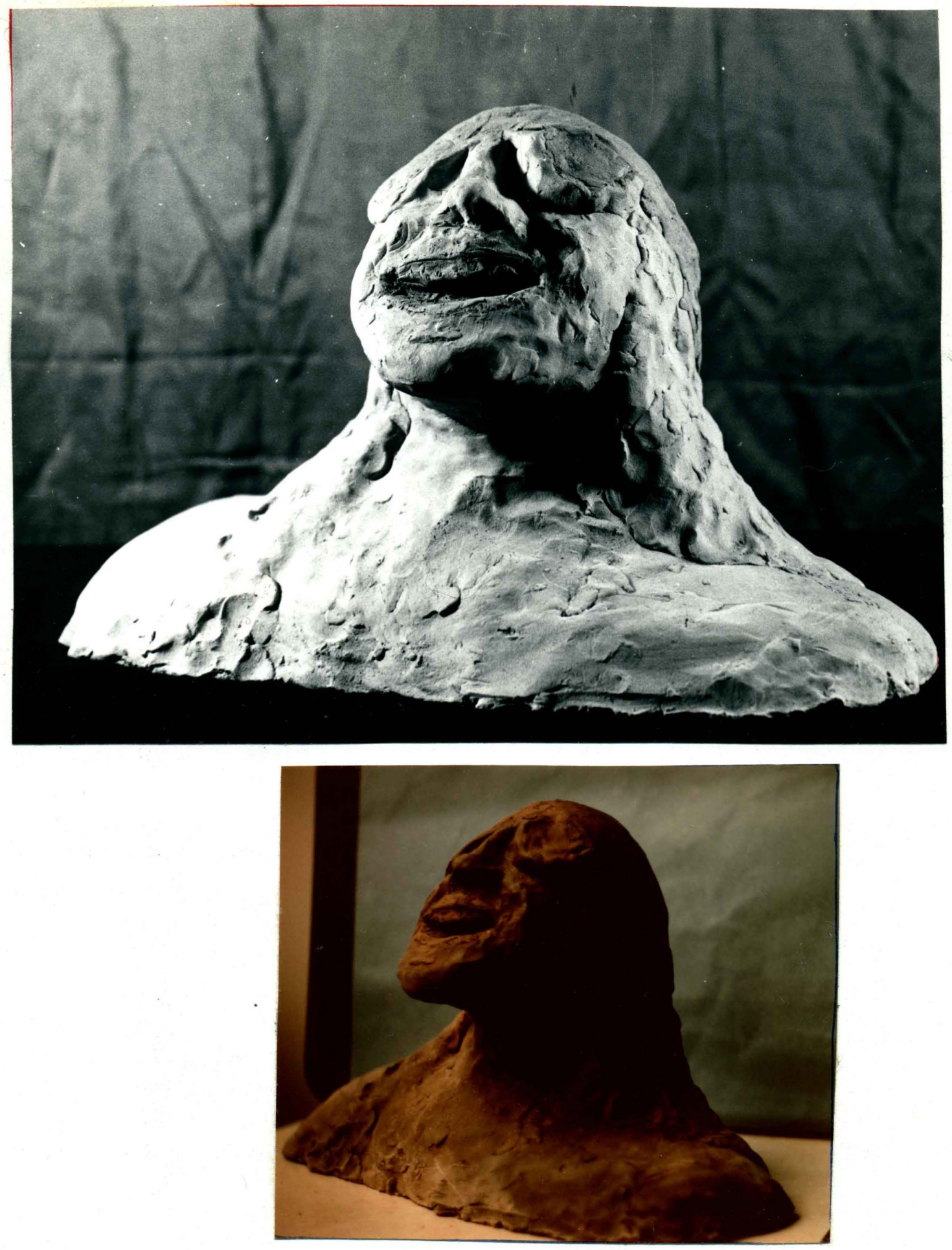

Headgear: Motorcyclist's Hat and Goggles

Figure 12. Results of Problem 3, p. 22 (continued). 

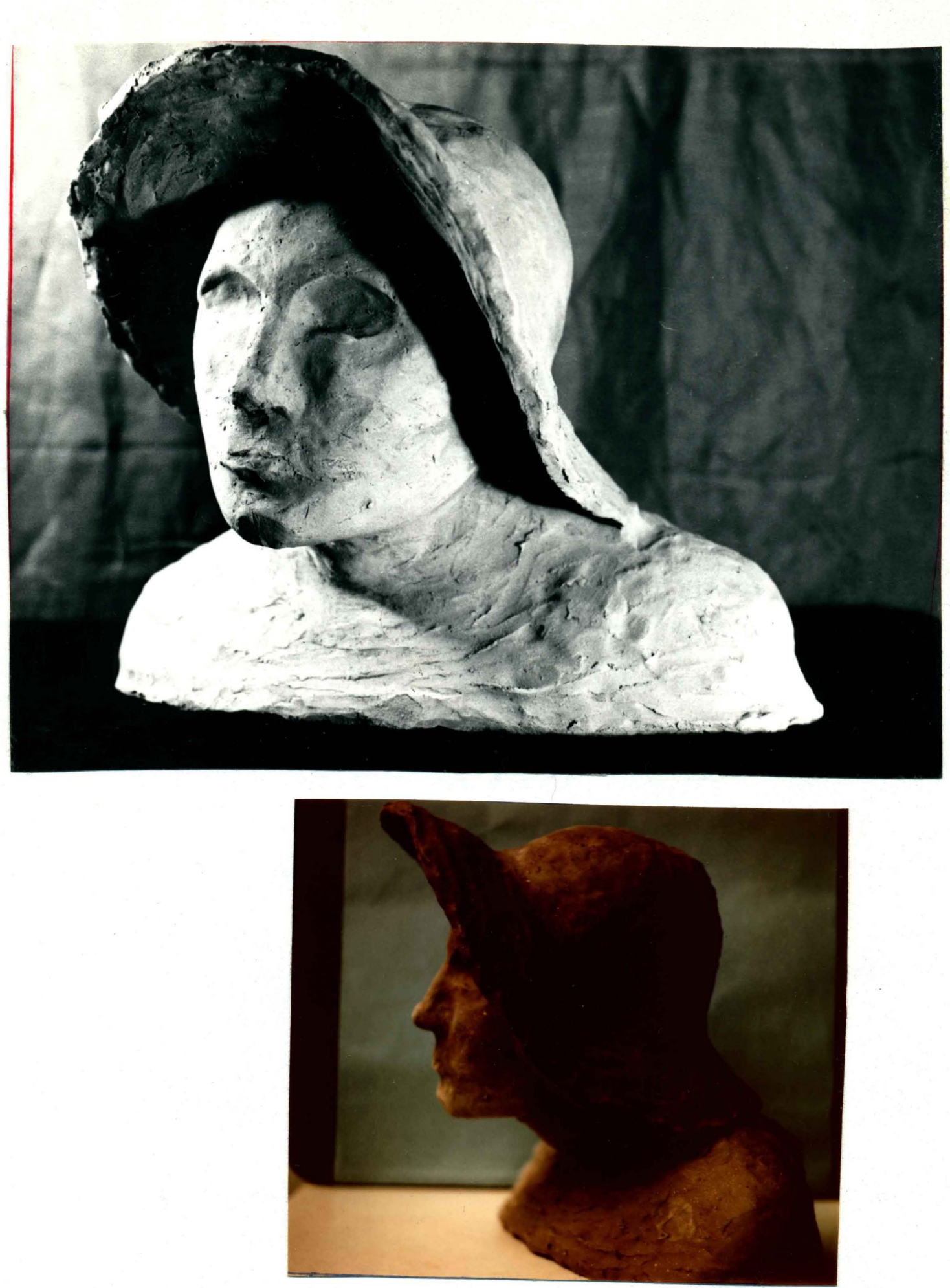

Headgear: Whaler's Hat

Figure 13. Results of Problem 3, p. 22 (continued). 


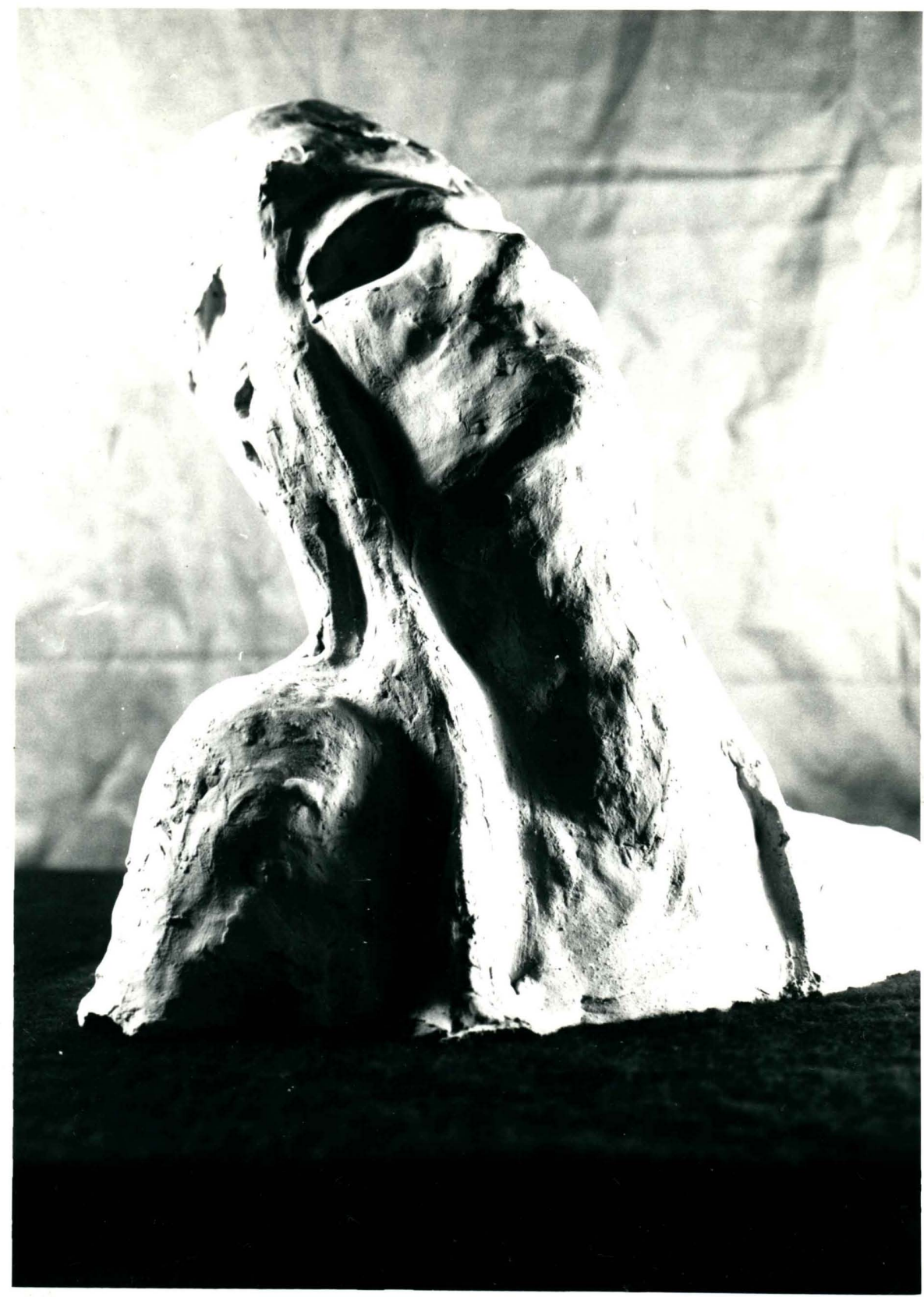

Headgear: Scuba Diver's Mask

Figure 14. Results of Problem 3, p. 22 (continued). 


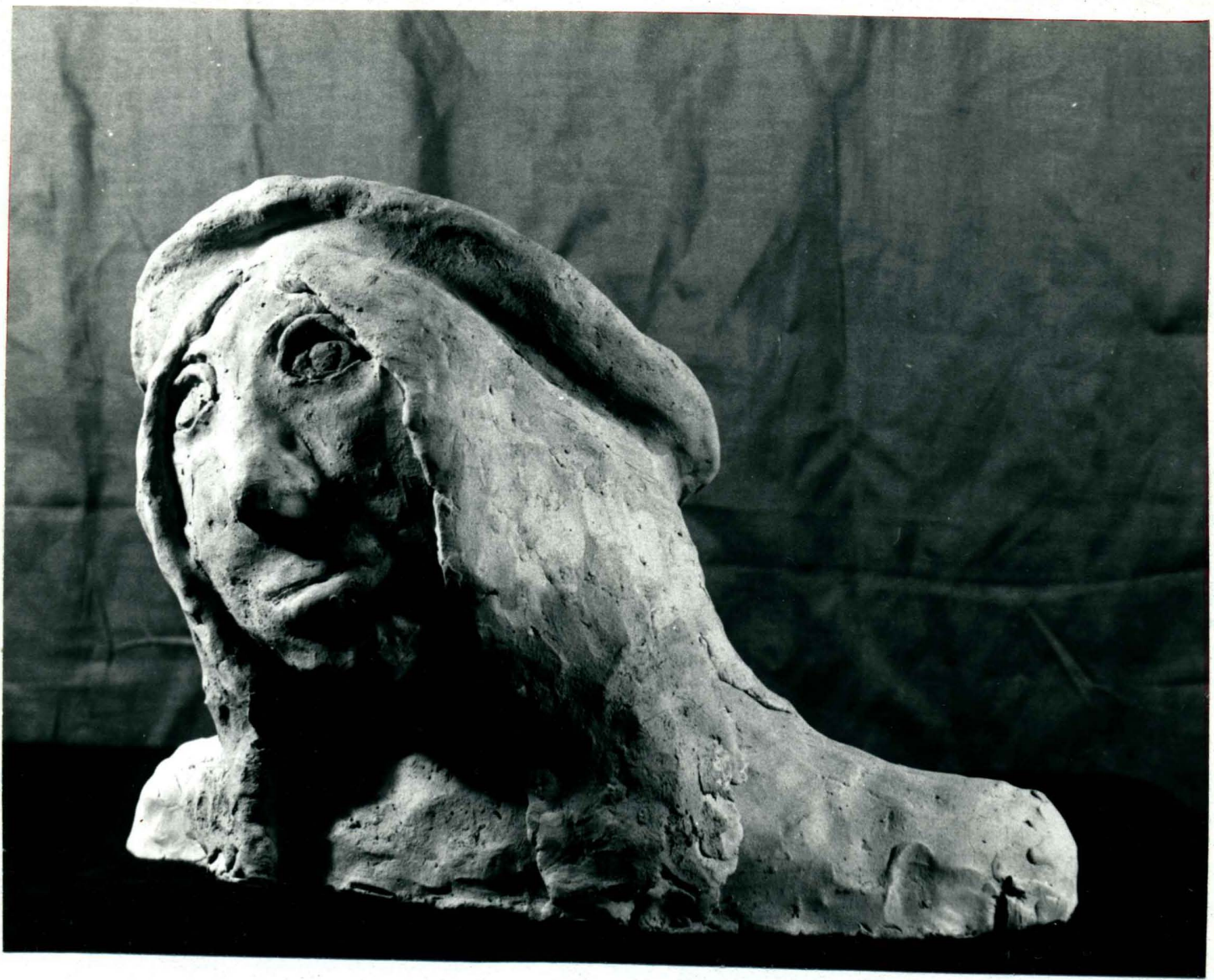

Headgear: Everyday Hat

Figure 15. Results of Problem 3, p. 22 (continued). 


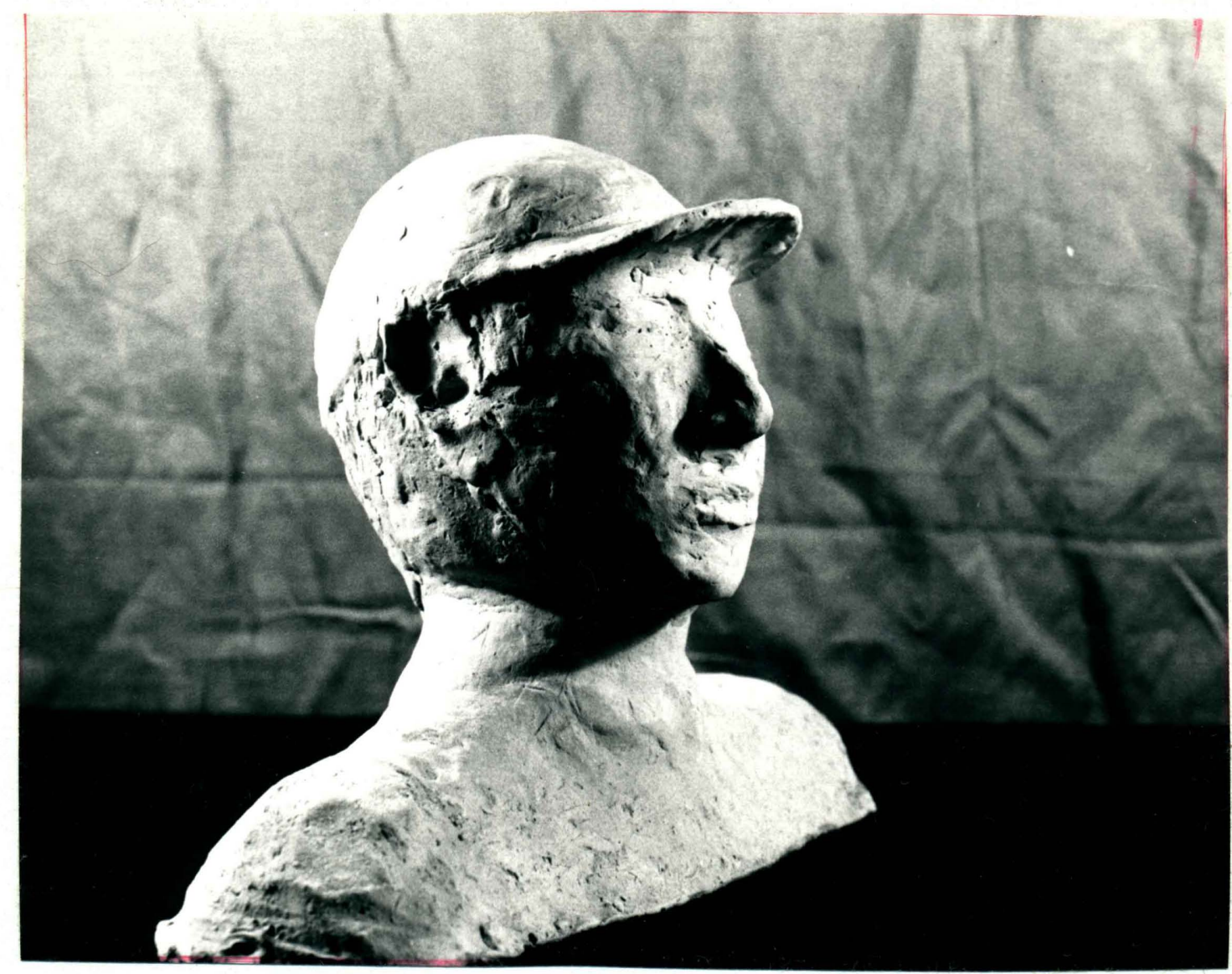

Headgear: Golfer's Cap

Figure 16. Results of Problem 3, p. 22 (continued). 


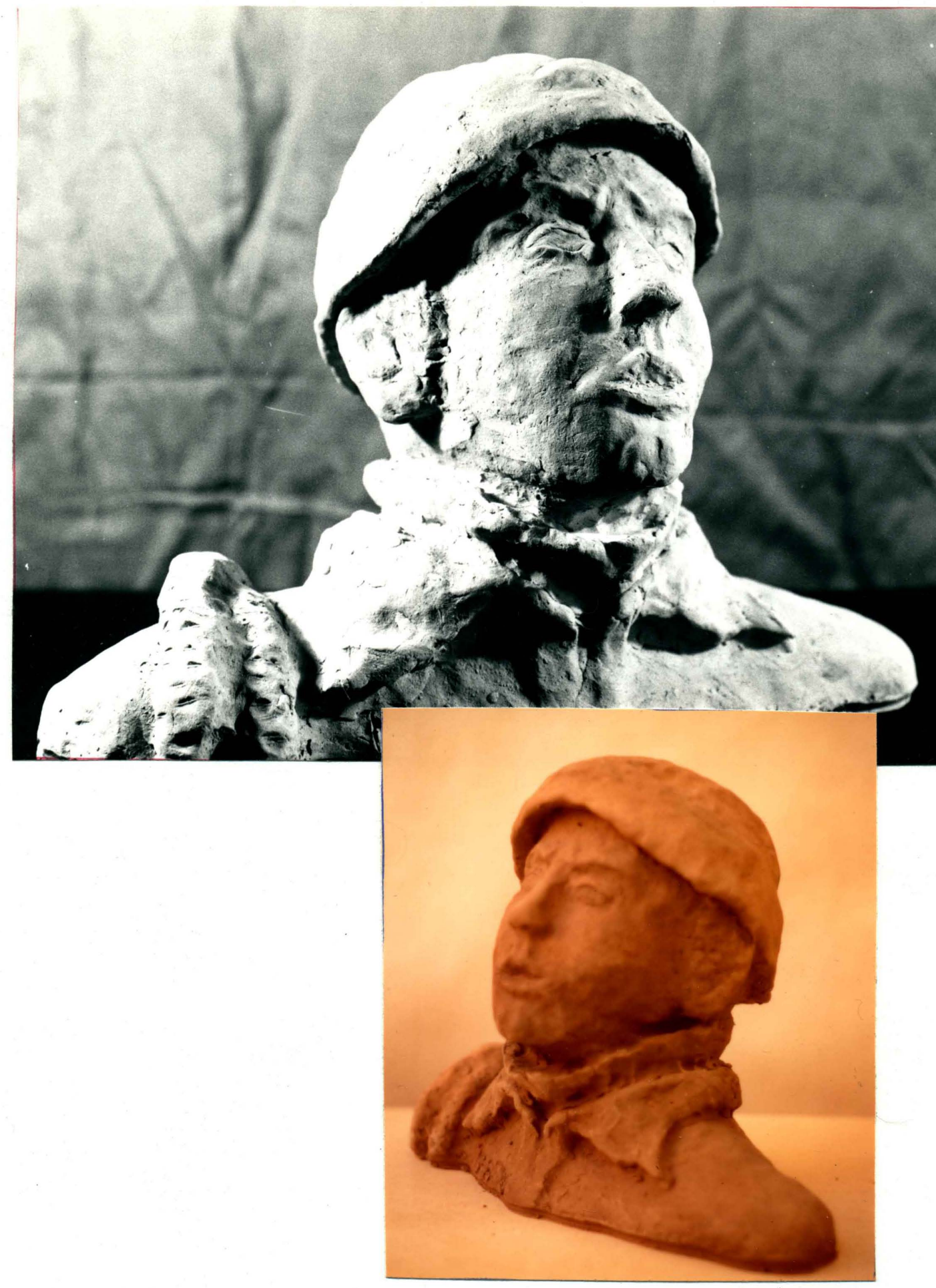

Headgear: Mountain Climber's Hat

Figure 17. Results of Problem 3, p. 22 (continued). 


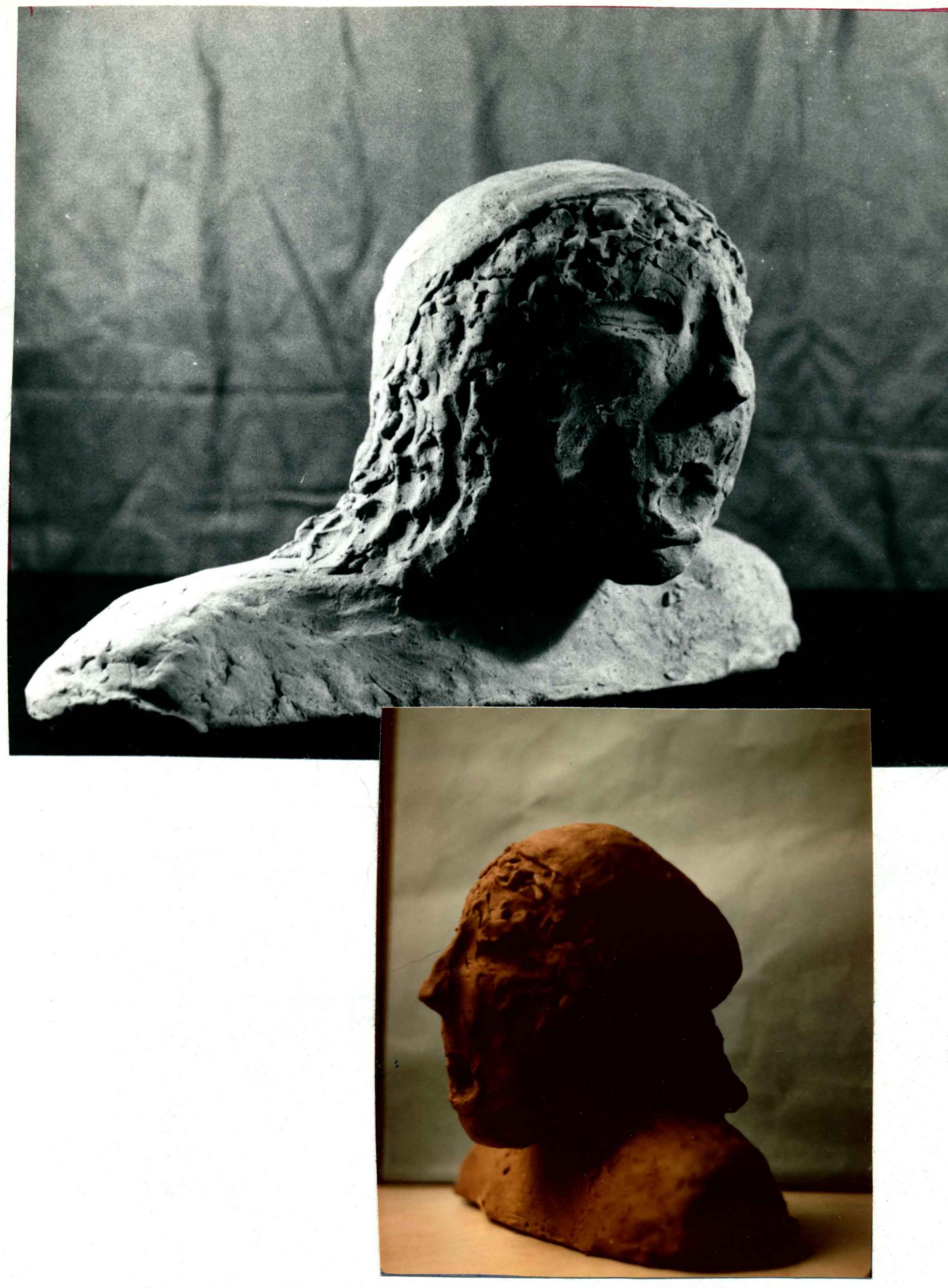

Headgear: Baseba11 Cap

Figure 18. Results of Problem 3, p. 22 (continued)。 


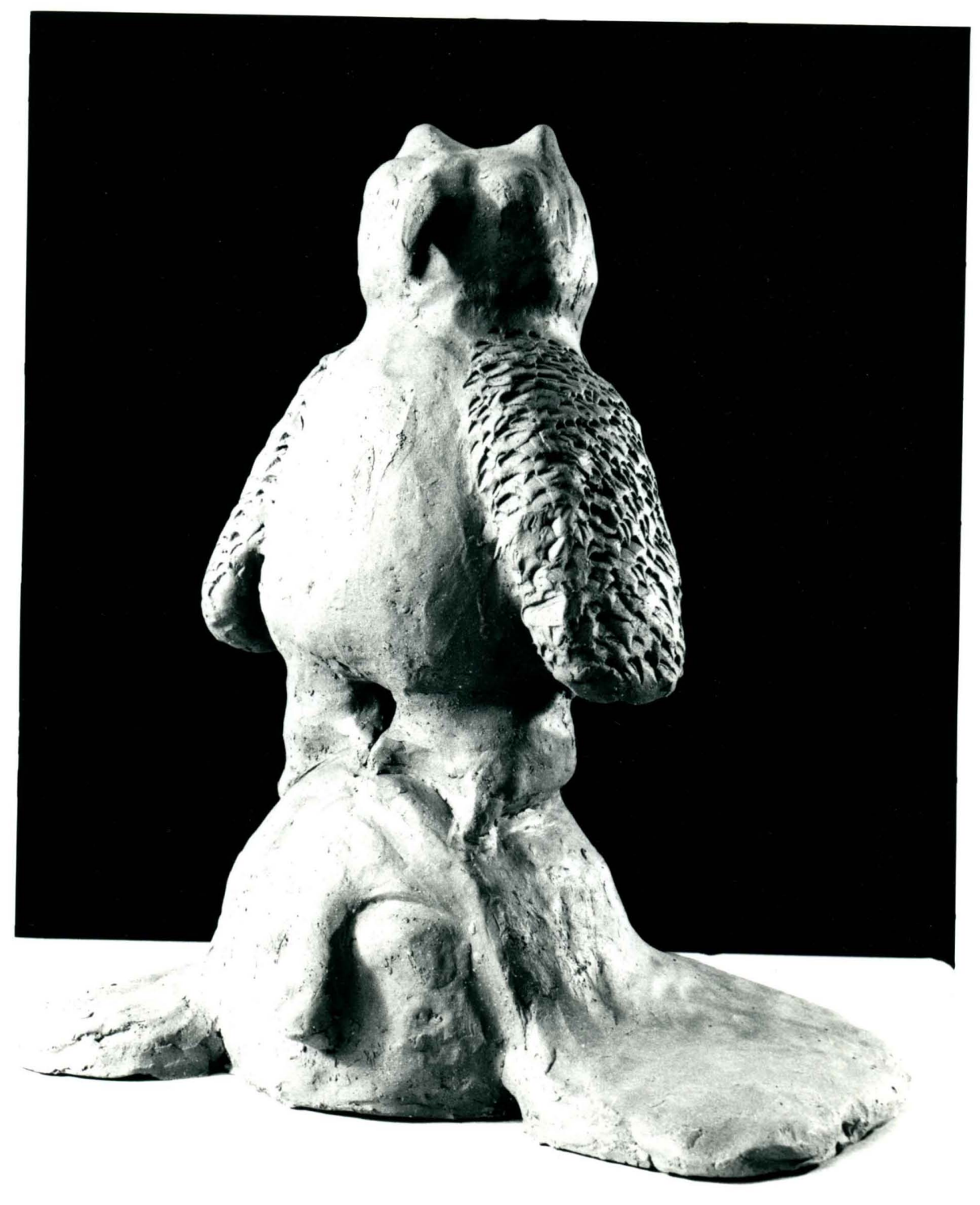

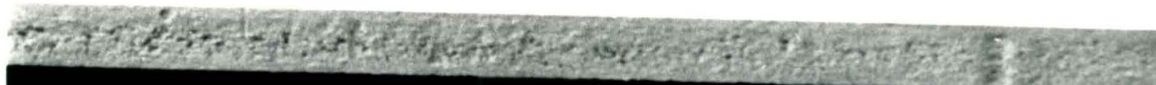

Figure 19. Results of Problem 4, p. 23. 

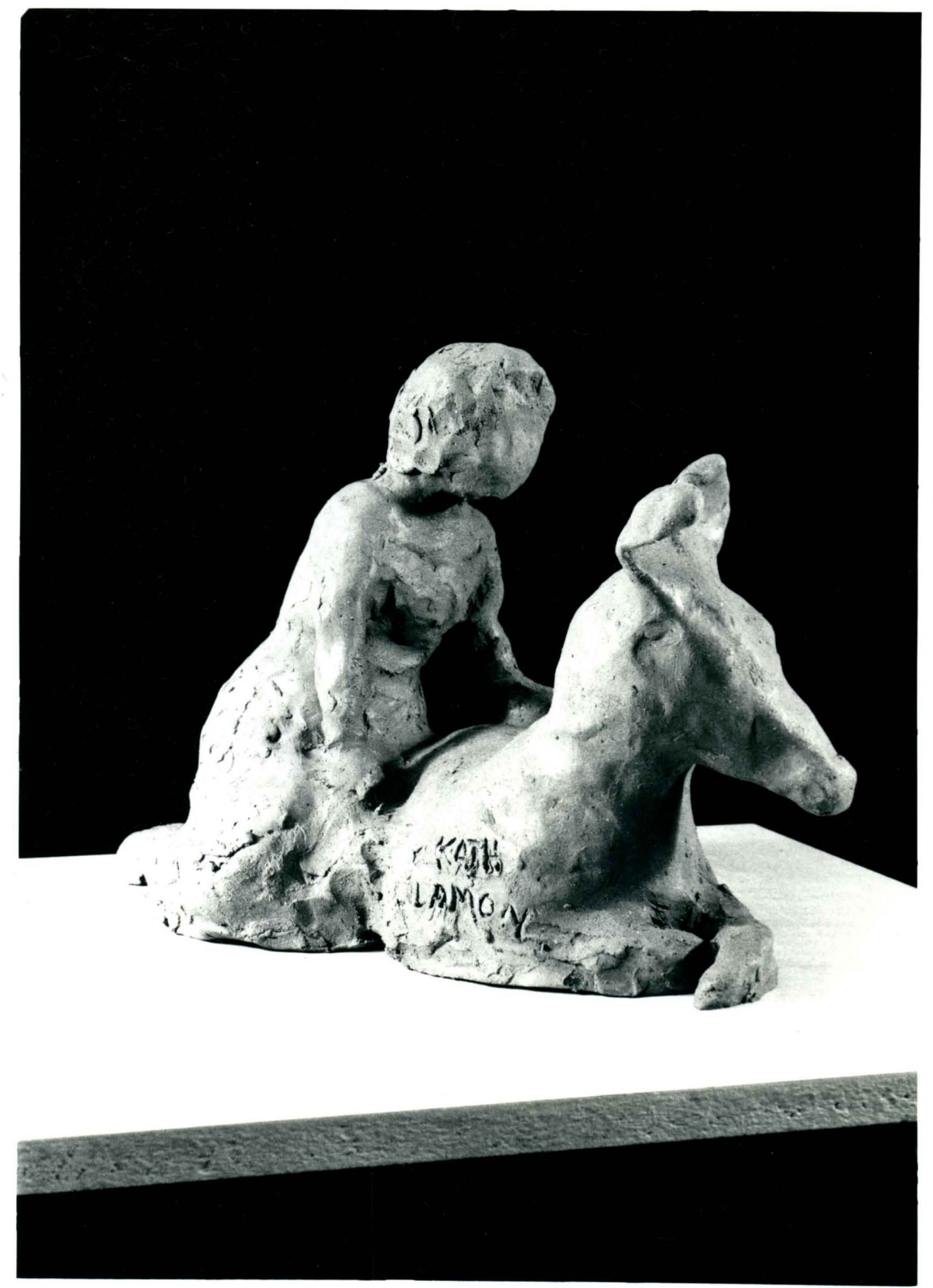

Figure 20. Results of Problem 4, p. 23 (continued). 

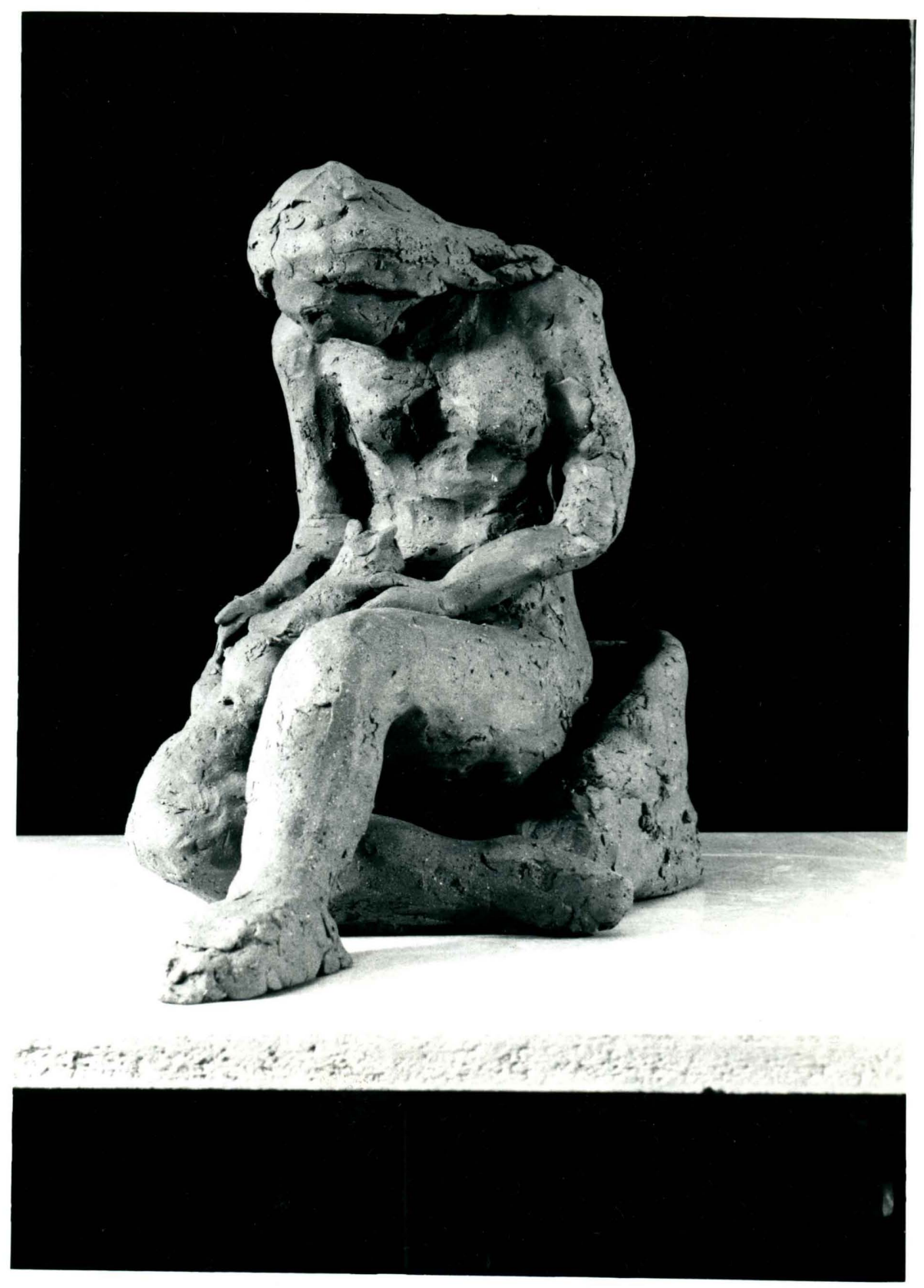

Figure 21. Results of Problem 4, p. 23 (continued). 

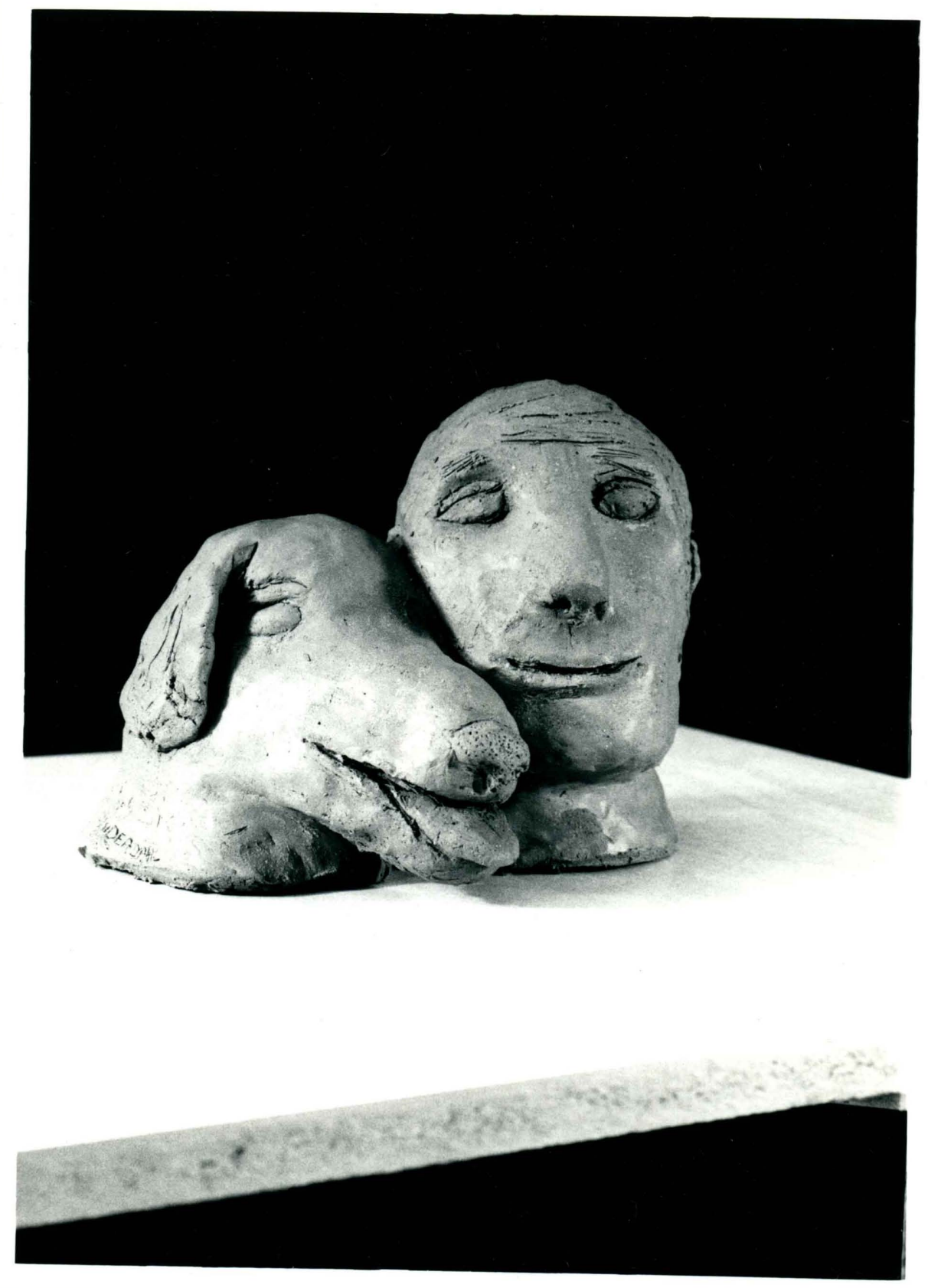

Figure 22. Results of Problem 4, p. 23 (continued). 


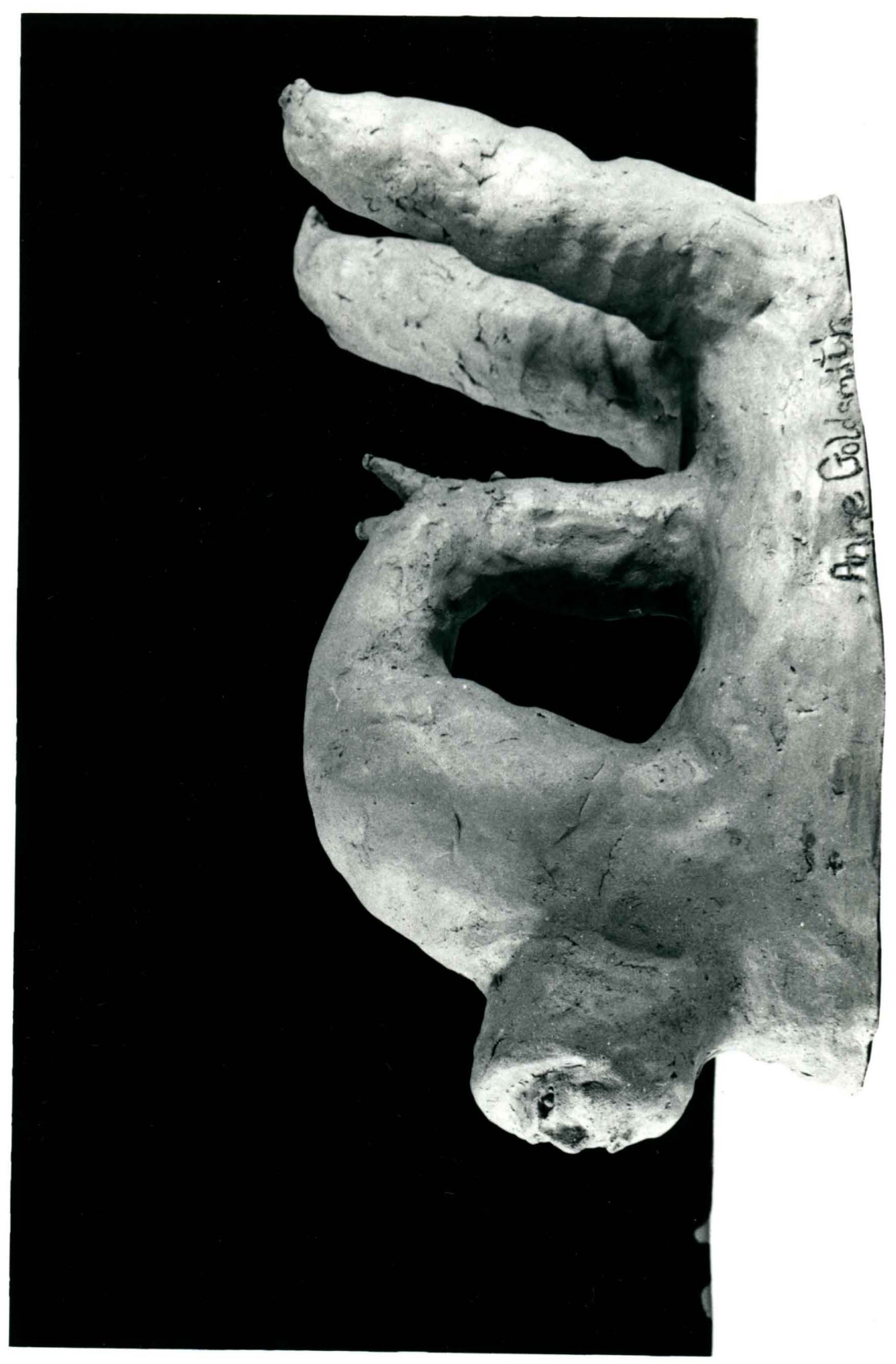

Figure 23. Results of Problem 4, p. 23 (continued) 

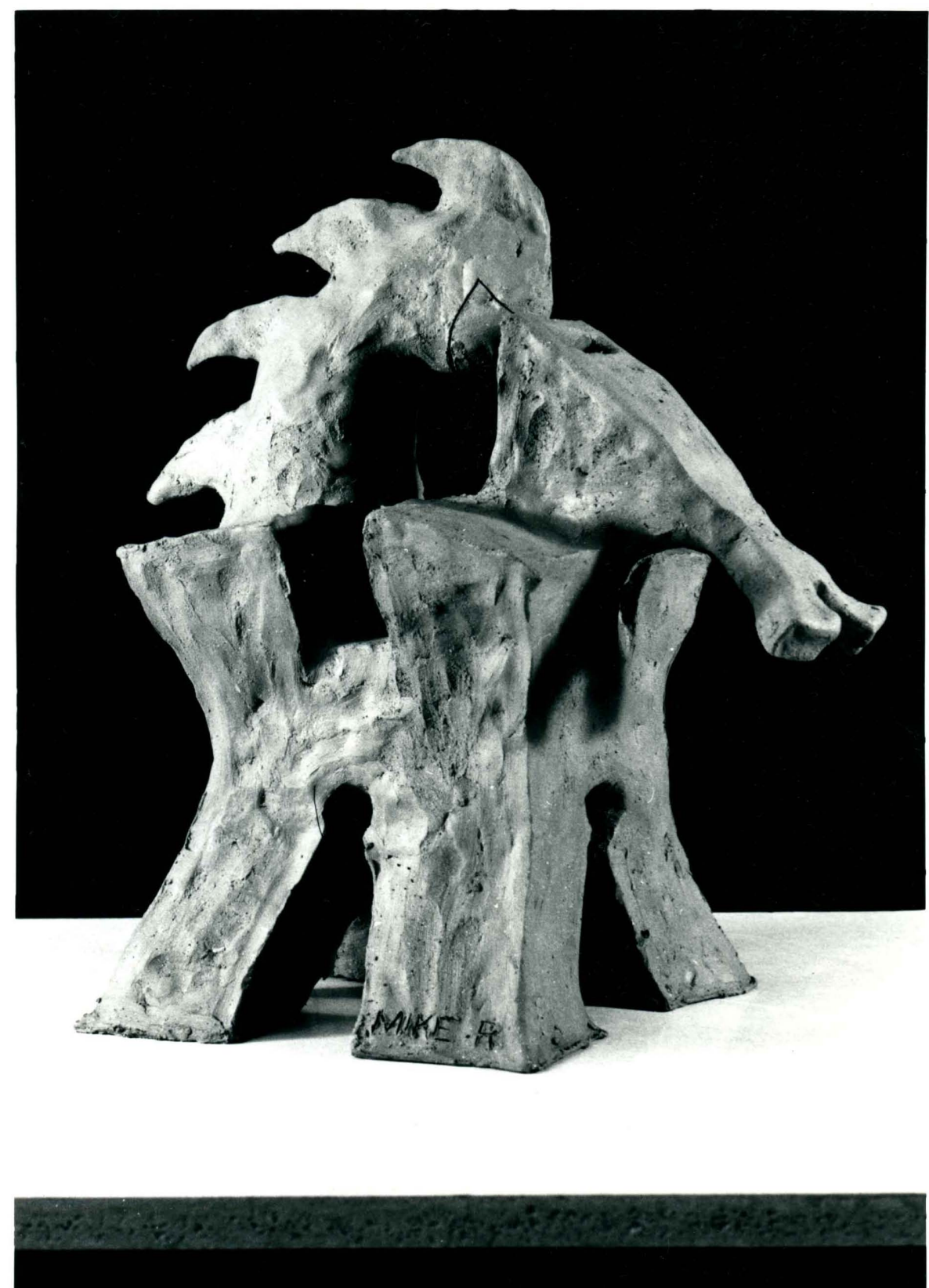

Figure 24. Results of Problem 4, p. 23 (continued) 
APPENDIX I

CLAY TECHNIQUES, ILLUSTRATED 

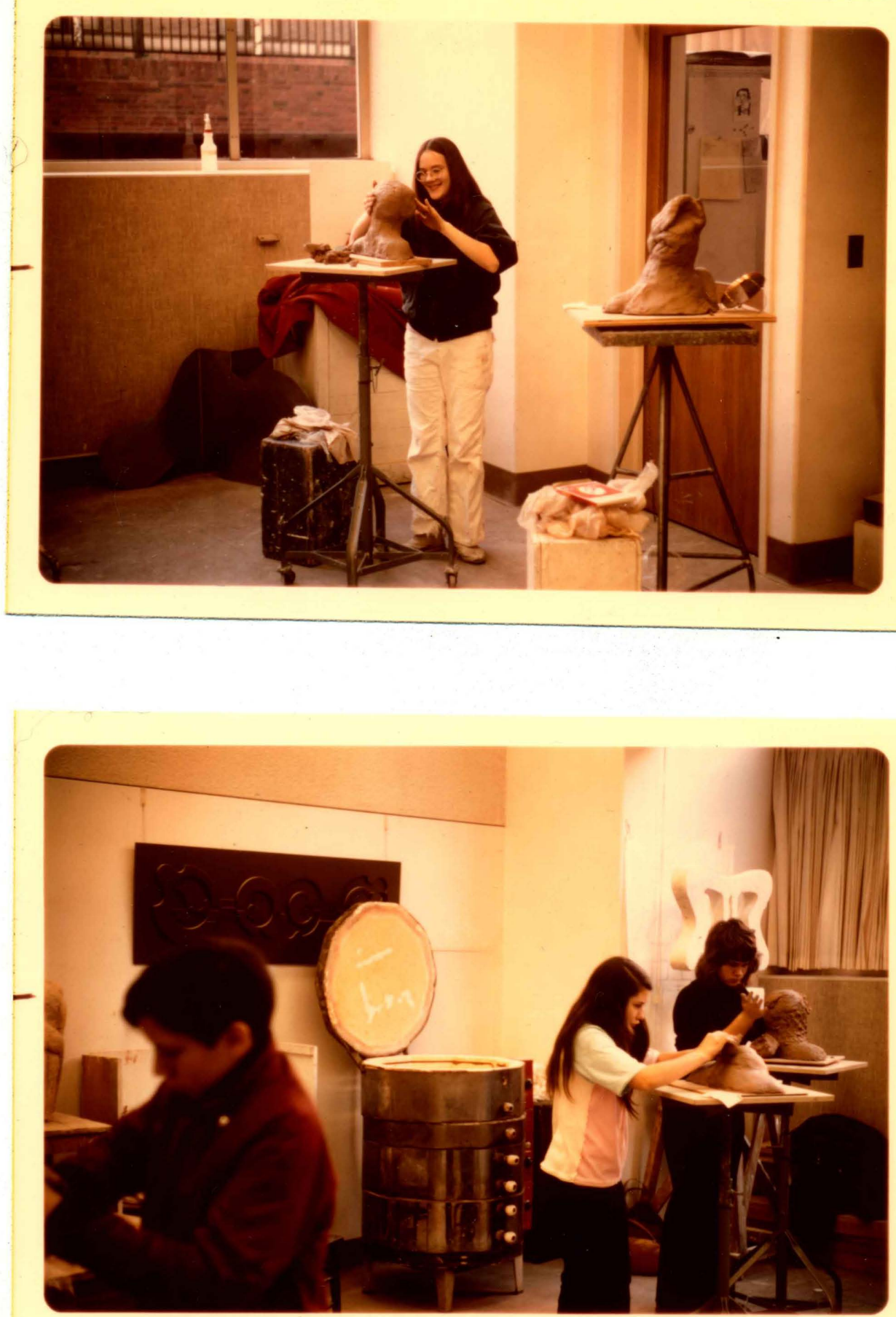

Figure 1. Classroom, Stands, and Kiln 

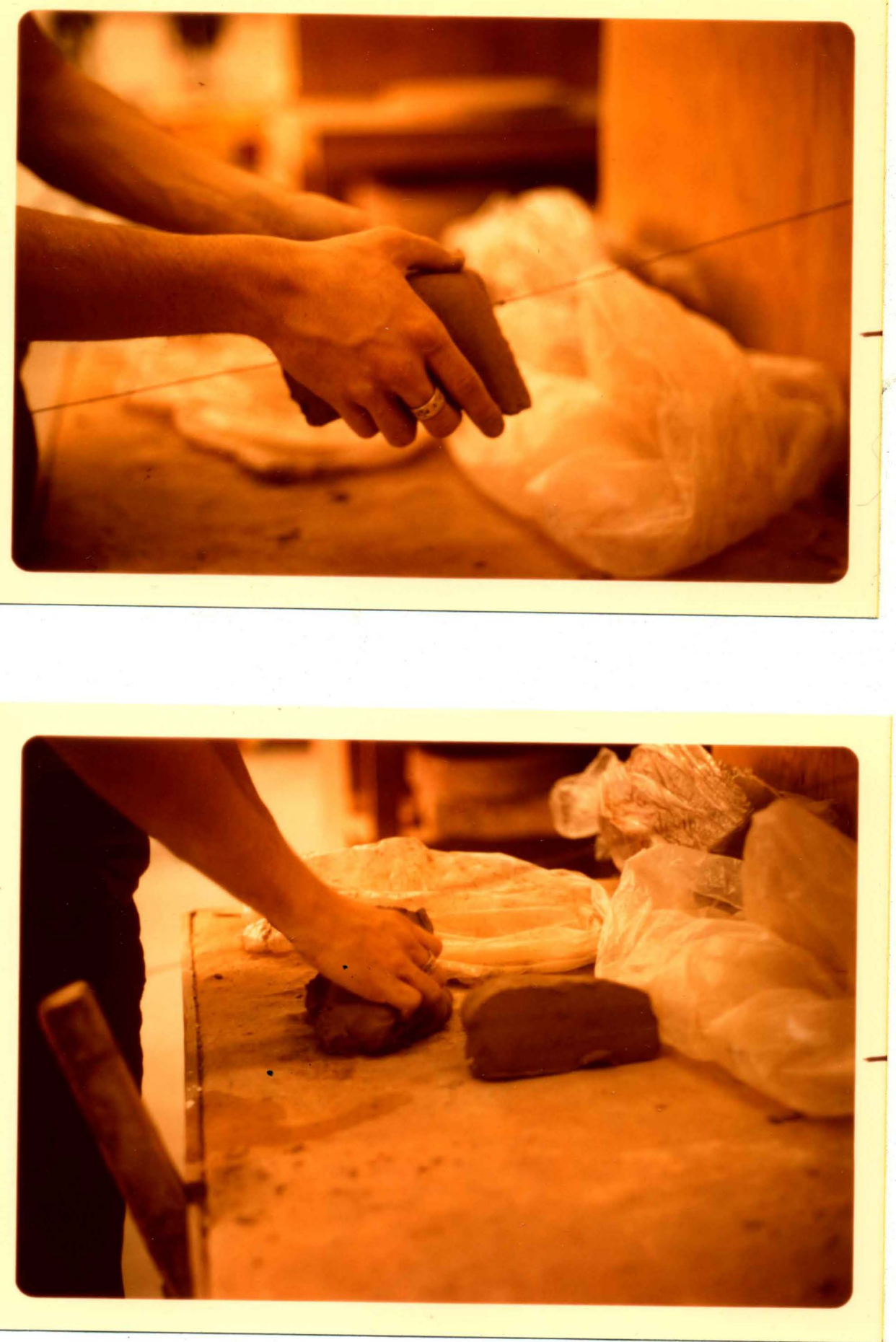

Figure 2. Cutting and Wedging Clay 


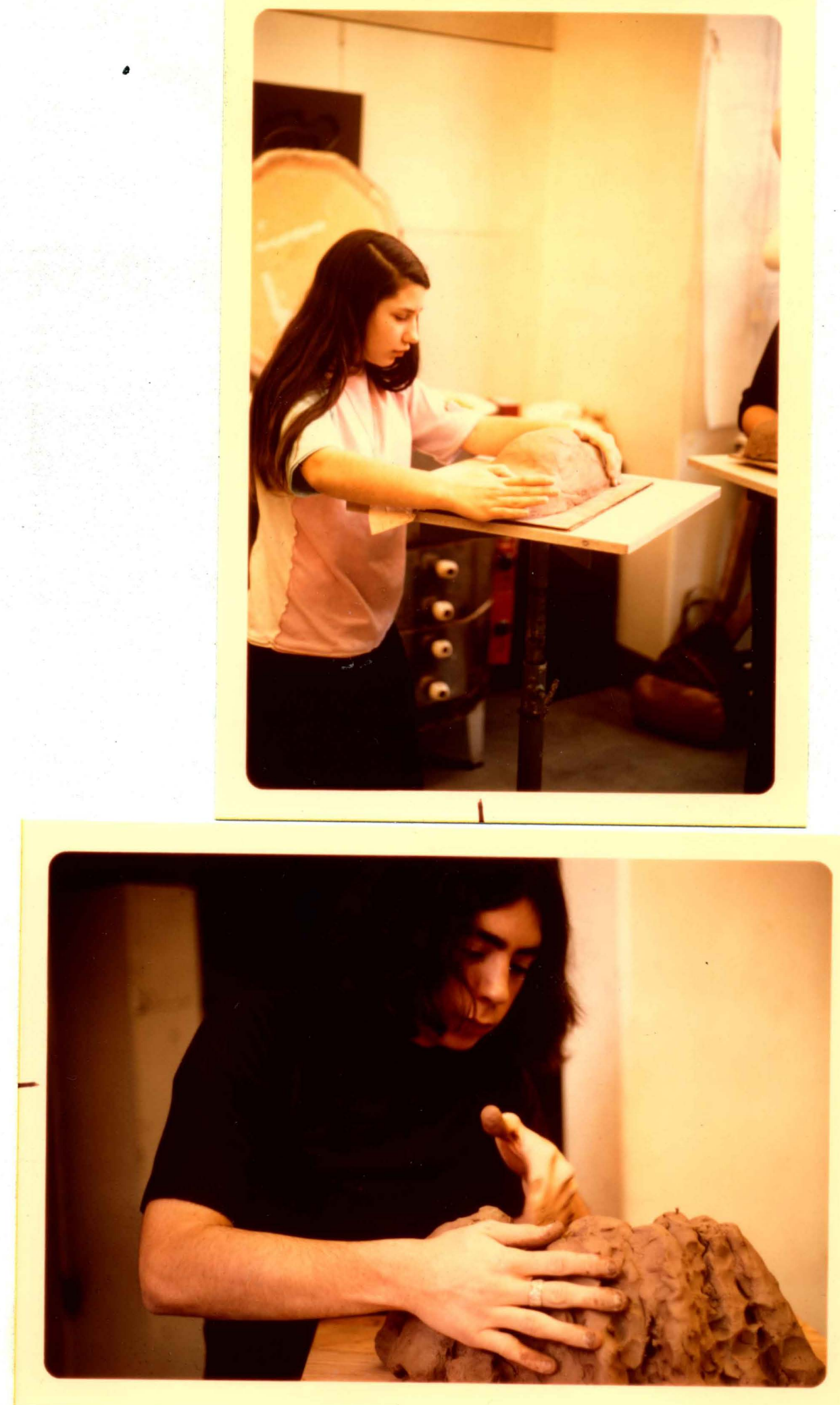

Figure 3. Building Clay on the Boards 


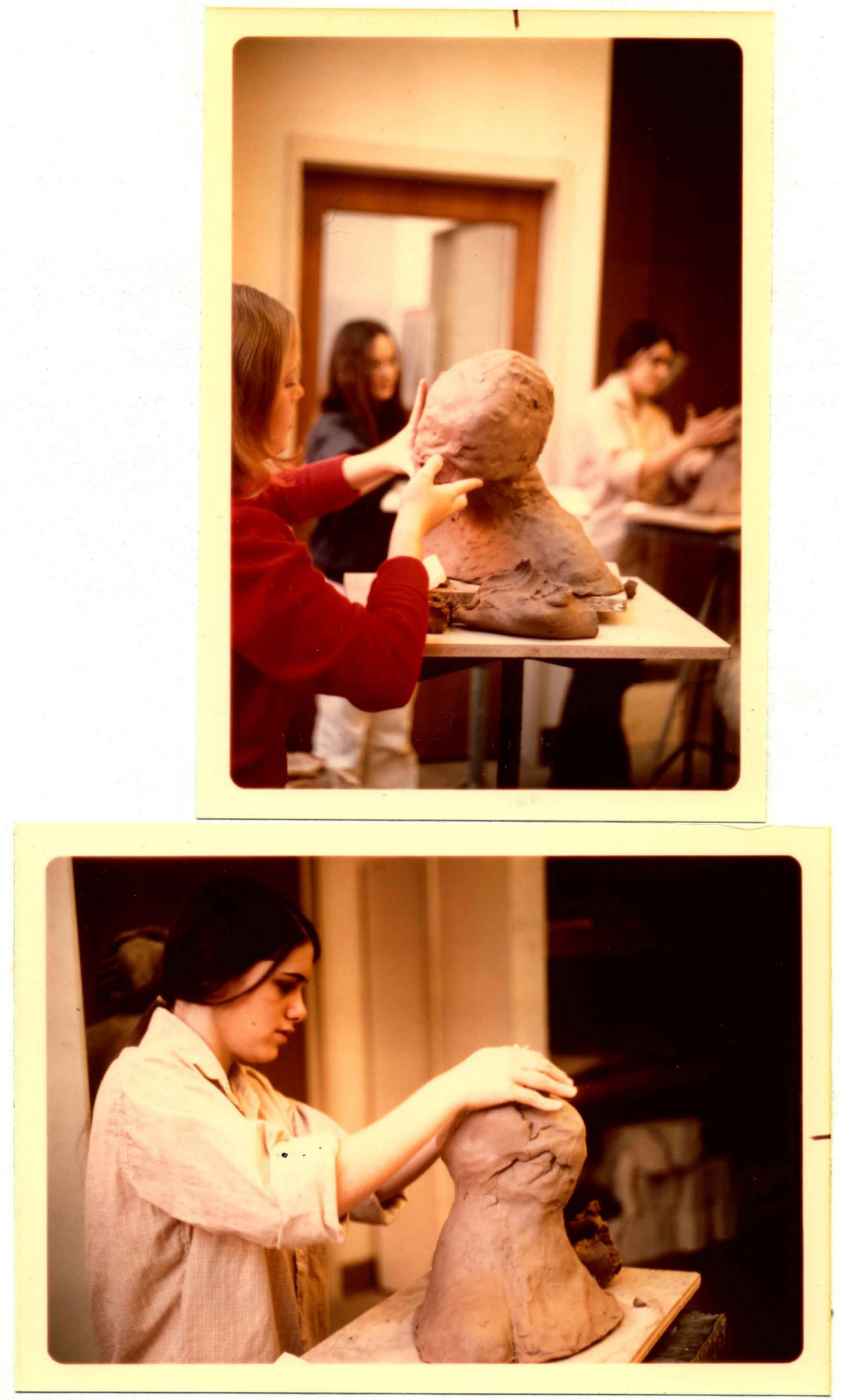

Figure 4. Developing Major Forms 

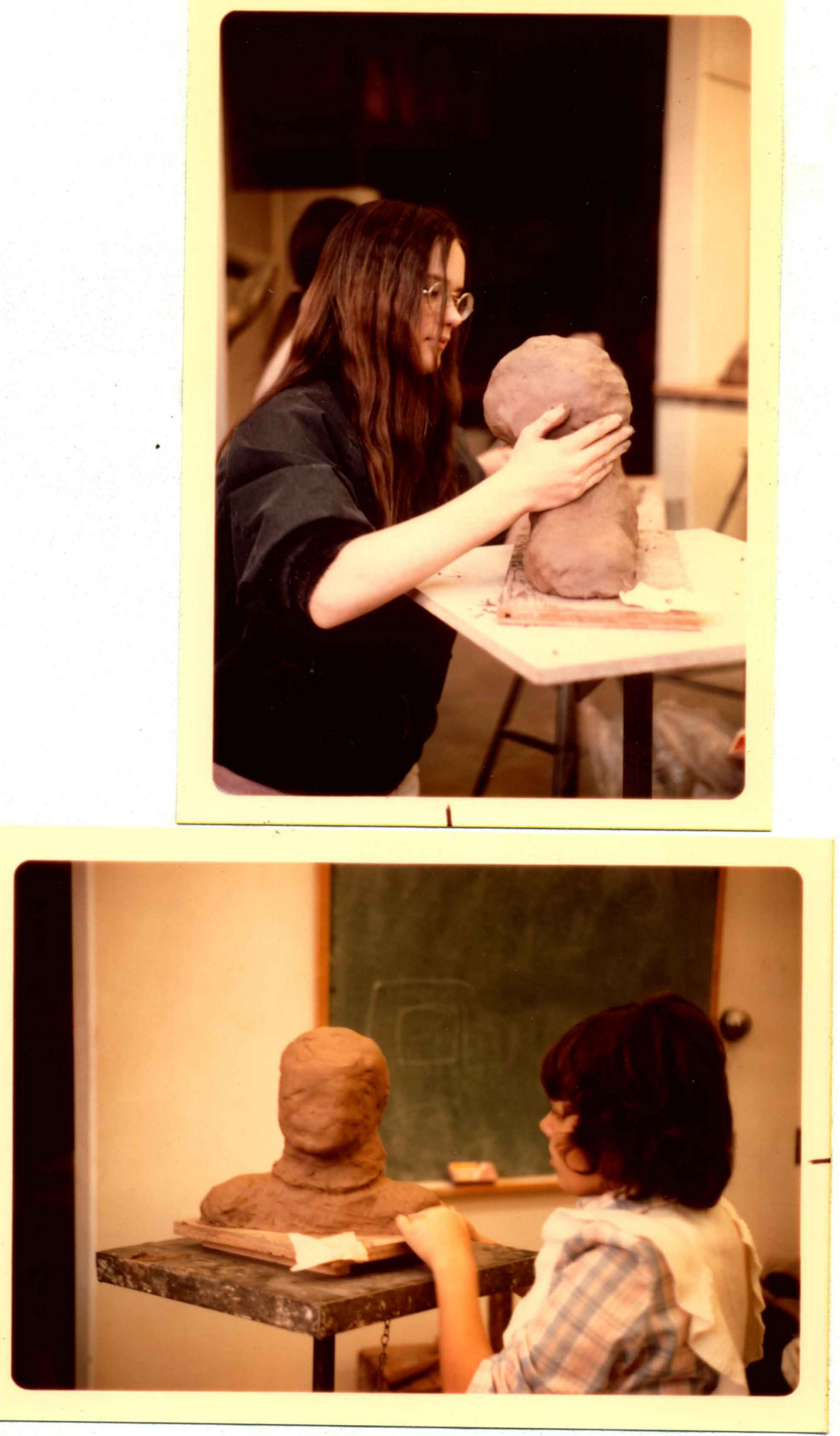

Figure 5. Developing Major Forms 


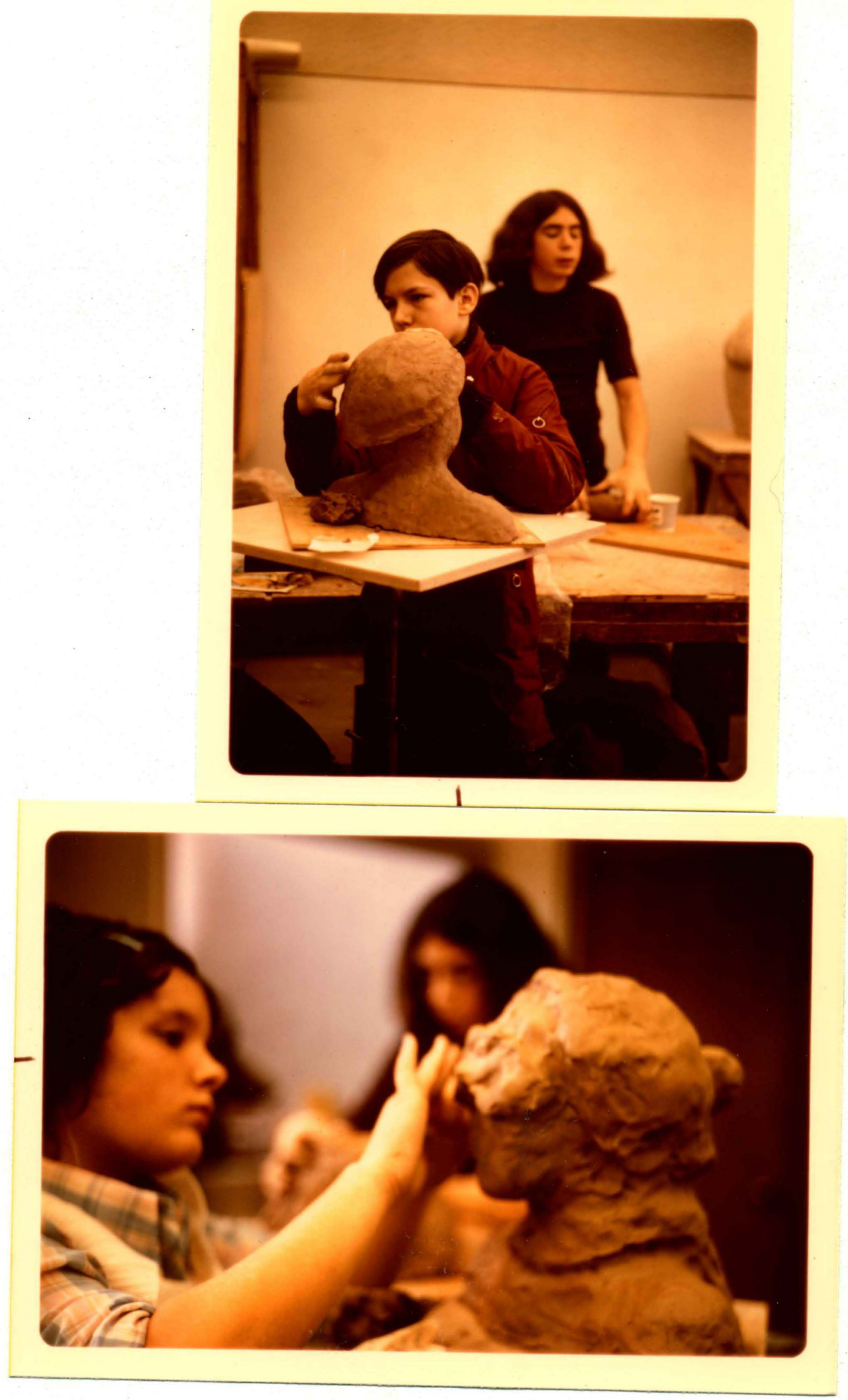

Figure 6. Adding Secondary Features 

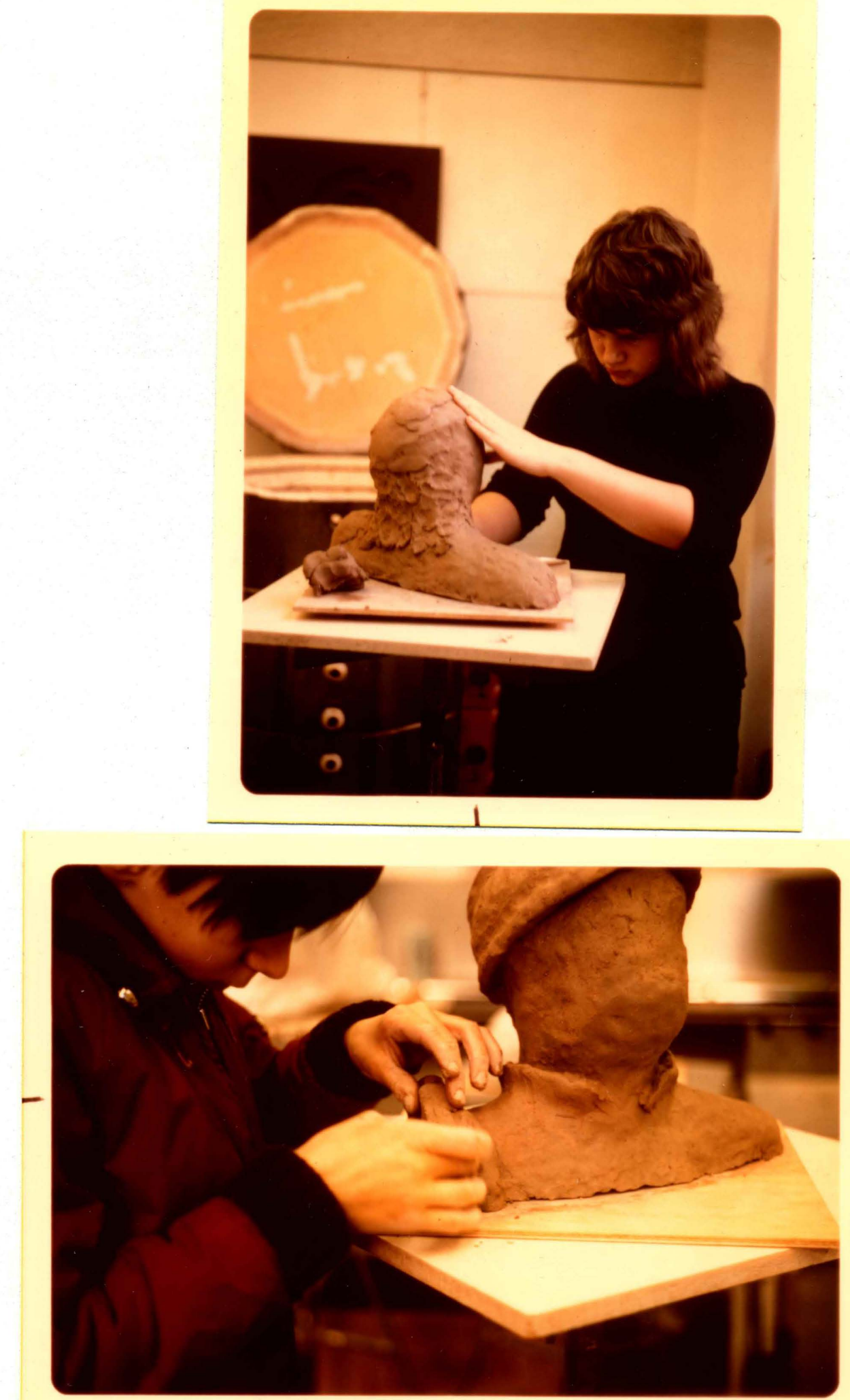

Figure 7. Adding Secondary Features 

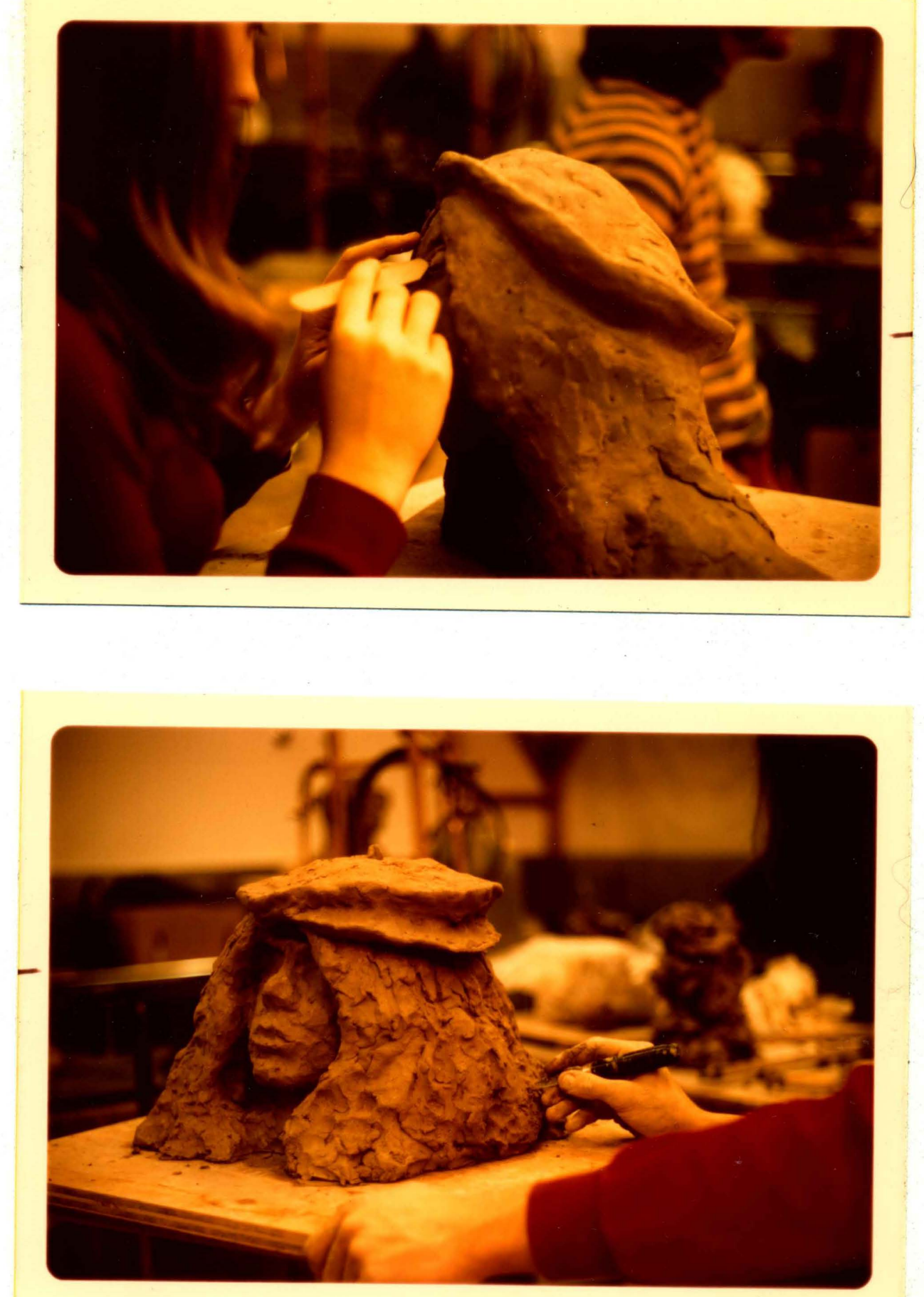

Figure 8. Using Tongue Depressors for Detail and Texture 

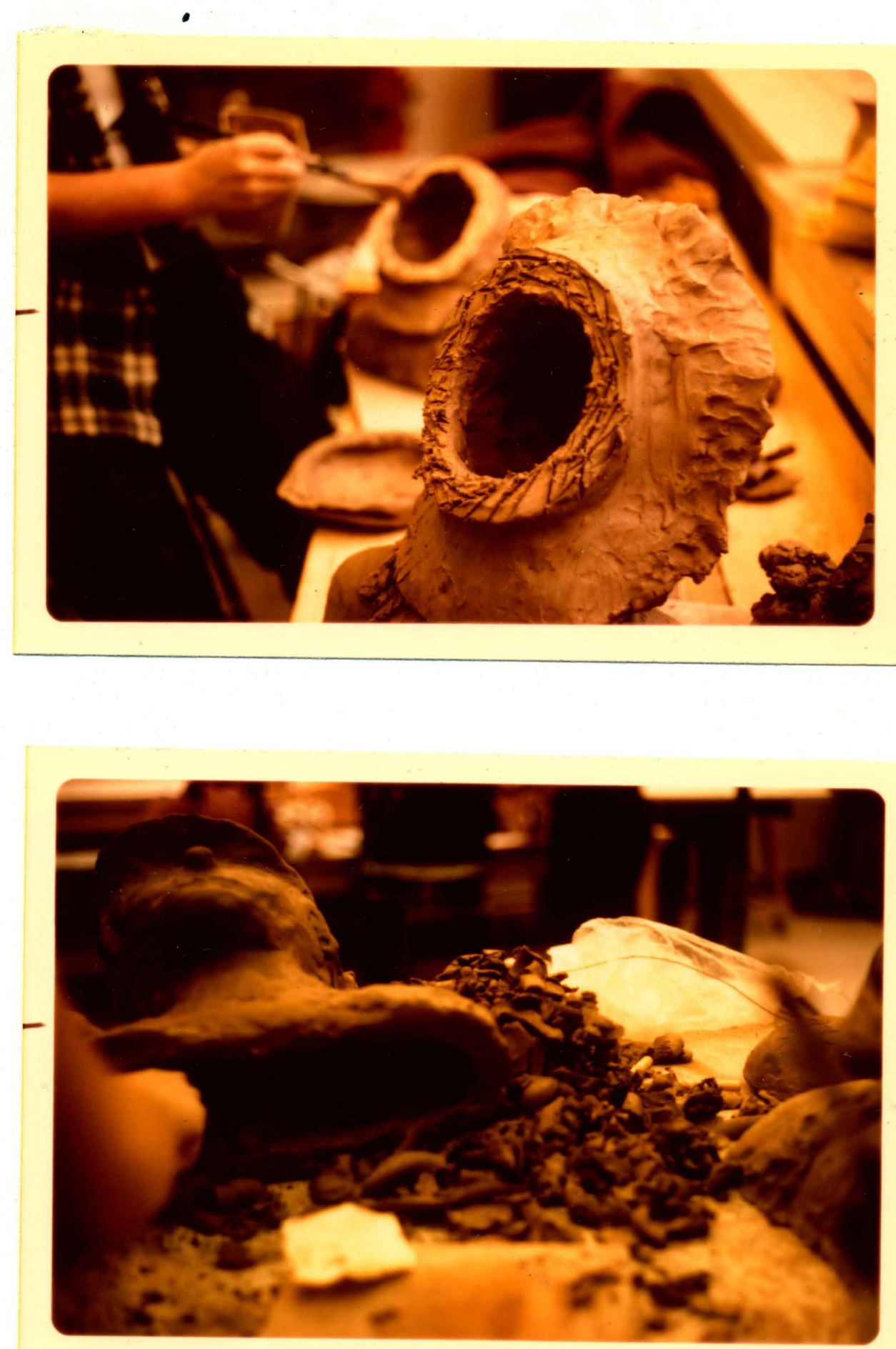

Figure 9. Hollowing the Heads 

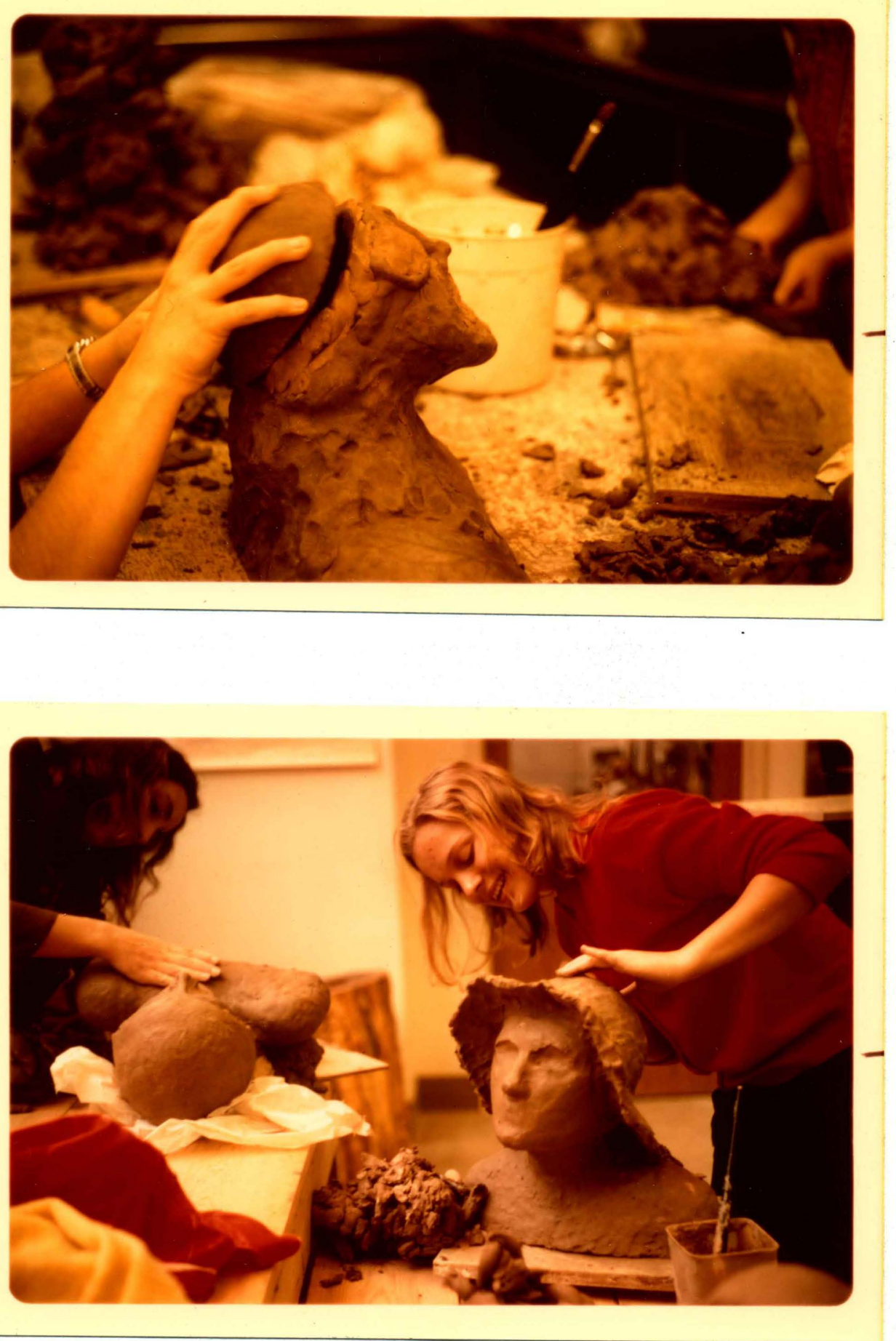

Figure 10. Reattaching the Tops 


\section{LIST OF FIGURES}

FIGURE

PAGE

1. Classroom, Stands, and Kiln ........... 58

2. Cutting and Wedging Clay ........... 59

3. Building Clay on the Boards ............ 60

4. Developing Major Forms .. . . . . . . . . 61

5. Developing Major Forms ............. 62

6. Adding Secondary Features . . . . . . . . . 63

7. Adding Secondary Features . . . . . . . . . . 64

8. Using Tongue Depressors for Detail and Texture . . . 65

9. Hollowing the Heads . . . . . . . . . . . 66

10. Reattaching the Tops .............. 67 
APPENDIX II

THE AUTHOR'S WORK 


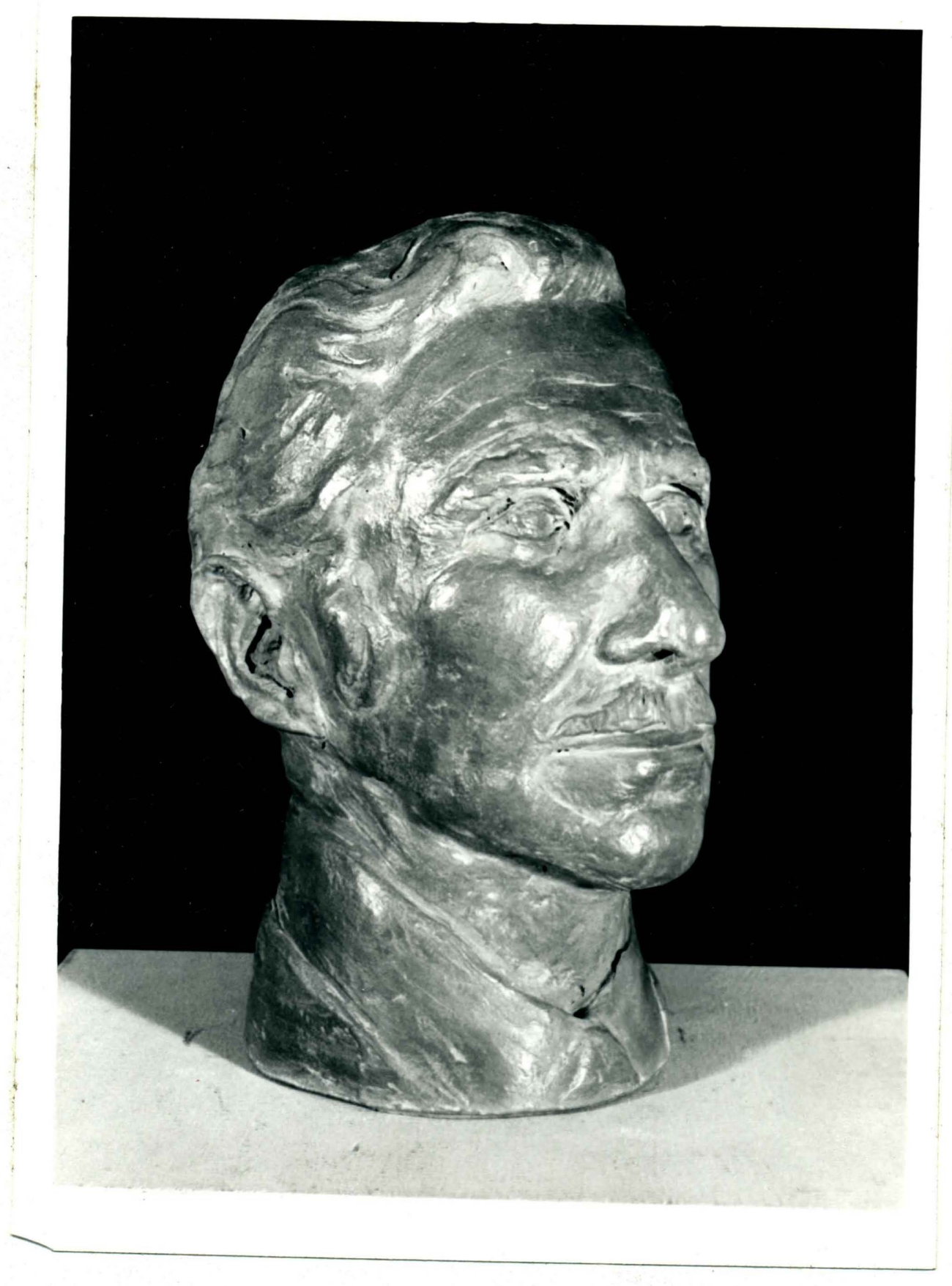

Figure 1. Head Study, Terracotta 


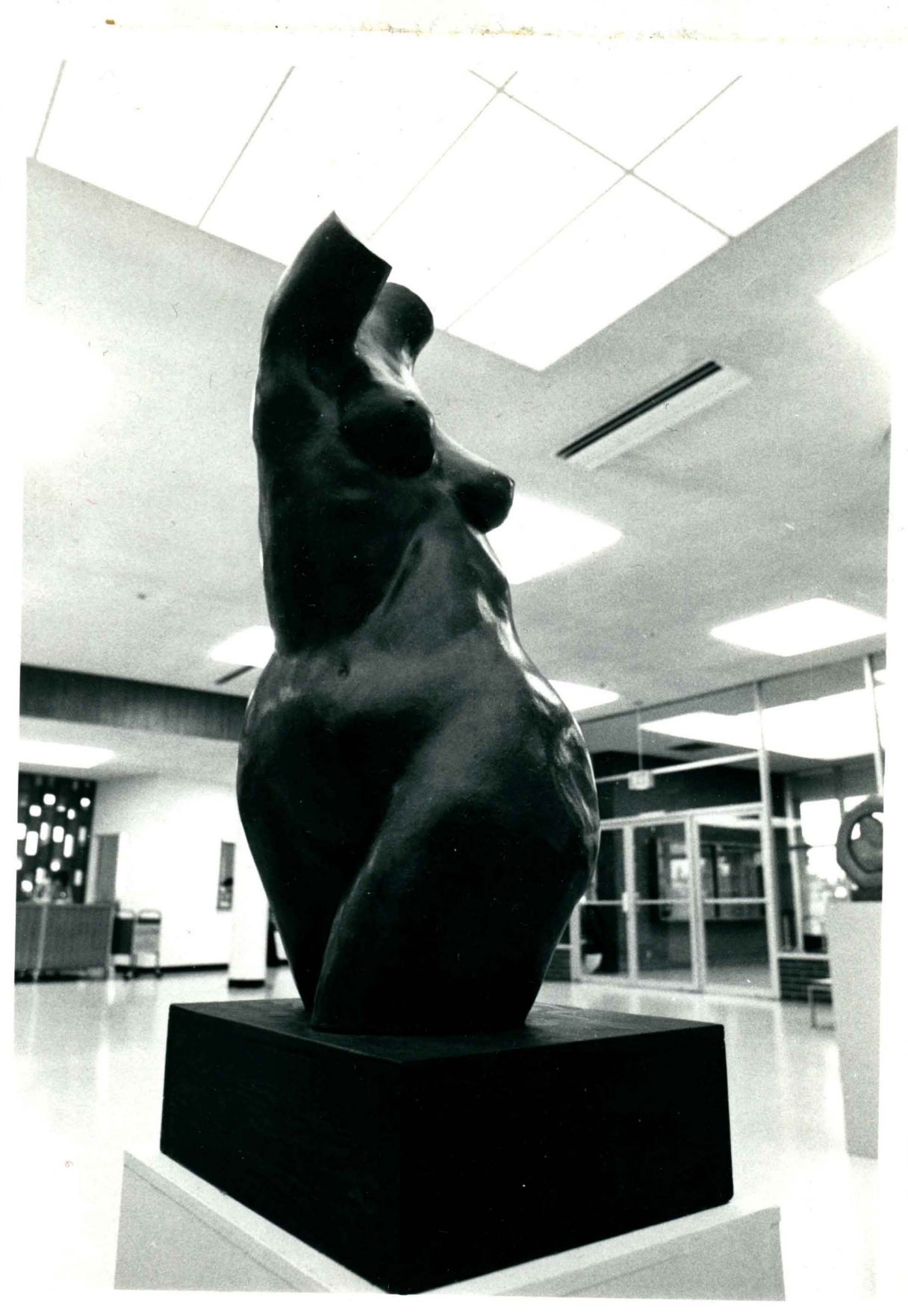

Figure 2. Figure Study, Hollow-built Terracotta 


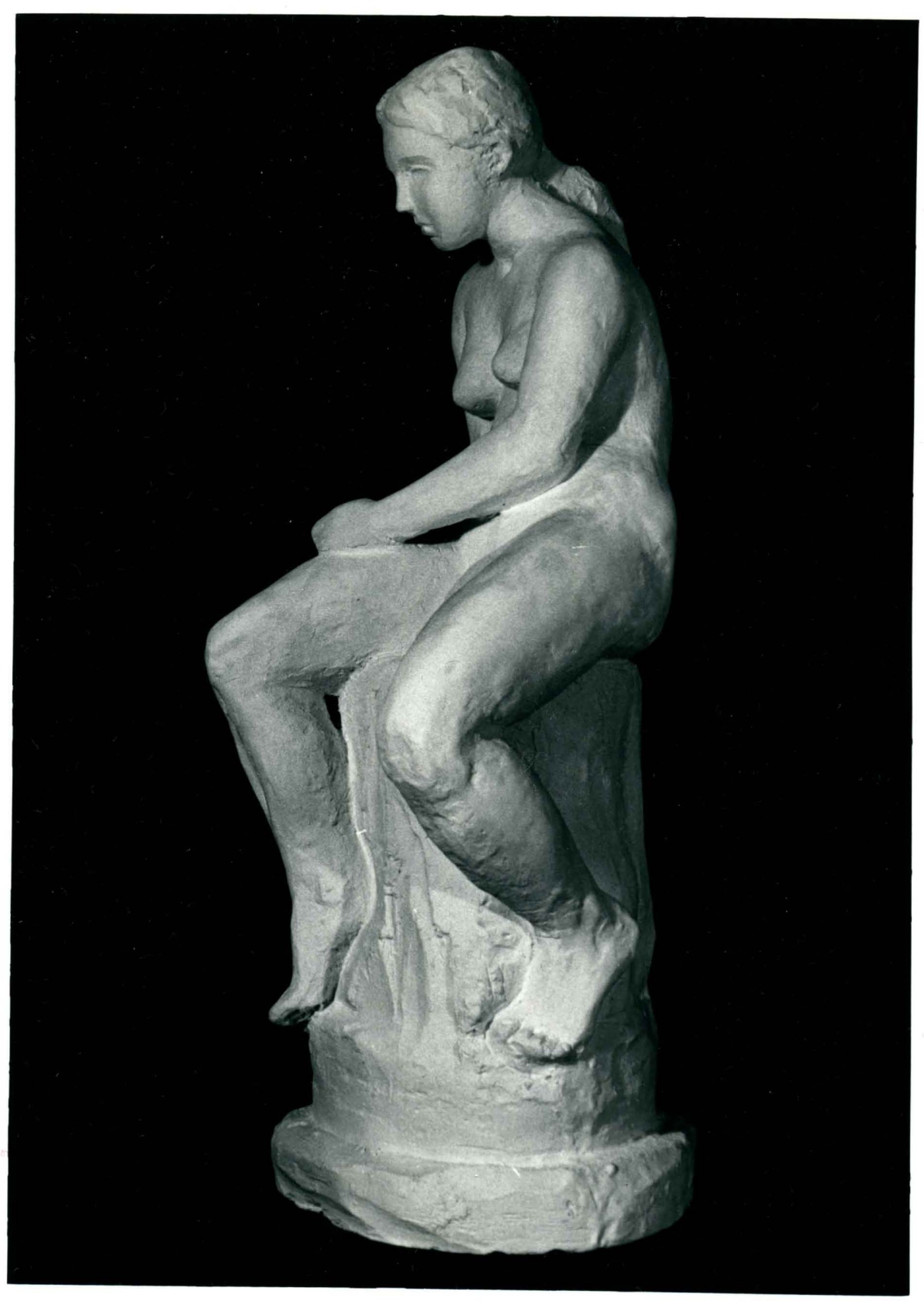

Figure 3. Figure Study, Cast Plaster 


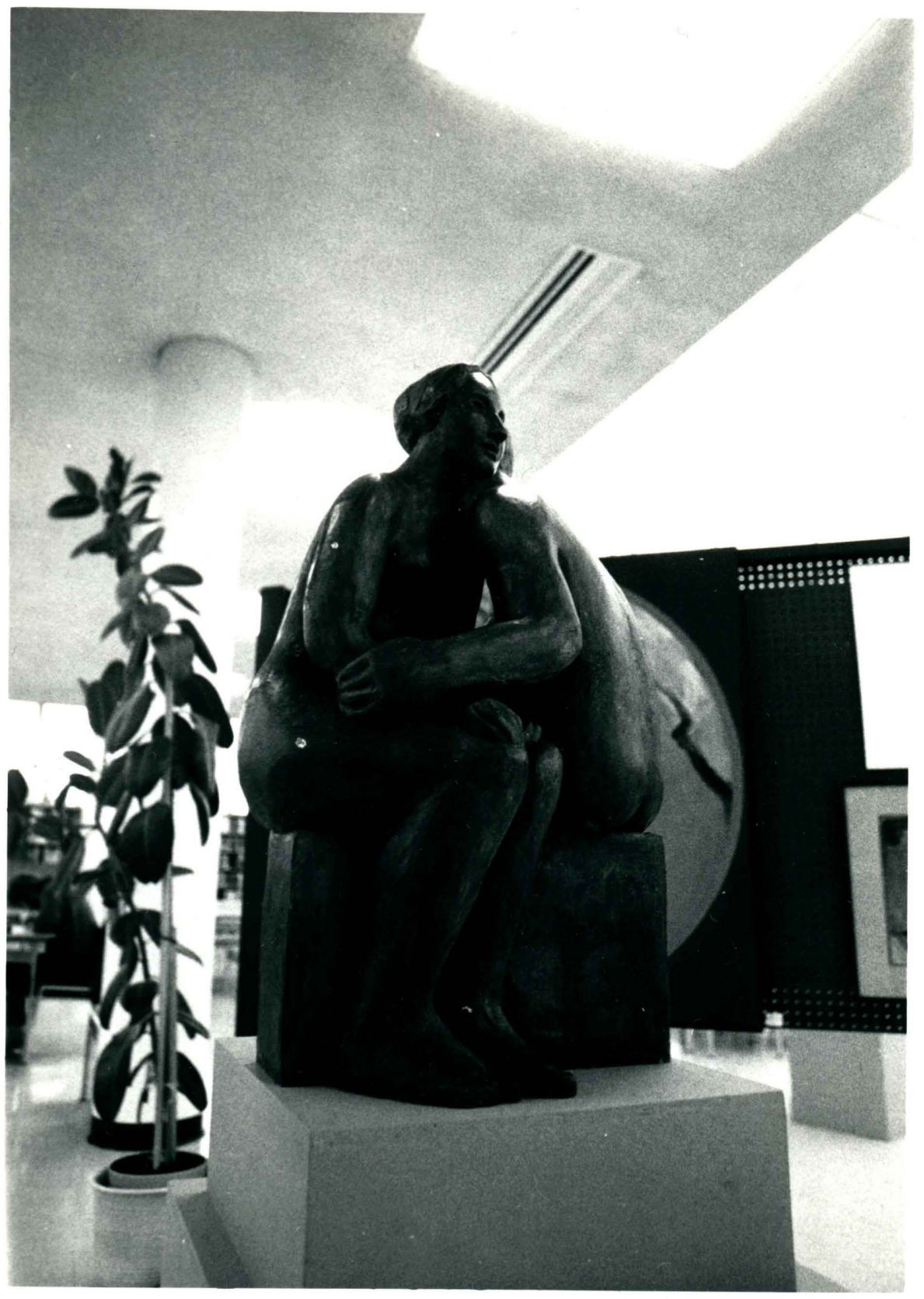

Figure 4. Figure Study, Terracotta 


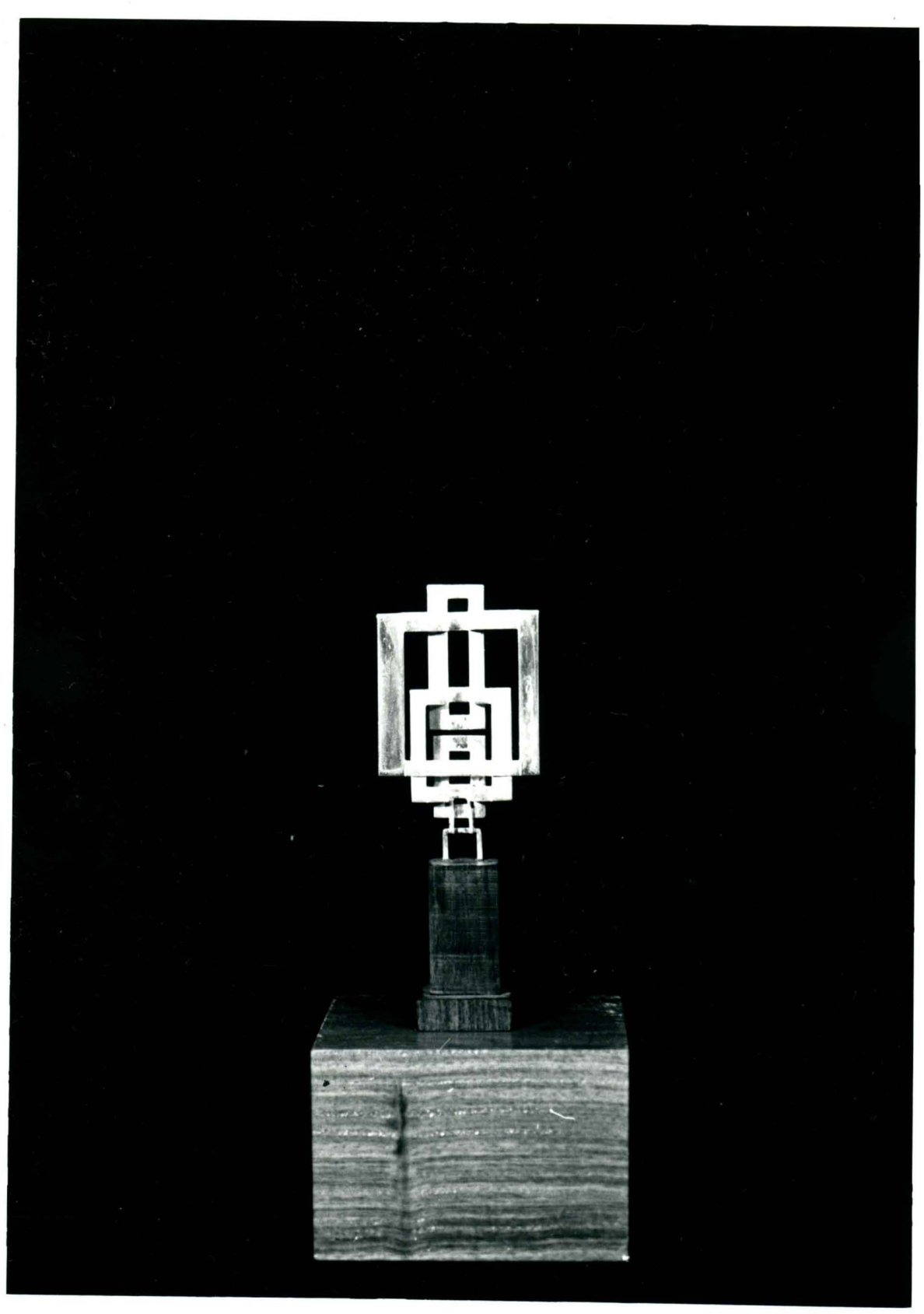

Figure 5. Geometric Shapes, Soldered Silver 


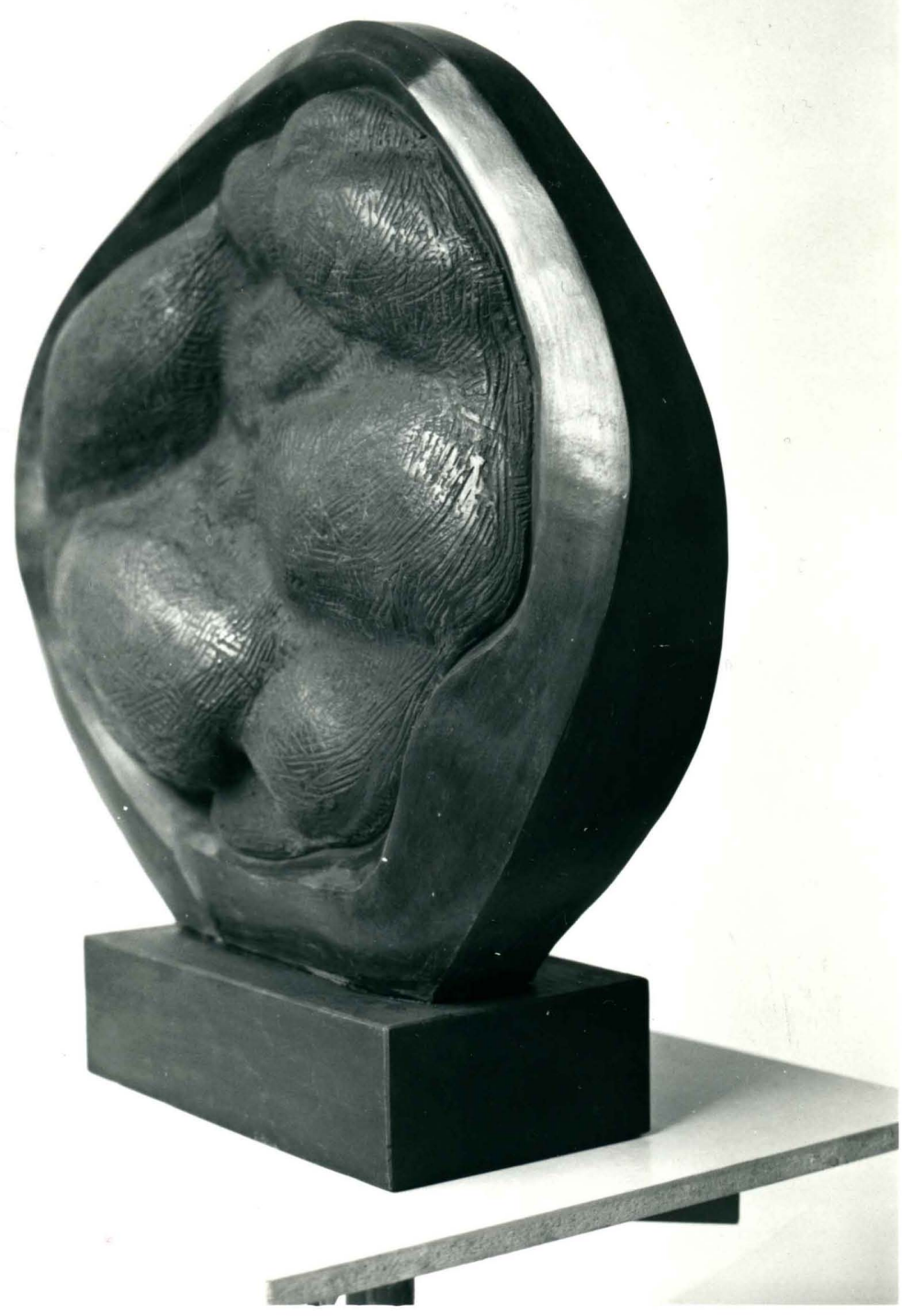

Figure 6. Circle Series, No. 1, Hollow-built Terracotta 


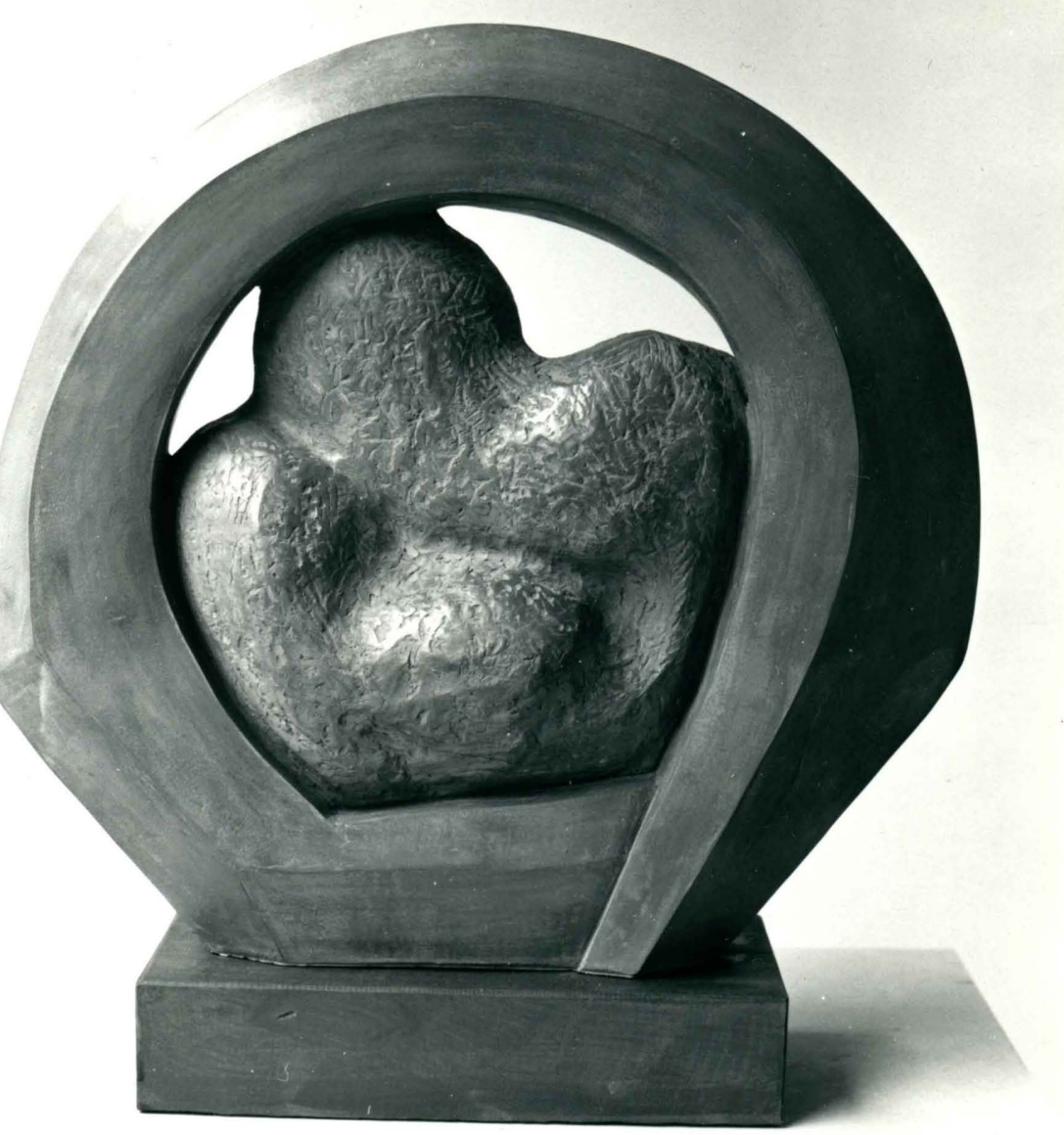

Figure 7. Circle Series, No. 2, Terracotta, Hollowed 


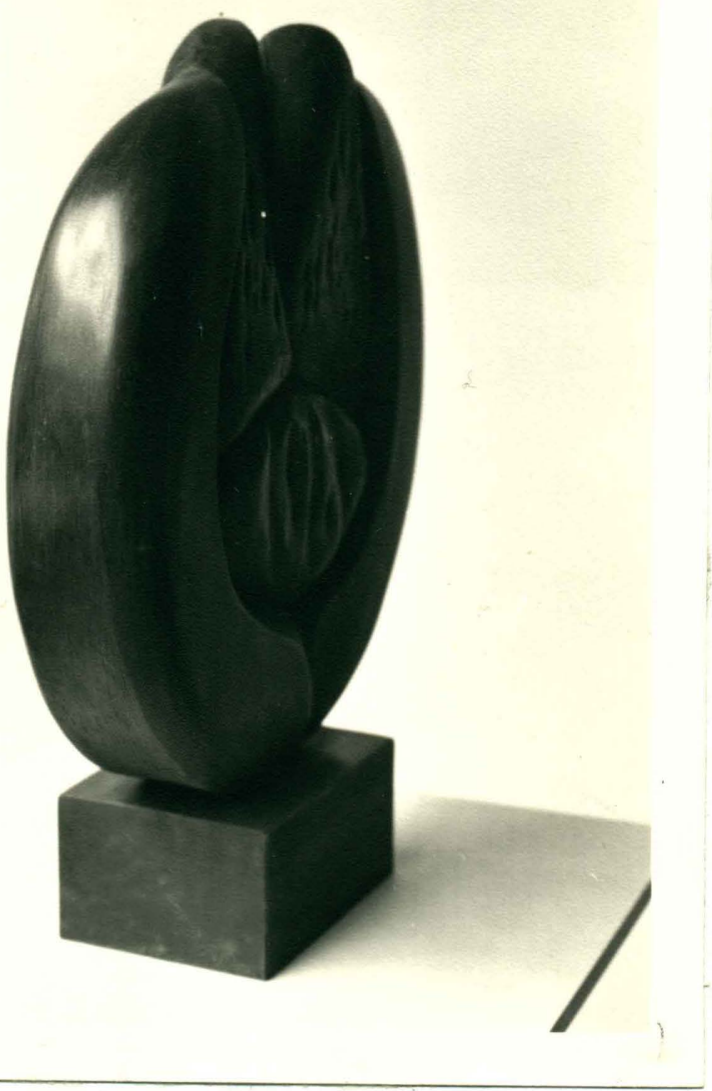

Figure 8. Circle Series, No. 3, Sugar pine 

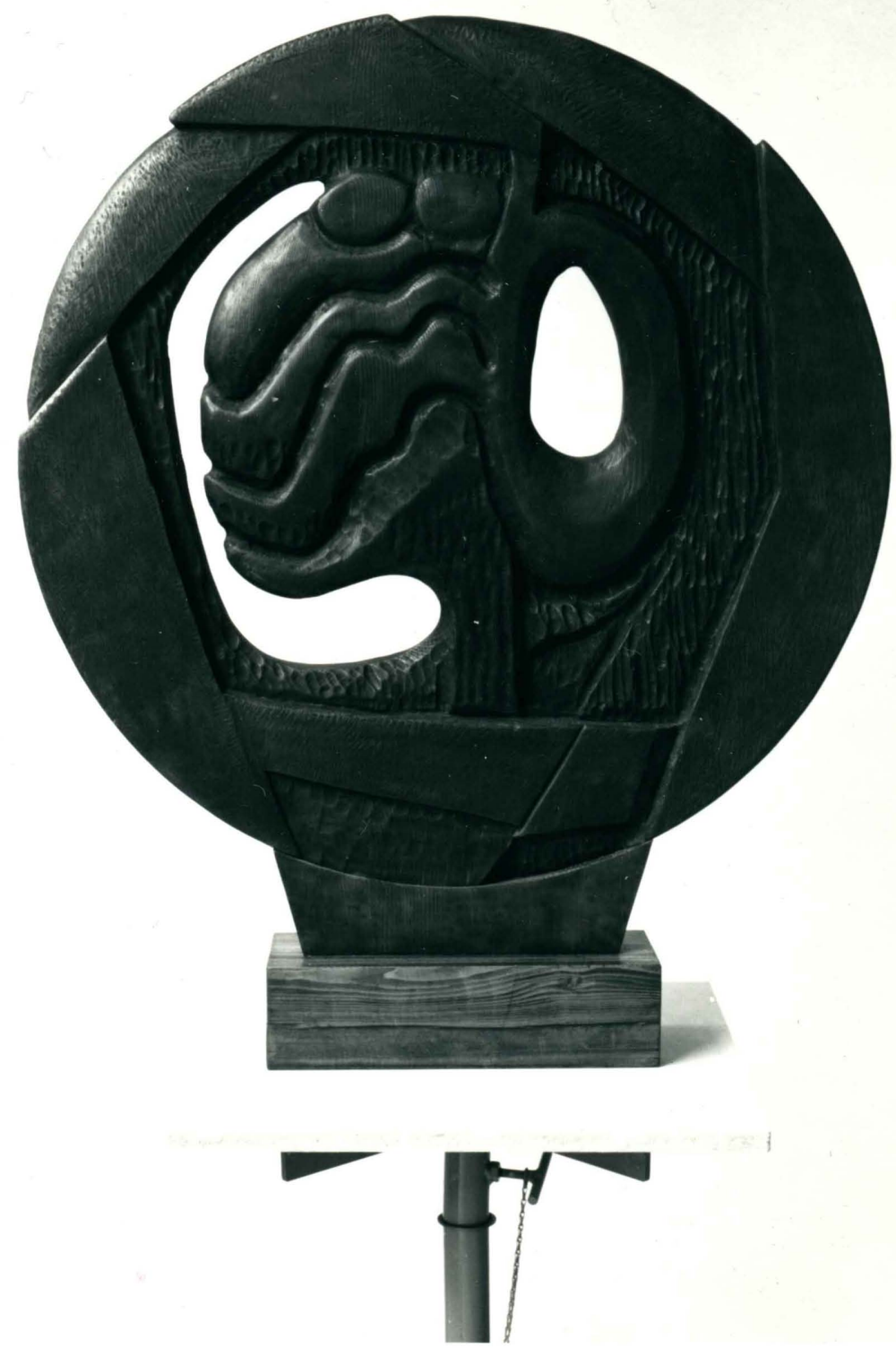

Figure 9. Circle Series, No. 4, Sugar pine 


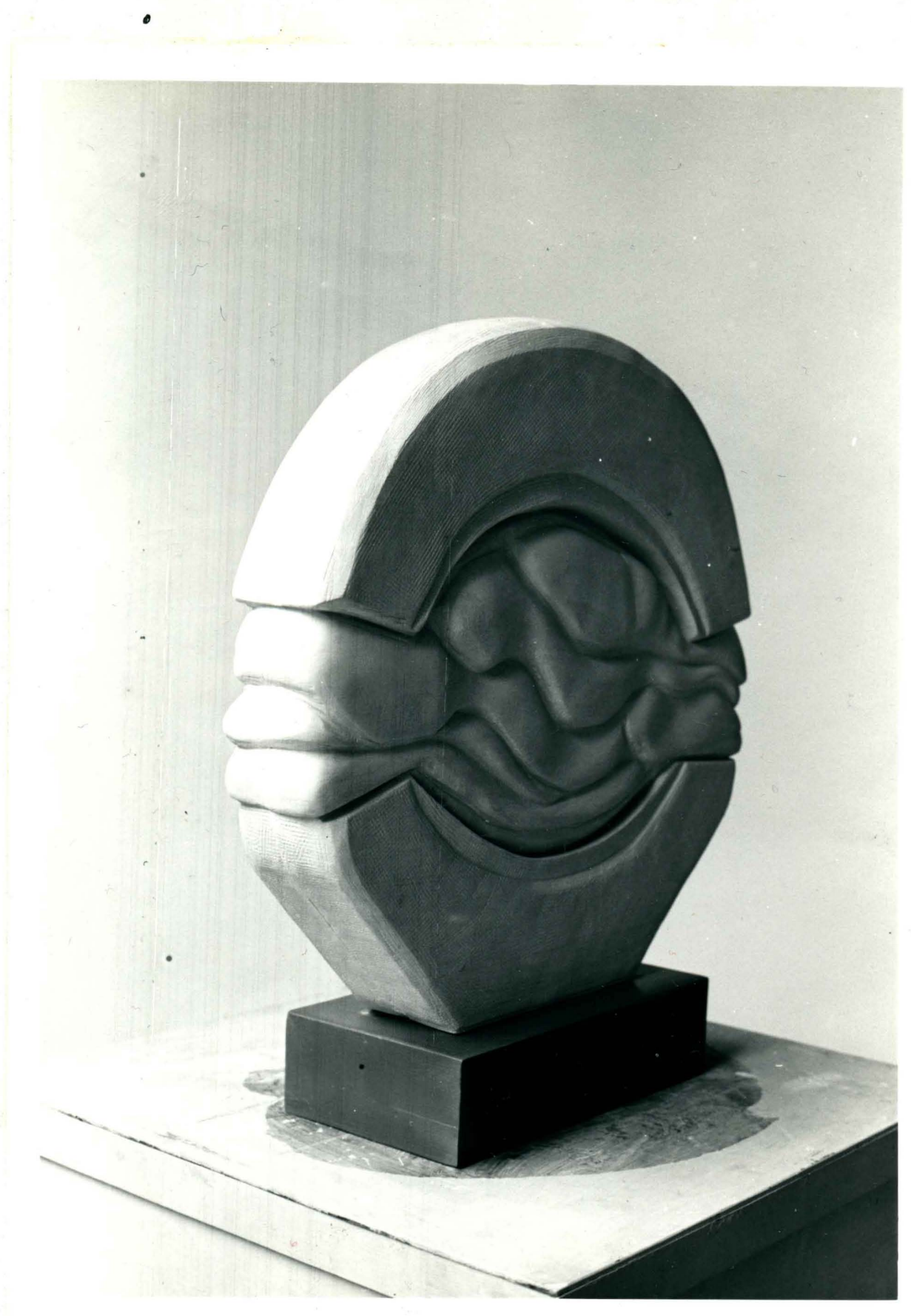

Figure 10. Circle Series, No. 5, Limestone 


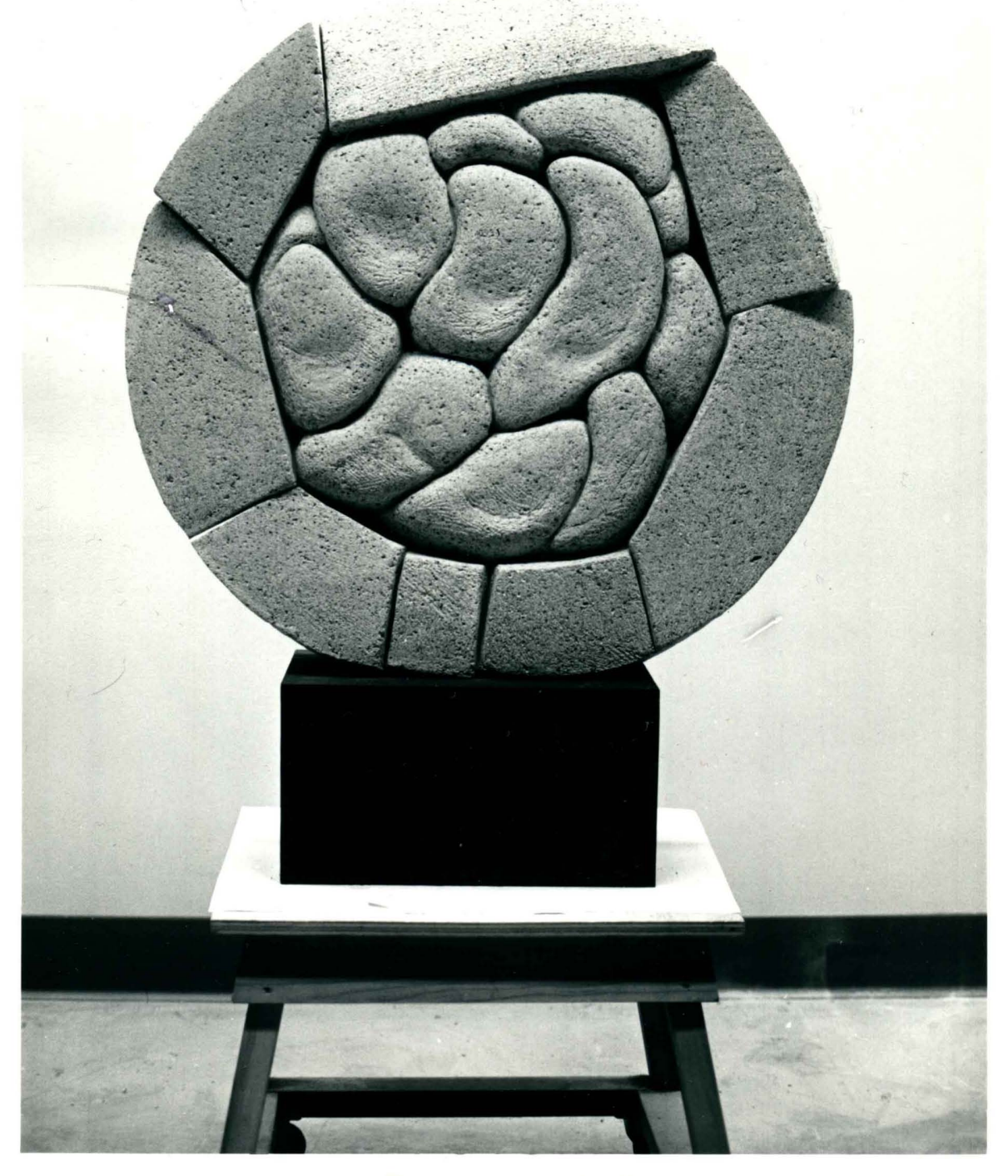

Figure 11. Circle Series, No. 6, Precast Concrete 


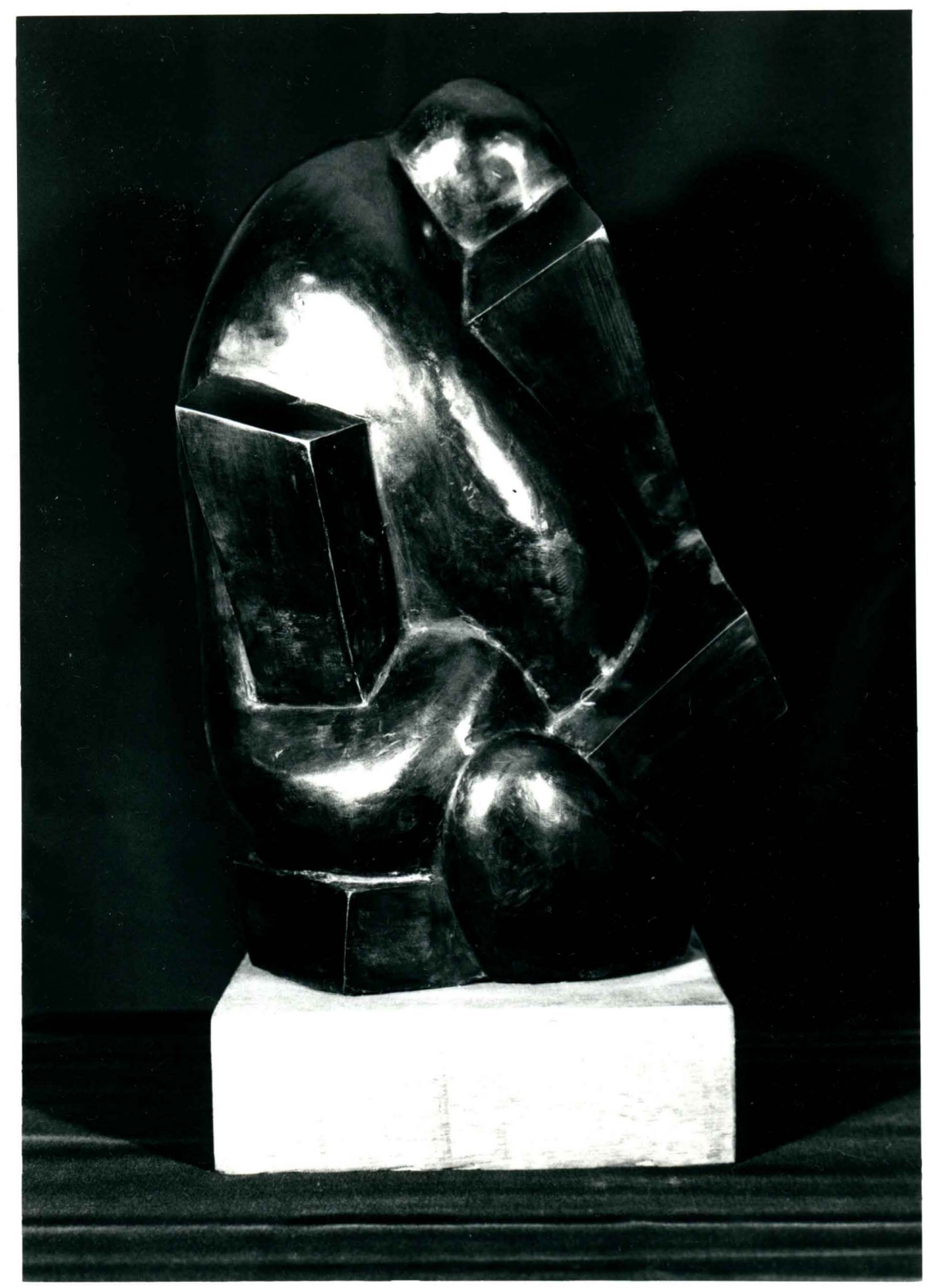

Figure 13. Growth Series, No. 1, Bronze 


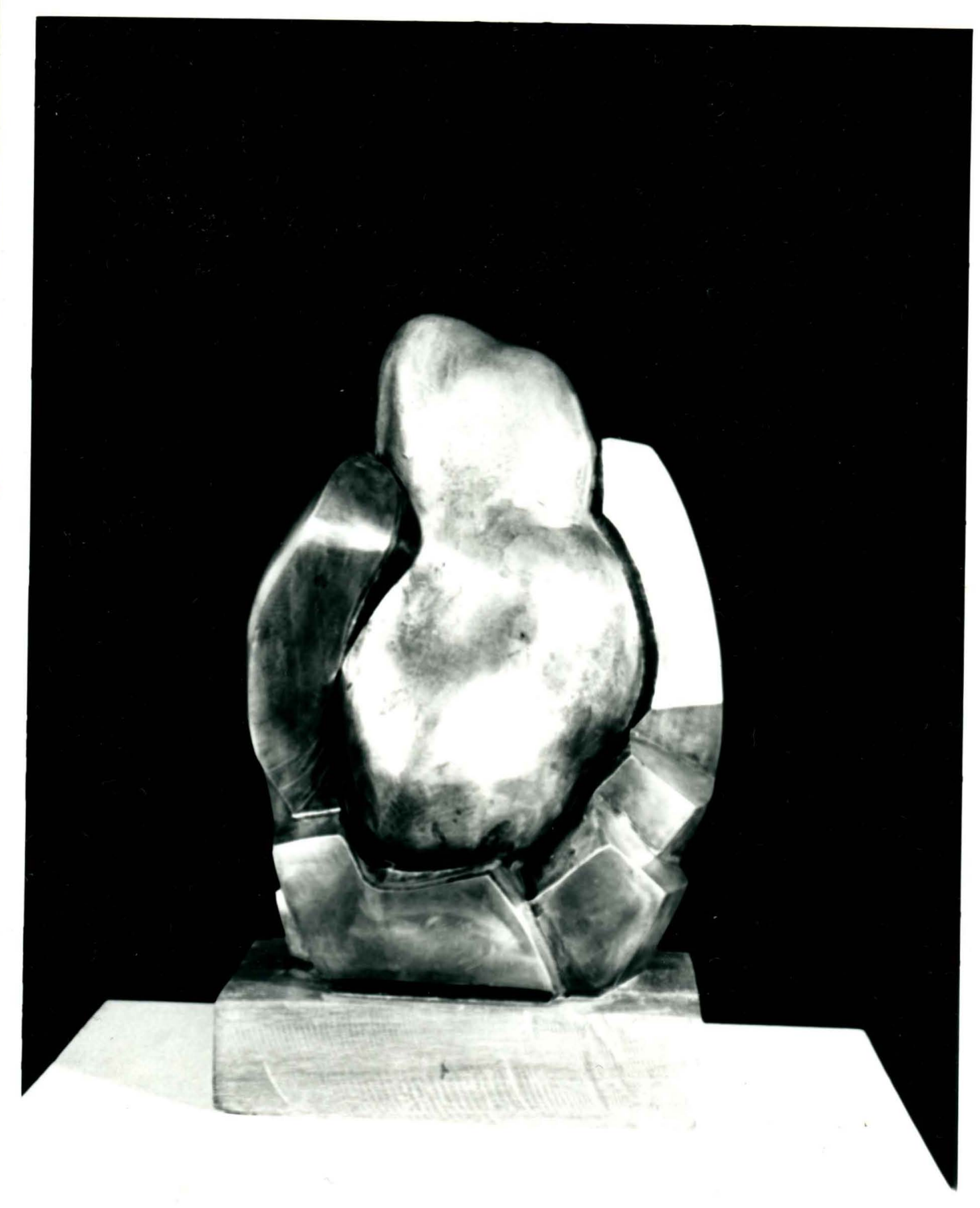

Figure 14. Growth Series, No. 2, Bronze 


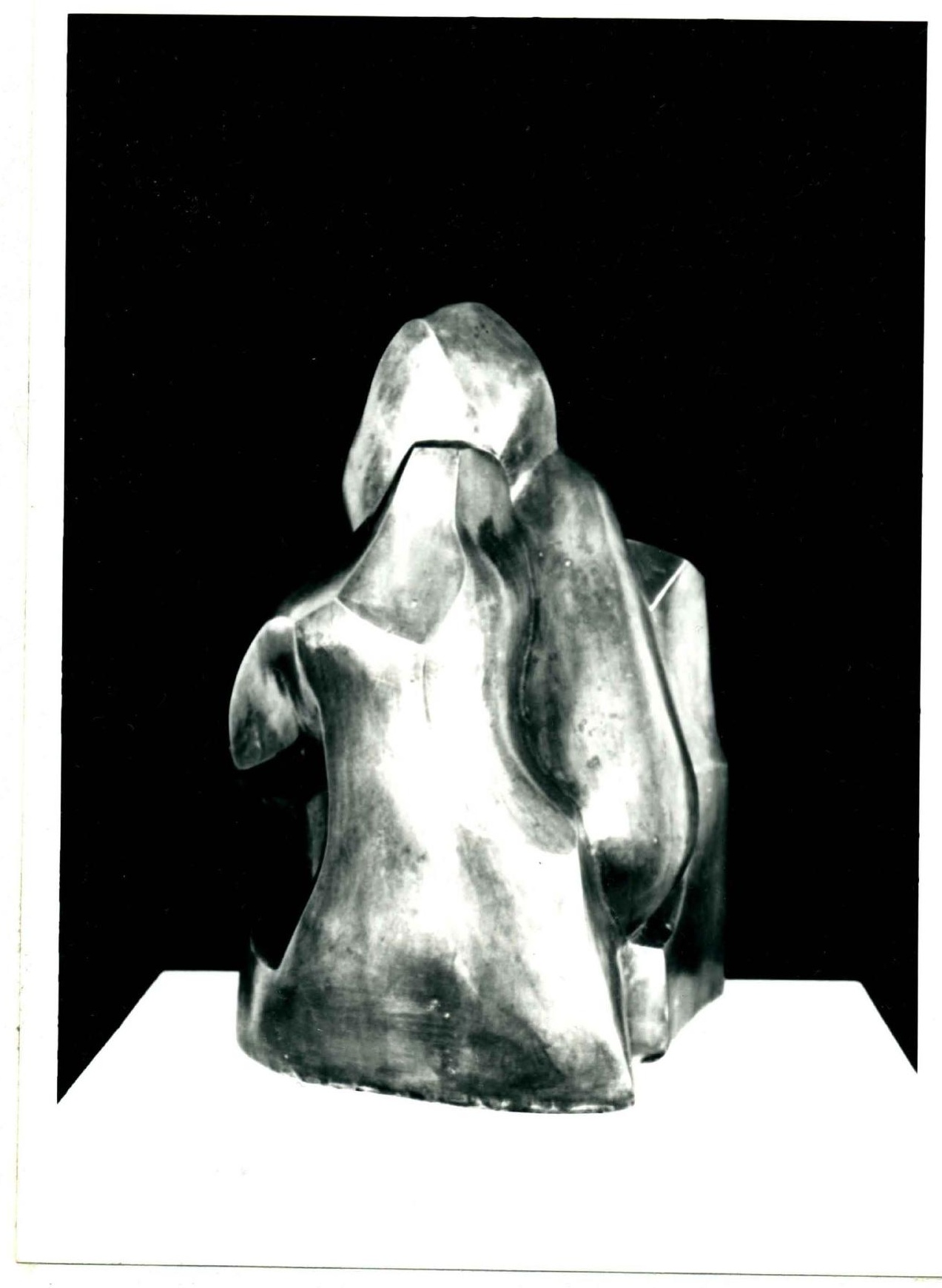

Figure 15. Growth Series, No. 3, Bronze 


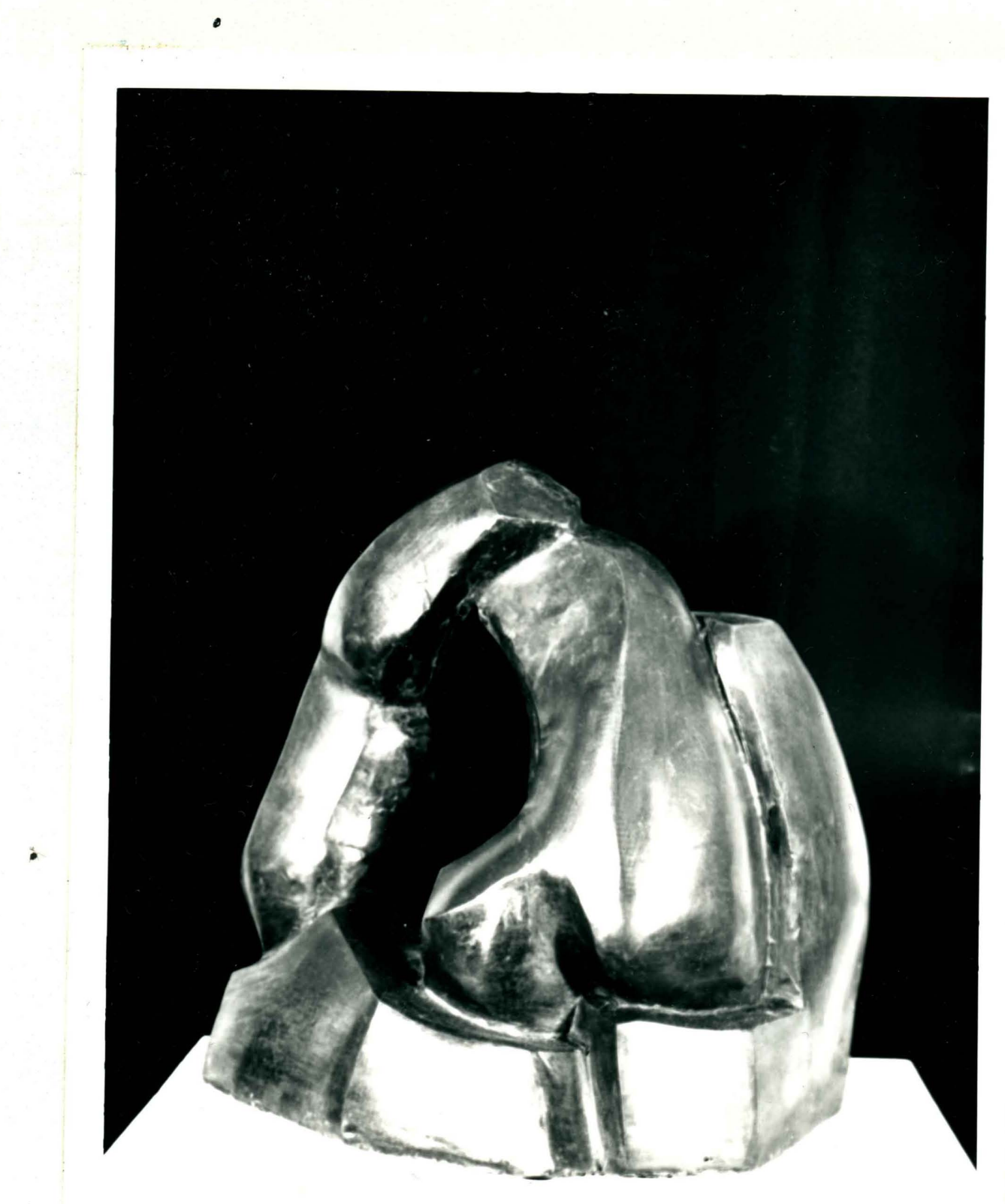

Figure 16. Growth Series, No. 4, Bronze 


\section{LIST OF FIGURES}

FIGURE

PAGE

1. Head Study, Terracotta . . . . . . . . . 70

2. Figire Study, Hollow-built Terracotta . . . . . . 71

3. Figure Study, Cast Plaster . . . . . . . . . 72

4. Figure Study, Terracotta . . . . . . . . . 73

5. Geometric Shapes, Soldered Silver . . . . . . . 74

6. Circle Series, No. 1, Hollow-built Terracotta . . . 75

7. Circle Series, No. 2, Terracotta, Hollowed . . . . 76

8. Circle Series, No. 3, Sugar pine . . . . . . 77

9. Circle Series, No. 4, Sugar pine ......... 78

10. Circle Series, No. 5, Limestone . . . . . . . 79

11. Circle Series, No. 6, Precast Concrete . . . . . 80

12. Circle Series, No. 7, Bronze ........... 81

13. Growth Series, No. 1, Bronze . . . . . . . . 82

14. Growth Series, No. 2, Bronze ........... 83

15. Growth Series, No. 3, Bronze . . . . . . . . 84

16. Growth Series, No. 4, Bronze . . . . . . . . 85 